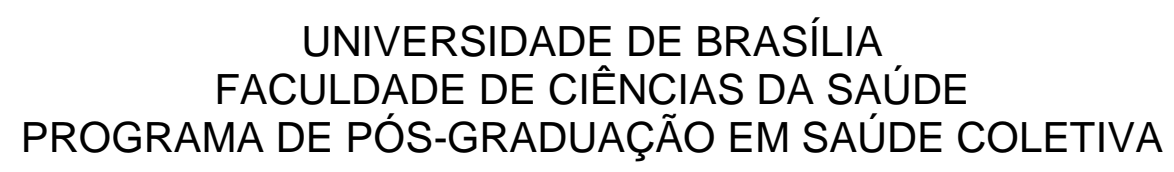

ANTÔNIO LEOPOLDO NOGUEIRA NETO

GESTÃO DE POLÍTICAS PÚBLICAS INTERSETORIAIS:

UMA ANÁLISE DA POLÍTICA NACIONAL DE PROMOÇÃO DA SAÚDE

Brasília, DF

2015 


\author{
UNIVERSIDADE DE BRASÍLIA \\ FACULDADE DE CIÊNCIAS DA SAÚDE \\ PROGRAMA DE PÓS-GRADUAÇÃO EM SAÚDE COLETIVA
}

ANTÔNIO LEOPOLDO NOGUEIRA NETO

GESTÃO DE POLÍTICAS PÚBLICAS INTERSETORIAIS:

UMA ANÁLISE DA POLÍTICA NACIONAL DE PROMOÇÃO DA SAÚDE

Dissertação apresentada como requisito parcial para obtenção do Título de Mestre em Saúde Coletiva pelo Programa de PósGraduação em Saúde Coletiva da Universidade de Brasília.

Orientador: Prof. Dr. Volnei Garrafa

Brasília, DF

2015 


\title{
GESTÃO DE POLÍTICAS PÚBLICAS INTERSETORIAIS: UMA ANÁLISE DA POLÍTICA NACIONAL DE PROMOÇÃO DA SAÚDE
}

\begin{abstract}
Dissertação apresentada como requisito parcial para obtenção do Título de Mestre em Saúde Coletiva pelo Programa de PósGraduação em Saúde Coletiva da Universidade de Brasília.
\end{abstract}

Aprovado em de de 2015

Prof. Dr. Volnei Garrafa (Presidente da Banca)

Universidade de Brasília

\author{
Prof ${ }^{a}$. Dra. Helena Eri Shimizu \\ Universidade de Brasília
}

Prof. Dr. José Francisco Nogueira Paranaguá de Santana Fundação Oswaldo Cruz 
AGRADECIMENTOS

Aos meus pais, Cesário e Tânia, pelo esforço empreendido para que eu pudesse chegar até aqui. E aos meus irmãos, César e Juliana, pelos exemplos de trabalho e superação.

À minha esposa, lara, e a meu filho, Miguel, pelo apoio dado ao longo destes dois anos e pela compreensão em relação às horas dedicadas à elaboração desta dissertação.

Aos professores, Dr. Volnei Garrafa, Dra. Helena Eri Shimizu e Dr. José Francisco Nogueira Paranaguá de Santana, pelos valiosos comentários e sugestões visando o aprimoramento deste trabalho. 


\section{RESUMO}

A proposta deste trabalho é refletir sobre a gestão intersetorial nas políticas sociais, tomando como estudo de caso a implementação da Política Nacional de Promoção da Saúde (PNPS) em dois momentos distintos: o primeiro, por ocasião de sua implantação, em 2006, e o segundo quando de sua revisão, em 2014. O objetivo é realizar uma análise comparativa dos documentos que criam e redefinem a Política com vistas a compreender o arranjo institucional constituído para sua articulação e gestão intersetorial. Considera-se Promoção da Saúde uma das estratégias do Desenvolvimento Sustentável que, articulada às demais políticas econômicas e sociais, contribui para a construção de ações transversais que possibilitem superar as iniquidades sociais. Suas principais características são abordagem integral do processo saúde-doença e reconhecimento dos determinantes sociais da saúde. O arcabouço teórico metodológico fundamenta-se nos conceitos de intersetorialidade, integralidade e transversalidade, que compreendem o ideário temático da PNPS, e agrega perspectivas de cogestão e governança que permeiam e integram esses conceitos no âmbito do Sistema Único de Saúde. A gestão intersetorial é entendida como um modelo de gestão voltado à constituição de estruturas de governança direcionadas ao desenvolvimento de capacidades relacionais, técnicas e administrativas, com vistas a assegurar legitimidade política e representatividade social para a tomada de decisão, para a construção de agendas e objetivos comuns e para a definição de instâncias e mecanismos de pactuação e cooperação entre os setores sociais, visando promover ações integradas e tratamento mais equânime das demandas sociais. Para contribuir com a avaliação de programas intersetoriais, desenvolve-se e aplica-se à PNPS um fluxo esquemático e uma escala de ponderação para verificar as capacidades relacionais, técnicas e administrativas das estruturas de governança que a compõem. Esse desenho de gestão é sustentado nos componentes de integralidade, para captar, compreender e analisar problemas e demandas sociais, e de transversalidade, para planejar estratégias e organizar arranjos institucionais mais democráticos e participativos. A análise permite concluir que houve avanços significativos na gestão intersetorial da PNPS, principalmente no que se refere as interações intrassetoriais e multiníveis, impulsionadas pela integração das perspectivas de vigilância e atenção à saúde e da regulamentação do princípio de regionalização do SUS. Contudo, observa-se que a PNPS ainda precisa fortalecer-se e otimizar os espaços de coordenação e articulação interinstitucional, visando consolidar a abordagem social e coletiva da promoção da saúde e ampliar sua contribuição para a formulação de políticas públicas saudáveis direcionadas à qualidade de vida e ao desenvolvimento sustentável.

Palavras-chave: Política Nacional de Promoção da Saúde; gestão intersetorial, integralidade; transversalidade; política pública. 


\section{ABSTRACT}

The purpose of this paper is to discuss the intersectoral management in social policies, taking as a case study the implementation of the National Health Promotion Policy (PNPS) at two different instances: the first, on the occasion of its implementation in 2006 and the second when it was amended in 2014. The aim is to conduct a comparative analysis of the documents that create and redefine policy in order to understand the institutional arrangements made for its articulation and intersectoral management. One of the Health Promotion strategies of sustainable development is considered which, in combination with the other economic and social policies, contribute to the construction of crosscutting actions that make it possible to overcome social inequities. Its main features are an integral approach to the health-disease process and recognition of the social determinants of health. The methodological theoretical framework is based on the concepts of intersectionality, completeness and mainstreaming, which comprise the thematic ideas of PNPS, and adds the prospects for comanagement and governance that permeate and integrate these concepts in the Unified Health System. The intersectoral management is understood as a management model focused on the creation of governance structures aimed at the development of relational, technical and administrative skills, comprising a view to ensure political legitimacy and social representation for decision making, for the construction of agendas and goals and to setting bodies and agreement and cooperation mechanisms between the social sectors to promote integrated actions and more equitable treatment of social demands. In order to contribute to the evaluation of intersectoral programs, a schematic flow and a balance scale are developed and applied to the PNPS to check the relational capabilities, technical and administrative governance structures that comprise it. This management design is sustained in the entirety of components to capture, understand and analyze problems and social demands, and mainstreaming, strategies to plan and organize more democratic and participatory institutional arrangements. The analysis shows that there have been significant advances in the PNPS intersectoral management mainly regarding the intra-sectoral and multi-level interactions, driven by the integration of perspectives surveillance and health care and regulation of SUS regionalization principle. However, it is observed that the PNPS still needs to be strengthened and their spaces of coordination and inter-institutional coordination optimized, to consolidate the social and collective approach to health promotion and increase its contribution to the formulation of healthy public policies aimed at quality of life and sustainable

development.

Keywords: National Health Promotion Policy; intersectoral management, completeness; transversal; public policy. 


\section{LISTA DE FIGURAS}

1 Modelo de intervenção em saúde desenvolvido por Leavell e Clark (1976)

2 Modelo da determinação social da saúde de Solar \& Irwin (2010).

3 Representação esquemática para análise de gestão intersetorial nas políticas públicas (elaborado pelo autor)

4 Modelo analítico de interação do arranjo institucional no desenvolvimento de capacidades estatais (GOMIDE;PIRES, 2014)

5 Gráfico de tipologia dos níveis de gestão intersetorial (adaptado pelo autor a partir de Navarro, 2011)

6 Relações e congruências dos campos da promoção e da vigilância em saúde (BRASIL, 2013)

7 Organograma da SVS/MS (MS, 2010)

8 Pontuação e classificação do arranjo intersetorial da PNPS/2006...

9 Matriz de conexão entre os componentes da PNPS (BRASIL, 2014)

10 Organograma do MS com destaque das estruturas envolvidas na gestão da PNPS (elaborado pelo autor).

11 Pontuação e classificação do arranjo intersetorial da PNPS/2014 .. 


\section{LISTA DE TABELAS}

Pág.

1 Descrição dos aspectos de análise de gestão intersetorial .............. 76

2a Identificação de instâncias permanentes e intersetoriais do MS ...... 114

2b Identificação de instâncias permanentes e intersetoriais do MS ...... 115

2c Identificação de instâncias permanentes e intersetoriais do MS ...... 116

3 Identificação de instâncias temporárias e intersetoriais do MS ........ 117

4 Identificação de instâncias permanentes e intrassetoriais do MS 119

5 Pontuação dos aspectos para classificação do arranjo intersetorial 134 da PNPS 2006.

6 Pontuação dos aspectos para classificação do arranjo intersetorial 142 da PNPS 2014. 


\section{LISTA DE ABREVIATURAS E SIGLAS}

ABS - Atenção Básica à Saúde

$\mathrm{AE}$ - Agenda Estratégica

AlH - Autorização de Internação Hospitalar

AIS - Ações Integradas de Saúde

ANS - Agência Nacional de Saúde

Anvisa - Agência Nacional de Vigilância Sanitária

BSM - Brasil sem Miséria

BSM - Programa Brasil Sem Miséria

Cepal - Comissão Econômica para América Latina e Caribe

CGDANT - Coordenação Geral de Doenças e Agravos Não Transmissíveis CGPNPS - Comitê Gestor da Política Nacional de Promoção da Saúde

CGR - Colegiado Gestor Regional

CIB - Comissão Intergestora Bipartite

CIMS - Comissões Interinstitucionais Municipais de Saúde

CIR - Comissões Intergestoras Regionais

CIS - Comissões Interinstitucionais de Saúde

CIT - Comissão Intergestores Tripartite

CNS - Conselho Nacional de Saúde

COAP - Contrato Organizativo da Ação Pública

Conasems - Conselho Nacional de Secretários Municipais de Saúde

Conass - Conselho Nacional de Secretários de Saúde

Conicq - Comissão Nacional de Implementação da Convenção-Quadro para Controle do Tabaco

CQCT - Convenção-Quadro para Controle do Tabaco

CTA - Comitês Técnicos Assessores 
DANT - Doenças e Agravos Não Transmissíveis

DCNT - Doenças Crônicas Não Transmissíveis

e-CAR - Controle, Acompanhamento e Avaliação de Resultados

Fiocruz - Fundação Oswaldo Cruz

Funasa - Fundação Nacional da Saúde

GT-VS - Grupo de Trabalho de Vigilância em Saúde

II PND - II Plano Nacional de Desenvolvimento

Inamps - Instituto Nacional de Assistência Média de Previdência Social

INCA - Instituto Nacional de Câncer

MDS - Ministério do Desenvolvimento Social

ME - Ministério da Educação

MS - Ministério da Saúde

ODM - Objetivos do Milênio

OMS - Organização Mundial de Saúde

ONGs - Organizações não Governamentais

ONU - Organização das Nações Unidas

OPAS - Organização Pan Americana para Saúde

PAA - Programa de Aquisição de Agricultura Familiar

PBF - Programa Bolsa Família

PNAE - Programa Nacional de Alimentação Escolar

PNAN - Política Nacional de Alimentação e Nutrição

Pnapo - Política Nacional de Agroecologia e Produção Orgânica

PNPS - Política Nacional de Promoção da Saúde

PNS - Plano Nacional de Saúde

PNUD - Programa das Nações Unidas para o Desenvolvimento

PPA - Plano Plurianual

PQA-VS - Programa de Qualificação das Ações de Vigilância em Saúde

Pronara - Programa Nacional de Redução de Agrotóxicos 
PSE - Programa Saúde na Escola

PVT - Projeto Vida no Trânsito

RAG - Relatório Anual de Gestão

RAS - Redes de Atenção à Saúde

Sisan - Sistema de Segurança Alimentar e Nutricional

SNVS - Sistema Nacional de Vigilância em Saúde

SUDS - Sistemas Unificados e Descentralizados de Saúde

SUS - Sistema Único de Saúde

SVS - Secretaria de Vigilância em Saúde

Vigitel - Vigilância de Fatores de Risco e Proteção para Doenças Crônicas por Inquérito Telefônico 


\section{SUMÁRIO}

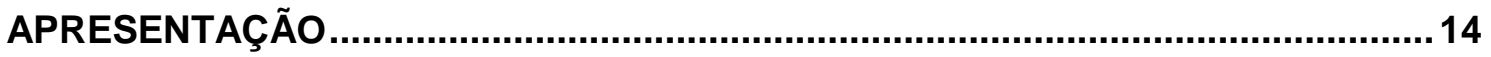

INTRODUÇÃO

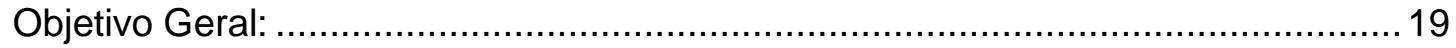

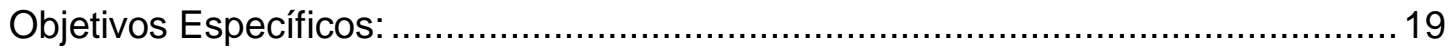

1. A CONFORMAÇÃO DAS POLÍTICAS PÚBLICAS DE PROTEÇÃO SOCIAL E

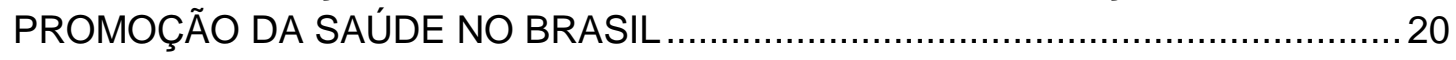

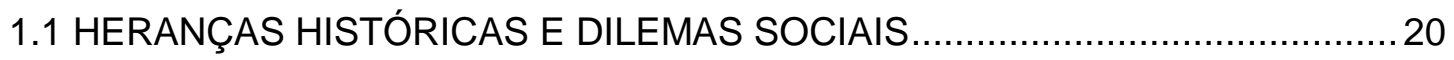

1.2 HISTÓRICO DO PARADIGMA DA PROMOÇÃO DA SAÚDE NO CONTEXTO

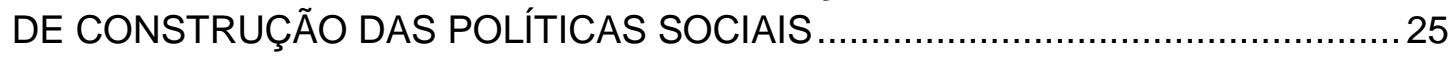

1.3 CONSOLIDAÇÃO DOS DETERMINANTES SOCIAIS E CONTRIBUIÇÃO DAS CONFERÊNCIAS INTERNACIONAIS PARA A PROMOÇÃO DA SAÚDE

1.4 ORGANIZAÇÃO HISTÓRICA DA POLÍTICA DE SAÚDE NO BRASIL E A CONSTRUÇÃO DO SISTEMA ÚNICO DE SAÚDE - SUS

1.5 PROMOÇÃO DA SAÚDE COMO ELEMENTO INDISSOCIÁVEL DA AGENDA DE DESENVOLVIMENTO SUSTENTÁVEL

2.REFERENCIAL TEÓRICO: ABORDAGEM DE POLÍTICAS PÚBLICAS E GESTÃO INTERSETORIAL

2.1 ESTRUTURAÇÃO DO APARATO GOVERNAMENTAL DAS POLÍTICAS SOCIAIS NO BRASIL

2.2 ABORDAGEM DE POLÍTICAS PÚBLICAS: ATORES, INSTITUIÇÕES, DISPUTAS E CONFLITOS COMO OBJETOS INERENTES À GESTÃO INTERSETORIAL.

2.3 INTERSETORIALIDADE COMO MECANISMO DE INOVAÇÃO DAS POLÍTICAS PÚBLICAS

2.4 ASPECTOS DA VISÃO INTEGRAL E DA GESTÃO TRANSVERSAL NOS ARRANJOS INSTITUCIONAIS DE POLÍTICAS PÚBLICAS: ELABORAÇÃO DE UM FLUXO ESQUEMÁTICO

2.5 ASPECTOS GERAIS PARA A CLASSIFICAÇÃO DA GESTÃO

INTERSETORIAL ENTRE POLÍTICAS PÚBLICAS

2.6 A OPÇÃO METODOLÓGICA PELO ESTUDO DE CASO 
3.1 CONFORMAÇÃO CONCEITUAL DA POLÍTICA NACIONAL DE PROMOÇÃO DA SAÚDE

3.2 INSTITUCIONALIZAÇÃO DA POLÍTICA NACIONAL DE PROMOÇÃO DA SAÚDE. 90

3.3 ASPECTOS DA IMPLEMENTAÇÃO DA POLÍTICA NACIONAL DE PROMOÇÃO DA SAÚDE. .98

3.4 QUALIFICAÇÃO DO MODELO DE GESTÃO DA PNPS 105

3.5 ORGANIZAÇÃO DA ESTRUTURA DE GOVERNANÇA E COORDENAÇÃO DA PNPS 110

3.6 ANÁLISE COMPARATIVA DOS MARCOS NORMATIVOS DE IMPLANTAÇÃO E ATUALIZAÇÃO DA POLÍTICA NACIONAL DE PROMOÇÃO DA SAÚDE 122

3.6.1 Portaria MS N687 MS/GM, de 30 de março de 2006 124

3.6.2 Portaria MS n².446 de 11 de novembro de 2014 136

CONSIDERAÇÕES FINAIS 144 


\section{APRESENTAÇÃO}

Este trabalho parte da premissa de que o processo de implementação de uma política pública é afetado por diversos fatores políticos, institucionais e relacionais. Nesse sentido, observar a implementação de políticas públicas a partir dos seus conteúdos, instituições e das relações que se estabelecem entre eles significa considerar esse processo como uma interação entre diversos atores que não agem somente como fiéis executores dos serviços orientados por normas e regras, mas desenvolvem seus papéis conduzidos também com base em suas experiências, valores, visão de mundo, e inseridos em um dado contexto político-institucional e social; e que, além disso, irão constituir seus elementos formais e informais de integração. Em uma política pública que tem como modelo de gestão a intersetorialidade, como no caso da Política Nacional de Promoção da Saúde (PNPS), esses fatores podem revelar-se de forma mais ou menos acentuada, tendo em vista, primeiramente, o número de atores envolvidos e, em segundo lugar, a grande quantidade de arenas de discussão, negociação, barganha e ainda da inevitável interdependência das ações entre os setores (NAVARRO, 2011).

Os recursos metodológicos utilizados para essa análise da PNPS foram aqueles adotados para o estudo de caso. O estudo de caso é reconhecido como um método eficiente de pesquisa para investigação empírica de um fenômeno contemporâneo complexo em que os limites do objeto de pesquisa e o contexto não são muito claros (YIN, 2001). Neste sentido, a abordagem de análise de políticas públicas aplicada a este estudo de caso pode ser considerada um caminho complementar para ampliar o poder explicativo sobre o objeto.

Preliminarmente, considerando a necessidade de organização dos aspectos teóricos que melhor configuram uma gestão intersetorial, optou-se pela revisão de literatura sobre a conformação das políticas sociais e pela 
construção de um esquema analítico que pudesse orientar o estudo de políticas intersetoriais. O esquema proposto fundamenta-se em dois componentes essenciais, que sugerem uma graduação hipotética de gestões segundo o nível de integralidade e transversalidade aplicado na estruturação de arranjos institucionais para a gestão intersetorial. No estudo de caso procedeu-se à análise dos fatores políticos e dos fatores institucionais da PNPS por meio de análise documental.

Para os fatores políticos, realizamos um levantamento histórico e análises conjunturais sobre as transformações políticas e institucionais ocorridas na implementação da PNPS, por meio da avaliação de instrumentos de planejamento e gestão governamental, relatórios de gestão e participação social, bem como agendas e planos de governo em âmbito federal. No que se refere aos fatores institucionais, foram examinados dados e documentos oficiais publicados, como, leis, normativas, decretos, entre outros, buscando compreender os organogramas e competências intersetoriais dessa política.

A seguir, apresentamos a estrutura deste trabalho e um resumo sucinto do que foi discutido em cada capítulo. O trabalho está dividido em três capítulos, além da Introdução e das Considerações Finais.

No primeiro capítulo, apresentamos uma contextualização histórica do processo de construção das políticas de proteção social e do paradigma de Promoção da Saúde no campo das políticas públicas, como forma de subsidiar o quadro conceitual da gestão intersetorial na implementação de políticas sociais de saúde. Para isso, realizamos uma revisão bibliográfica sobre a organização das políticas sociais no Brasil e da conformação da perspectiva de Promoção da Saúde. No segundo capítulo abordamos o referencial teórico metodológico. Dessa forma, abrimos a discussão sobre a intersetorialidade como um modelo alternativo de gestão das políticas públicas de seguridade social e saúde; procuramos aprofundar a compreensão dos determinantes sociais de saúde e dos componentes de integralidade e transversalidade na perspectiva da gestão intersetorial, além de abordar alguns aspectos relacionados à análise de políticas públicas e o estudo de caso. Por fim, 
propomos um fluxo esquemático para orientar a análise do arranjo institucional para a gestão intersetorial da PNPS.

No terceiro capitulo, tratamos da análise da Política Nacional de Promoção da Saúde em dois momentos distintos de sua implementação: a implantação em 2006 e a revisão em 2014, tendo por arcabouço metodológico o estudo de caso da política em questão, por meio da análise documental dos normativos, manuais, relatórios e planos de saúde e de gestão federal relacionados à PNPS.

Nas Considerações Finais, são apresentadas algumas conclusões acerca do nível de gestão intersetorial observado e operacionalizado no âmbito da Política Nacional de Promoção da Saúde, bem como considerações relativas às oportunidades e limitações do estudo.

Portanto, este trabalho procura observar os diversos fatores que influem sobre a implementação de uma política pública intersetorial, a PNPS, considerando sua dinâmica, incentivos e constrangimentos tanto políticos como institucionais, assim como a relação entre os diferentes setores envolvidos na promoção das ações. Entre as questões de pesquisa para as quais buscamos respostas, vale a pena destacar as seguintes: Quais os principais aspectos teóricos e estruturais que melhor configuram um arranjo de gestão intersetorial de políticas sociais? e Como se conforma o arranjo institucional da Política Nacional de Promoção da Saúde? 


\section{INTRODUÇÃO}

A motivação principal para este estudo está em compreender como funciona a gestão intersetorial na produção de políticas públicas federais, diante da amplitude e diversidade das demandas sociais da atualidade, da tendência da gestão pública na implementação de políticas por temáticas, assim como da persistência de agendas complexas associadas ao enfrentamento das desigualdades sociais e à promoção da qualidade de vida da população, que cada vez mais exigem a adoção de abordagens multidimensionais e a implicação de diferentes setores da sociedade.

Neste sentido, este estudo procura problematizar as características e 0 funcionamento da Política Nacional de Promoção da Saúde (PNPS), tendo por referência a organização dos seus arranjos institucionais voltados a intersetorialidade, considerando dois marcos temporais de sua implementação: o momento da sua implantação em 2006 e o processo de revisão ocorrido em 2014. A opção pela Política Nacional de Promoção da Saúde (PNPS) como estudo de caso desta pesquisa se justifica quando observamos que as condições, estilo e situação de vida são alguns dos termos que compõem o campo semântico de qualidade de vida, que tem no conceito de promoção da saúde sua estratégia central.

Compreende-se aqui que o tratamento de temáticas complexas, como a Promoção da Saúde da população, é multideterminado e multifatorial, e não encontra resolutividade de modo setorizado ou por simples mudanças na gestão pública, visto que há limites estruturais na produção das desigualdades sociais e sua superação implica mudanças profundas no plano organizacional do Estado e no campo da economia. Também a sociedade se transformou a tal ponto de o Estado não mais se defrontar somente com indivíduos, mas também com um número crescente de atores corporativos, institucionais e transnacionais, que marcam a face da sociedade moderna. Nesta direção, diversos autores assinalam a importância de buscar no conhecido paradigma da interdisciplinaridade e/ou da transdisciplinariedade a possibilidade de análise global dos problemas reais e, na estratégia de gestão intersetorial, a 
oportunidade de reorganização institucional e promoção de práticas sociais mais eficazes em relação à questão social atual (MONNERAT; SOUZA, 2009).

De modo geral, a gestão intersetorial pode ser caracterizada como uma inovação nos processos de implementação e coordenação das políticas sociais, que tem na diretriz da intersetorialidade uma das bases para instrumentalizar e aprimorar o aparato governamental no desenvolvimento de capacidades políticas e administrativas mais condizentes com as relações societais do Estado de Direito. O conceito de intersetorialidade nas políticas públicas tem apontado para a construção de interfaces entre setores e instituições governamentais e não governamentais, visando o enfrentamento de problemas sociais complexos que ultrapassem a alçada de um só setor de governo ou área de política, diante da tarefa inadiável de promover capacidades de governo que minimizem as características históricas de fragmentação setorial das políticas sociais (MONNERAT; SOUZA, 2011). Entretanto, ainda que a intersetorialidade conste como diretriz explícita ou implícita em várias políticas públicas, inúmeros são os entraves constatados na sua operacionalização, a iniciar por suas configurações históricas condicionadas a desenhos jurídico-administrativos hierárquicos e setoriais nos três níveis de governo (TUMELEIRO, 2012).

Dessa forma, pretendemos ampliar a reflexão sobre a apropriação de conceitos e a aplicação de práticas intersetoriais na formulação e implementação da PNPS, tendo em vista que o seu aprimoramento no espaço da gestão pública pode trazer impactos relevantes no plano da inclusão social, da garantia de direitos sociais, da participação política da população e da qualificação do acesso aos serviços públicos essenciais. Assim, a partir da abordagem da intersetorialidade e, considerando a importância dos fatores políticos e institucionais para esse tipo análise, realizamos uma revisão bibliográfica acerca do histórico de implantação e conformação das políticas sociais no Brasil e uma análise documental da Política Nacional de Promoção da Saúde. 
Objetivo Geral:

O Objetivo Geral deste estudo é analisar o arranjo institucional da Política Nacional de Promoção da Saúde a partir dos documentos e materiais que orientam suas estratégias de articulação e gestão intersetorial.

Objetivos Específicos:

1 - Realizar um levantamento histórico da conformação das políticas sociais no Brasil, buscando identificar os aspectos teóricos e estruturais que compõem a intersetorialidade no campo da Promoção da Saúde;

2 - Analisar o arranjo institucional constituído para articulação e gestão intersetorial da Política Nacional de Promoção da Saúde. 


\title{
1. A CONFORMAÇÃO DAS POLÍTICAS PÚBLICAS DE PROTEÇÃO SOCIAL E PROMOÇÃO DA SAÚDE NO BRASIL
}

\subsection{HERANÇAS HISTÓRICAS E DILEMAS SOCIAIS}

\begin{abstract}
Do ponto de vista governamental, todo o problema consistiu em conciliar uma política de acumulação que não exacerbasse as iniquidades sociais a ponto de torná-las ameaçadoras, e uma política de equidade que não comprometesse - e, se possível, ajudasse - os esforços de acumulação (SANTOS, 1979).
\end{abstract}

A manifestação mais importante da questão social na América Latina é caracterizada pela desigualdade social e consequente miséria. Sua constituição tem raízes históricas, que vão desde o colonialismo e, em alguns casos como o Brasil, a escravidão; raízes políticas, ligadas ao profundo conservadorismo das elites mantenedoras do poder econômico e político; e raízes econômicas, determinadas por um padrão de desenvolvimento tardio, periférico e dependente, cujo modelo econômico sempre foi concentrador de renda e gerador de desigualdades. Essas raízes se combinam entre si e seus componentes estruturais se reproduziram ao longo da história a partir das diferentes conjunturas sociais, políticas e econômicas (SOARES, 2012).

Desde a década de 1950, a construção e reconhecimento dos direitos humanos e de cidadania - respeito às liberdades individuais, à participação na organização da vida social, a perspectiva do bem-estar coletivo e à garantia de um nível mínimo de consumo para todos - caminharam pressionados entre os interesses econômicos e as responsabilidades do Estado. Muitos foram os avanços que inspiraram as reformas administrativas, políticas e sociais da estrutura pública dos "países em desenvolvimento" no último século. Entretanto, em boa parte, tais medidas foram importadas dos "países desenvolvidos" de forma acrítica pelas elites patrimoniais, como inovações imprescindíveis à manutenção da ordem social e progresso econômico do país, sem, contudo, considerar as diferentes realidades sociais oriundas dos seus próprios territórios.

Na perspectiva dos direitos sociais, a desigualdade e a exploração na esfera econômica entraram em constante contradição com a igualdade 
necessária à consolidação dos Estados modernos, qual seja, a existência de indivíduos iguais e livres que estabelecem voluntariamente relações de troca e que se encontram protegidos por um poder político que se exerce em nome de todos, sem distinção, e que é legitimado pelos cidadãos. A postulação da igualdade abstrata (TOCQUEVILLE, 1945) ${ }^{1}$ que marca o início da era das relações contratuais, na qual os indivíduos estão no mesmo plano, possibilitou a emergência da ação política e a vocalização das camadas excluídas pela sociedade industrial. Porém, da simples composição abstrata de igualdade perante uma comunidade nacional ao compartilhamento de padrões de inclusão social, há um grande espaço, que requereu a mobilização política em torno da institucionalização de direitos universais inseridos na ação do Estado, por meio de políticas públicas capazes de concretizar o status de cidadania (FLEURY, 2008).

Segundo Marshall (1967 apud FLEURY; OVERNEY, s/d), a cidadania é um status concedido a todos os membros integrantes de uma comunidade política, como um princípio de justiça social que possui função normativa na organização do sistema político, sendo este contemporâneo ao desenvolvimento dos Estados Modernos e do modo de produção capitalista. A cidadania é considerada um atributo central da democracia, uma vez que a igualdade é ampliada pela expansão do escopo da cidadania e cada vez mais pessoas têm acesso a essa condição. Paradoxalmente, o status político da cidadania foi estendido de forma conjunta com um sistema econômico fundamentado na diferenciação de classe baseada na propriedade. Neste sentido, a relação de poder entre os indivíduos e o Estado representou uma grande transformação na estrutura social da modernidade.

Tendo o alcance da cidadania se constituído como a base do sistema político, os Estados modernos esforçaram-se em instrumentalizar o aparato governamental para o exercício da democracia por meio da estruturação das

\footnotetext{
${ }^{1}$ Tocqueville foi o primeiro pensador dos tempos modernos que empreendeu uma investigação global de forma que o princípio democrático da igualdade funcionaria como causa primeira, formando e afetando de certa forma todos os aspectos da vida dentro da sociedade (ZETTERBAUM, 2001, p. 716). Para Tocqueville a compreensão de igualdade abstrata deveria estabelecer bases nos ideais sociais e nas situações atuais dos povos, em vez de tentar partir dos estágios primitivos e naturais dos seres humano (Cleto,2005). http://www.sapientia.pucsp.br/tde busca/arquivo.php?codArquivo=2252
} 
políticas sociais. Uma das explicações para as políticas sociais considera que estas deveriam ser vistas como respostas às "necessidades" do trabalho e às "necessidades" do capital, compatibilizando-se entre si. Dessa forma, o projeto de "normalização" das relações sociais, buscado através das políticas sociais, tentou concretizar-se, subordinando os objetivos sociais da política estatal a fins propriamente econômicos.

No caso brasileiro, a expressão das políticas sociais teve seu uso generalizado no período posterior a 1964, principalmente após 1970. Foi no II Plano Nacional de Desenvolvimento - II PND, que se anunciou oficialmente a necessidade de a política social ter "objetivo próprio", independente das metas da política econômica. No capítulo do documento citado relativo à "estratégia do desenvolvimento social", por exemplo, foi enfatizada a necessidade de superar as desigualdades regionais, sendo constatados os problemas de qualidade do sistema educacional. Explicitou-se ainda quão insatisfatória era a distribuição de renda, sendo proposta a redução substancial da "pobreza absoluta", definida como "o contingente de famílias com nível de renda abaixo do mínimo admissível quanto à alimentação, saúde, educação e habitação"2 (BRASIL, II PND, 1975, p. 54). A despeito disso, não foram explicitamente estabelecidas prioridades setoriais, não ficando caracterizado com clareza o papel do Estado na condução dessa estratégia.

Dois argumentos ajudam a esclarecer as razões que levaram o Estado brasileiro a aumentar seu interesse pela área social. $O$ primeiro deles foi constatar que a intensificação do processo de concentração de renda no período, acentuado pelo desenvolvimento excludente e pela urbanização acelerada, exigia a intervenção estatal no sentido de atender — ou, pelo menos, de atenuar - as carências da população, potencializadas pela pauperização crescente. A agudização de necessidades sociais fez explicitar, muitas vezes de forma explosiva, uma série de tensões originárias da própria dinâmica das relações em processo na sociedade brasileira. Essa explicitação

\footnotetext{
${ }^{2}$ Disponível em http://www.planalto.gov.br/ccivil 03/leis/1970-1979/anexo/ANL6151-74.PDF. Acesso em 1 jun 2014.
} 
das tensões contribuiu para que o Estado assumisse os "problemas sociais" como questões de "sua" responsabilidade.

O outro argumento que the é complementar refere-se à percepção de que a legitimação e a estabilidade do regime autoritário à época deveriam apoiar-se firmemente na expansão das políticas sociais. Colocado no centro desse processo, o Estado poderia, com mais facilidade, revestir-se do caráter de entidade representativa do interesse geral (AUGUSTO, 1989).

O simples enunciado de boas intenções, contudo, não foi suficiente para que esse processo pudesse ser percebido como apto, quer para distribuir benefícios, quer para instituir direitos que atingissem todos os segmentos da sociedade. Apesar do rápido e notável crescimento dos recursos alocados, não houve melhora substantiva, seja na qualidade dos serviços sociais produzidos no país, seja na "qualidade de vida" da população por eles beneficiada. Ainda que sua oferta tenha se expandido, a procura aumentou com maior rapidez, de modo que sua expansão quantitativa não se fez acompanhar pela melhoria de qualidade. Esta última também foi dificultada pela crescente burocratização do atendimento. Fazia-se necessária alguma forma de ação efetiva no reconhecimento de direitos e na criação de canais de reivindicação e participação populares (ANDRADE, 2006).

Neste sentido, o processo de instituição das políticas de proteção social foi uma resposta ao processo de desenvolvimento das sociedades capitalistas industrializadas e suas consequências, entre elas o aumento da divisão do trabalho, a expansão dos mercados e a perda das funções de seguridade das organizações tradicionais como a família; injunções circunstanciais que buscavam uma nova estabilidade e segurança, gerando um novo tipo de solidariedade em um contexto de alta mobilização social. $O$ primeiro passo nesse processo ocorreu com o próprio reconhecimento político de que a pobreza e a precariedade das condições materiais de existência das camadas de trabalhadores urbanos tornavam-se, com a emergência da sociedade capitalista, um problema a ser enfrentado coletivamente, ou seja, emerge uma questão prioritária que requer resposta política e institucional dos diferentes setores da sociedade, sob pena de rompimento das estruturas sociais. 
O movimento de redefinição das relações entre o Estado e a Sociedade, buscando transformar em direito o que era tratado como carência, começou a emergir no Brasil na segunda metade da década de 1980, no contexto da democratização do país. Esse processo resultou na chamada "Constituição cidadã" de 1988, que consagrou como direitos sociais: a educação, a saúde, o trabalho, o lazer, a segurança, a previdência social, a proteção à maternidade $\mathrm{e}$ à infância e a assistência aos desamparados. A ideia de se instituir uma rede de políticas de proteção social no Brasil, no sentido de se reduzir as desigualdades sociais por meio da prevenção a situações de risco decorrentes da pobreza, da privação e do precário acesso aos serviços públicos, consolidou-se no objetivo fundamental do Estado brasileiro de erradicar a pobreza, a marginalização e reduzir as desigualdades sociais e regionais (BRASIL, 1988). Do ponto de vista normativo, a perspectiva da seguridade social inaugurou um novo momento na organização das políticas sociais e no reconhecimento dos direitos fundamentais no país.

A implementação das políticas sociais passou a exigir esforços conjuntos dos diferentes atores governamentais e societais no sentido de garantir a proteção e promoção dos direitos sociais. Fazia-se necessária a organização de ações sociais mais efetivas e o desenvolvimento de novas capacidades estatais capazes de compreender e alcançar os territórios e grupos populacionais alijados dos mínimos sociais e de qualidade de vida, bem como de equalizar a distribuição de recursos e ampliar o potencial de produtividade dos diferentes grupos e regiões do país.

Assim, impulsionada por um amplo processo de mobilização e lutas sociais, a estruturação do aparato governamental das políticas sociais passou então, no plano legal, a ter uma dinâmica multifacetada que incluiu: (1) ações intervencionistas na forma de distribuição de recursos e oportunidades, (2) a promoção de igualdade e dos direitos de cidadania e (3) a afirmação de valores humanos como ideais a serem tomados como referência para a organização de nossa sociedade. Contudo, o processo de institucionalização das políticas de seguridade social percorreu caminhos desconexos incapazes de realizar a plenitude conceitual do texto constitucional. 
No tocante às discussões da Política de Saúde no âmbito das Políticas de Proteção Social, a inclusão da previdência, da saúde e da assistência como partes da seguridade social, introduziu no Brasil a noção de direitos sociais universais como parte da condição de cidadania. Além do reconhecimento dos direitos sociais, o novo padrão de seguridade social caracterizou-se pela afirmação do dever do Estado, a universalidade na cobertura, a subordinação das práticas privadas à regulação em função da relevância pública das ações e serviços nessas áreas, e na perspectiva 'publicista' de cogestão governo/sociedade, em um arranjo organizacional descentralizado (FLEURY, 2012).

\subsection{HISTÓRICO DO PARADIGMA DA PROMOÇÃO DA SAÚDE NO CONTEXTO DE CONSTRUÇÃO DAS POLÍTICAS SOCIAIS}

A relação entre saúde e condições gerais de vida das populações foi constatada e explicitada na própria origem da medicina moderna. Especialmente no fim do século XVIII e na primeira metade do século XIX, o processo de urbanização e industrialização na Europa provocou grandes transformações sociais: a deterioração das condições de vida e de trabalho nas cidades se fez acompanhar de um aumento da ocorrência de epidemias. Os médicos envolvidos com o intenso movimento social que emergiu nesse período, ao relacionarem a doença com o ambiente, articulavam-no também às relações sociais que o produziam. A medicina fundia-se à política e expandiase em direção ao espaço social, como expressou o médico alemão Rudolf Virchow": "A medicina é uma ciência social e a política nada mais é do que a medicina em grande escala". As ocorrências das doenças foram então associadas às condições de existência e às formas de vida dos sujeitos, tornando-se efeitos de processos históricos.

\footnotetext{
${ }^{3}$ Promoção da Saúde: contexto histórico. Junho de 2012. Disponível em https://www.portaleducacao.com.br/Artigo//mprimir/13463. Acesso em 20 jun 2014.
} 
Esse pensamento identificava-se na época com a perspectiva anticontagionista, que atribuía a doença a um desequilíbrio do conjunto de circunstâncias que interferem na vida de um sujeito ou de uma população, constituindo uma predisposição favorável ao surgimento de doenças. $O$ movimento contagionista, ao contrário, enfatizava a necessidade de precisar uma causa específica como origem da doença, o que na época era considerado conservador e ultrapassado (ACKERKNECHT, 1948).

O conflito entre aqueles que propunham prioritariamente causas e intervenções gerais - por exemplo, sobre a fome e a miséria - e os que buscavam prioritariamente causas e intervenções específicas continuou existindo. Mckeown ${ }^{4}$ (1979), por exemplo, demonstrou que a redução da mortalidade na Inglaterra depois de 1840 foi, em escala muito maior, devida ao desenvolvimento econômico, a uma melhor nutrição e a outras mudanças favoráveis no nível de vida do que às intervenções específicas da medicina.

No entanto, a poderosa influência da bacteriologia no desenvolvimento da medicina interferiu para o privilégio de intervenções específicas, individualizadas, de cunho predominantemente biológico, centradas no hospital, com progressiva especialização e incorporação indiscriminada da tecnologia. Consolidou-se a posição privilegiada da medicina e dos médicos na definição dos problemas de saúde e na escolha das ações necessárias ao controle, tratamento e prevenção das doenças (CZERESNIA, 2003).

Entretanto, em um contexto de crítica à medicina curativa, no período entre 1920 e 1950, surge o movimento da medicina preventiva. Esse movimento propôs uma mudança da prática médica por meio da reforma no ensino médico e buscava a formação de profissionais médicos com uma nova

\footnotetext{
${ }^{4}$ Thomas McKeown (1912-1988), conceituado epidemiologista inglês, publicou, em 1979, o livro $O$ papel da medicina - sonhos, miragem e nêmeses, cujo conteúdo gera polêmica até os dias atuais. Entre outros problemas de saúde, McKeown analisou o histórico das taxas de mortalidade por tuberculose na Inglaterra, de meados do século XIX até o início da década de 1970 (portanto, antes da ressurgência da doença), observando que a tendência de redução dessas taxas, na população inglesa, já era marcante na primeira metade do século XIX e se manteve em queda por todo o período analisado. (BARRETO, Maurício L., Menos pobreza, menos doença. Revista CH Hoje, 17/10/2014. Disponível em http://cienciahoje.uol.com.br/revista-ch/2014/319/menos-pobreza-menos-doenca. Acesso em 20 jun 2014)
} 
atitude nas relações com os órgãos de atenção à saúde; ressaltava a responsabilidade dos médicos com a Promoção da Saúde e a prevenção de doenças; introduzia a epidemiologia dos fatores de risco e privilegiava a estatística como critério científico de causalidade (AROUCA, 2003). Segundo Arouca (2003), o discurso da medicina preventiva emergiu em um campo formado por três vertentes: a higiene; a discussão dos custos da assistência médica e a redefinição das responsabilidades médicas.

O termo "Promoção da Saúde" foi utilizado pela primeira vez por Sigerist, historiador da medicina, quando, em 1945, ele definiu quatro funções da medicina: Promoção da Saúde, prevenção da doença, restauração do doente e reabilitação. A partir daí, a base conceitual do movimento da medicina preventiva foi sistematizada no livro de Leavell e Clark, Medicina Preventiva (1976), cuja primeira edição foi publicada em 1958. Esses autores discutem três conceitos importantes para a construção de políticas de saúde: a "tríade ecológica", a história natural das doenças e a prevenção.

A "tríade ecológica" define o modelo de causalidade das doenças a partir das relações entre agente, hospedeiro e meio ambiente. O conceito de história natural das doenças é definido como

\footnotetext{
todas as inter-relações do agente, do hospedeiro e do meio ambiente que afetam o processo global e seu desenvolvimento, desde as primeiras forças que criam o estímulo patológico no meio ambiente (pré-patogênese), passando pela resposta do homem ao estímulo, até as alterações que levam a um defeito, invalidez, recuperação ou morte (patogênese) (LEAVELL; CLARK, 1976).
}

O conceito de prevenção trata da "ação antecipada, baseada no conhecimento da história natural a fim de tornar improvável o progresso posterior da doença" (LEAVELL; CLARK, 1976). A prevenção apresenta-se em três fases: primária, secundária e terciária.

O conceito de Promoção da Saúde aparece como um dos níveis da prevenção primária (pré-patogênese), definido como um conjunto de ações que contribuem para o desenvolvimento de uma saúde "ótima". Um segundo nível seria a proteção específica, com foco na criação de barreiras que impedissem o contato com agentes contaminados do meio ambiente e exterminassem agentes patológicos. A fase da prevenção secundária também se apresenta em 
dois níveis: no primeiro, o diagnóstico e tratamento precoce, e no segundo, a limitação da invalidez. Por fim, a prevenção terciária, que diz respeito a ações de reabilitação (LEAVELL; CLARK, 1976). A seguir, o modelo de intervenção em saúde desenvolvido por Leavell e Clark (Figura 1).

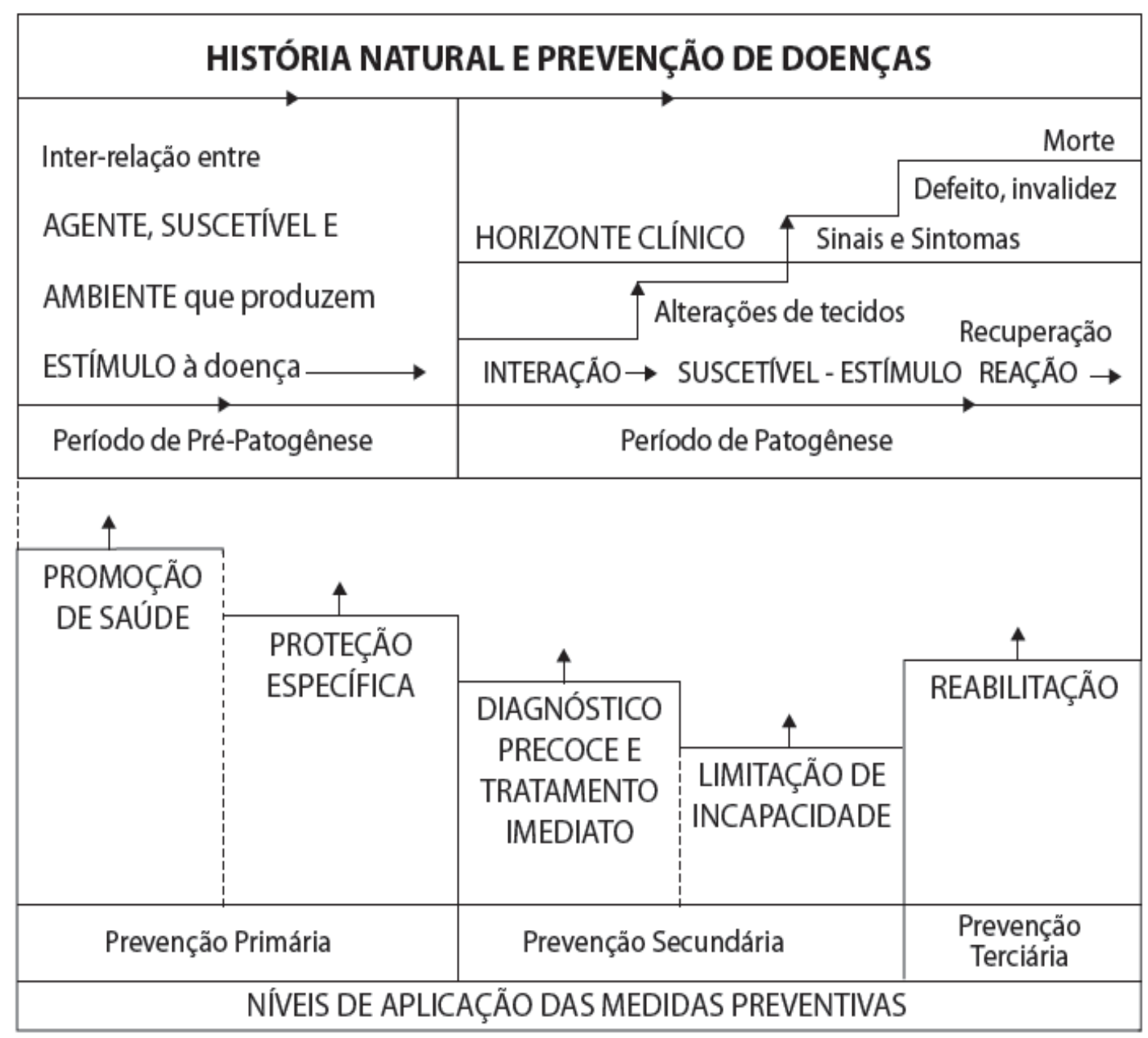

Figura 1. Modelo de intervenção em saúde desenvolvido por Leavell e Clark (1976).

O modelo explicativo e as ações propostas por Leavell e Clark significaram um grande avanço na década de 1960, uma vez que olhavam a doença sob uma perspectiva multicausal e processual.

Esses autores chamaram a atenção dos profissionais de saúde para o potencial das ações sobre o ambiente e sobre os estilos de vida na prevenção de doenças. Inovaram, também, na proposição de medidas preventivas, incluindo ações educativas, comunicacionais e ambientais às já existentes - 
como as laboratoriais, clínicas e terapêuticas - como complementação e reforço da estratégia. As ações sugeridas por Leavell e Clark para a Promoção da Saúde privilegiavam ações educativas normativas voltadas para sujeitos, famílias e grupos (BUSS, 2003).

Entretanto, as ações de Promoção da Saúde apresentadas como componente da prevenção primária ainda estavam longe da profunda relação entre saúde e sociedade analisada pela medicina social no século XIX. Contudo, é importante observar que a concepção de Leavell e Clark, incorporou-se ao discurso da Medicina Comunitária e orientou o estabelecimento de níveis de atenção nos sistemas e serviços de saúde que vigoram até hoje.

Já durante as décadas de 1970 e 1980, quase todos os países do continente europeu e da América do Norte enfrentavam a crise do Estado de Bem-Estar Social em função do esgotamento dos recursos dos Estados e da incapacidade de atenderem às necessidades de toda população, que demandava por benefícios e auxílios. Ficou mais evidente para as autoridades sanitárias desses países o reconhecimento da influência de outras condições determinantes da saúde e da qualidade de vida, além da assistência à saúde, quais sejam: as políticas globais, nacionais e locais; as mudanças sociais; as diferenças culturais, étnicas e até religiosas.

Esse reconhecimento inspirou a reformulação das políticas de saúde nesses países, tendo como marco referencial a reforma das políticas de saúde no Canadá. Em 1974, a divulgação do documento A New Perspective on the Health of Canadians, pelo governo canadense, inaugura o aparecimento de uma nova forma de definir as prioridades na produção de saúde, a partir da adoção do conceito de campo de saúde e da constituição do movimento de Promoção à Saúde no Canadá (CARVALHO, 2002).

A motivação central desse documento, mais conhecido como Informe Lalonde (nome do ministro da saúde à época), era econômica, política e técnica, pois se tentava encontrar um caminho para enfrentar o progressivo aumento dos custos com assistência médica e os seus resultados pouco eficazes (BUSS et al., 2000). O Informe questionou os investimentos realizados 
em tecnologia de assistência à saúde pelos governos anteriores, a partir dos resultados em termos de melhoria de indicadores de saúde, realizou investigações sobre a causalidade do processo saúde-doença no país e verificou que os estilos de vida e ambiente eram responsáveis por $80 \%$ das causas das doenças e que não estava havendo investimento no controle dessas causas (OPAS, 1996; RESTREPO, 2001). Além disso, o Informe defendeu que, diante do envelhecimento populacional, queda da morbimortalidade por doenças infecciosas e elevação dos casos de patologias crônico-degenerativas, as intervenções no campo da saúde deveriam visar à qualidade de vida de modo que os sujeitos vivessem mais e melhor, desfrutando do aumento dos índices de desenvolvimento socioeconômico (CARVALHO, 2002).

O Informe Lalonde, além de seguir a definição dos determinantes de saúde, indicando um entendimento ampliado da saúde, propôs cinco estratégias para a abordagem dos problemas neste campo: promoção da saúde, regulação, eficiência da atenção sanitária, investigação e estabelecimentos de objetivos. Entretanto, apesar de apontar na direção da complexidade da produção social da saúde, o Informe Lalonde insere-se na corrente comportamentalista da Promoção da Saúde, focalizando, principalmente, o estilo de vida e priorizando estratégias como: marketing social, educação para a saúde e estímulo à autoajuda (CARVALHO, 2005). O Informe defendeu que as políticas de saúde deveriam informar, influenciar e assistir os sujeitos e as organizações a responsabilizarem-se pela adoção de atitudes saudáveis, as quais reduziriam sua exposição aos riscos de adoecimento e de morte (CARVALHO, 2005).

\subsection{CONSOLIDAÇÃO DOS DETERMINANTES SOCIAIS E CONTRIBUIÇÃO DAS CONFERÊNCIAS INTERNACIONAIS PARA A PROMOÇÃO DA SAÚDE}

O direito à saúde praticamente se confunde com o direito à vida. Ter saúde exige alimentação adequada, condições de trabalho saudáveis, moradia digna, saneamento básico eficiente, meio ambiente protegido e bem conservado, possiblidade de lazer, informação. É, portanto, resultado de um conjunto de determinantes. 
Garantir a saúde da população é tarefa de todas as áreas de governo e de toda a sociedade (RODRIGUEZ NETO, 1994, p. 31).

Os debates sobre o conceito de determinantes sociais da saúde iniciaram-se nos anos de 1970 e 1980, ou seja, são contemporâneos do desenvolvimento da Promoção da Saúde e compartilhavam com ela o entendimento de que as intervenções curativas e orientadas para o risco de adoecer eram insuficientes para a produção da saúde e da qualidade de vida em uma sociedade. A partir dos movimentos da medicina preventiva e das contribuições do Informe Lalonde para a reformulação de políticas sociais de saúde, a saúde e a doença passaram a expressar uma complexa rede de interrelações e interdependências em que não se poderia precisar uma origem última ou uma causalidade linear. Nessa lógica da complexidade, em 1973, Laframboise formulou o modelo de campo de saúde, segundo o qual a saúde é determinada por múltiplas variáveis que foram agrupadas em quatro categorias denominadas determinantes de saúde (CARVALHO, 1996; BUSS et al., 2000):

- Determinante biológico: refere-se a toda manifestação relativa à saúde física ou mental que ocorra em decorrência do organismo individual - herança genética, processo de crescimento e envelhecimento e os diferentes sistemas internos complexos.

- Ambiente: remete aos fatores externos ao corpo humano, que estão além do controle pessoal, como, por exemplo, a qualidade do ar que se respira ou a pureza dos alimentos que se consome.

- Estilo de vida: conjunto das condições envolvidas nas decisões que o sujeito adota no que diz respeito à sua própria saúde, estando sob seu controle. São os ditos riscos autocriados, relativos aos hábitos, às normas, aos valores, ao nível de escolaridade e à consciência que condicionarão a saúde individual.

- Determinante serviço de saúde: refere-se à disponibilidade, quantidade e qualidade de recursos (bens e serviços) reservados aos cuidados em saúde e da forma como estes são dispostos nas ações de prevenção, cura e recuperação da condição de bem-estar. 
Neste sentido, os esforços de produção de novas ferramentas teóricas e metodológicas na saúde, a partir dos seus determinantes, repercutiram mais significativamente após a convocação, pela Organização Mundial de Saúde (OMS), da I Conferência Internacional sobre Atenção Primária de Saúde, realizada em Alma-Ata, no ano de 1978. Na ocasião, a saúde foi reconhecida como um direito a ser atendido não só pela melhoria do acesso aos serviços de saúde, mas também por um trabalho de cooperação com os outros setores da sociedade.

A Conferência de Alma-Ata recomendou que, para alcançar a meta de "Saúde para todos até o ano 2000", um conjunto de oito estratégias eram essenciais: educação dirigida aos problemas de saúde prevalentes e métodos para sua prevenção e controle, fornecimento de alimentos e nutrição adequada, abastecimento de água e saneamento básico apropriados, atenção materno-infantil e planejamento familiar, imunização contra as principais doenças infecciosas, prevenção e controle das doenças endêmicas, tratamento apropriado de enfermidades comuns e acidentes, e a distribuição de medicamentos essenciais (BUSS et al., 2000). As recomendações, o objetivo e a centralidade da Atenção Primária em Saúde na organização dos serviços e sistemas de saúde defendidos em Alma-Ata serviram para retomar a perspectiva mais ampla da Promoção da Saúde e fortalecer politicamente seus defensores, tanto na OMS quanto nos diferentes países.

No Brasil, diferentes materiais direcionados aos gestores de saúde reforçam a visão de Ashton (1993) de que as iniciativas no campo da Promoção da Saúde se orientavam, principalmente, pelo interesse em promover a equidade social, pela necessidade de reorientação dos serviços de saúde e de ampliação da participação comunitária. O autor destacou ainda que a Promoção da Saúde guia-se pela necessidade do desenvolvimento de coalizões entre o setor público, setor privado e o voluntariado, que, juntos, podem desenvolver ações cuja amplitude possa permitir o enfrentamento da multicausalidade do processo saúde-doença. Nessa direção, o conceito mais amplo de Promoção da Saúde, assim como o desenvolvimento de novas 
práticas coerentes com suas bases político-ideológicas foi amadurecendo gradualmente.

Já na I Conferência Internacional de Promoção da Saúde, em 1986, com a aprovação da Carta de Ottawa, documento considerado o mais importante marco conceitual da Promoção da Saúde, afirmou-se o conceito de saúde como um estado de bem-estar holístico definido pela composição de aspectos biológicos, sociais, econômicos, educacionais, culturais e ambientais. A Carta destaca que para atingir um estado de completo bem-estar físico, mental e social, um sujeito ou grupo deve ser capaz de identificar e realizar aspirações, satisfazer necessidades e mudar e se adaptar ao meio. Saúde é, portanto, vista como recurso para a vida diária, não objetivo da vida. Saúde é um conceito positivo que enfatiza recursos sociais e pessoais assim como capacidades físicas (PROMOCIÓN DE LA SALUD, 2000, p. 12).

A dimensão da Promoção de Saúde, que reforça a importância da ação ambiental e da ação política, bem como a mudança do estilo de vida, foi muito importante como referência para a Conferência. Promoção de Saúde foi conceituada como um processo de capacitação dos sujeitos e coletividades para identificar os fatores e condições determinantes da saúde e exercer controle sobre eles, de modo a garantir a melhoria das condições de vida e saúde da população (ibid.).

Nessa visão positiva do processo, que ressalta o papel das potencialidades individuais e socioculturais para a produção social da saúde, a saúde deixa de ser um objetivo a ser alcançado, tornando-se um recurso para o desenvolvimento. A capacitação das coletividades referida na Carta de Ottawa deveria ser realizada em dois sentidos: (1) mais voltado para a melhoria das condições objetivas de vida, por meio da participação na formulação de políticas públicas saudáveis que Ihes permitissem alcançar funcionalidades elementares, tais como alimentar-se, obter abrigo e saúde; e (2) um sentido mais subjetivo, relacionado ao alcance de funcionalidades que envolvem 0 autorrespeito, as habilidades que favorecem a integração social, a capacidade para participar da vida social e outras. Essa capacitação, somada às ações de ampliação de poder e mobilização da população de modo geral, deveria 
contribuir, até mesmo, para que a saúde fosse considerada como um critério de governo no processo de tomada de decisões sobre desenvolvimento econômico-social.

A partir da concepção de saúde definida na Carta de Ottawa, firmaramse compromissos para a implementação da promoção de saúde que extrapolam o setor e exigem parcerias com outros setores do governo e da sociedade. Fazia-se necessário, portanto, convocar outras forças sociais para participarem desse movimento de ampliação da Promoção da Saúde. Era preciso fortalecer a capacidade de convocação do setor saúde para mobilizar recursos na direção da produção social da saúde e na responsabilização sobre ela. O projeto da Promoção da Saúde centrou-se, a partir de então, na obtenção da equidade sanitária, assegurando a igualdade de oportunidades e proporcionando os meios que possibilitassem a toda a população desenvolver ao máximo sua "saúde potencial" (BUSS et al., 2000, p. 173).

Nos anos seguintes, várias conferências internacionais de Promoção da Saúde foram realizadas pela Organização Mundial de Saúde (OMS). Neste sentido, o Ministério da Saúde tem compartilhado as principais conclusões e recomendações abordadas nas declarações e cartas que reforçam o referencial teórico da Promoção da Saúde em construção, conforme apresentado a seguir.

A II Conferência Internacional de Adelaide, realizada na Austrália, em 1988, elegeu como tema central as políticas públicas saudáveis, expressão que passou a caracterizar as políticas públicas de interesse de todas as áreas em relação à saúde e equidade. Nessa direção, houve um importante destaque para a intersetorialidade e para a construção de alianças e compromissos em torno de impactos positivos para promover a saúde.

Em 1991, quando ocorreu a III Conferência Internacional de Promoção da Saúde, em Sundsvall, na Suécia, o bloco soviético já entrara em decadência e já vinha se instalando um novo projeto de sociedade em torno do avanço neoliberal e globalização da economia. Essa Conferência teve o grande papel de colocar o tema ambiente na agenda da saúde. O "ambientalismo", como um movimento social desencadeado pela ampliação da consciência em relação 
aos problemas, aos desastres e às crises ambientais, estava, nesse momento, tornando-se uma nova utopia, passando a mobilizar muitos segmentos da sociedade. Na Conferência Internacional realizada no Brasil, em 1992, a ECO 92, foi reforçada a importância da construção de ambientes de apoio à Promoção da Saúde, a necessidade de políticas públicas saudáveis na área ambiental e, principalmente, o respeito à sustentabilidade nos processos de desenvolvimento.

Durante a Conferência Internacional de Jacarta, em 1998, na Indonésia, tanto a globalização da economia como a modernização tecnológica, em especial no campo da comunicação, já constituíam-se no ápice do processo de internacionalização do mundo capitalista. A ideologia hegemônica inaugura uma nova fase do capitalismo, a economia de mercado global, que passa a interferir na dinâmica da vida e do trabalho. Assim, uma pauta polêmica procurou discutir questões de marketing e do setor privado na tentativa de lidar com a diversidade e ampliar o envolvimento de maior número de setores. As conclusões foram que, para o desenvolvimento das ações, especialmente as relacionadas às políticas públicas, seria importante que os profissionais buscassem estabelecer parcerias e alianças para a resolução dos problemas, a partir da discussão conjunta e de sua causalidade, considerando os conflitos de interesses, as questões éticas, e desenvolvendo técnicas de negociação para a tomada de decisão.

Na Declaração de Jacarta, estabeleceram-se cinco prioridades para a Promoção da Saúde até o século XXI, com o intuito de enfrentar o novo tempo com novos conhecimentos e novas estratégias, quais sejam: 1) promover a responsabilidade social pela saúde; 2) aumentar a capacidade da comunidade e o poder dos sujeitos para controlar as ações que pudessem interferir nos determinantes da saúde; 3) expandir e consolidar alianças para a saúde; 4) aumentar as investigações para o desenvolvimento da saúde; e 5) assegurar a infraestrutura para a Promoção da Saúde.

$\mathrm{Na}$ V Conferência Internacional de Promoção da Saúde, ocorrida no México, no ano 2000, observou-se que a maioria dos compromissos assumidos durante as Conferências anteriores não havia sido cumprida. Uma nova 
metodologia de trabalho foi adotada privilegiando a discussão com os representantes ministeriais dos países lá representados. Os ministros assinaram a Declaração Presidencial, afirmando reconhecer a contribuição das estratégias de Promoção da Saúde para a manutenção das ações de saúde em nível local, nacional e internacional, e comprometendo-se a elaborar Planos Nacionais de Ação para monitorar o progresso da incorporação das estratégias de Promoção da Saúde na política nacional e local. Os técnicos presentes rediscutiram os assuntos relacionados às prioridades estabelecidas na reunião ministerial, reafirmando também a importância da Promoção da Saúde, da focalização dos determinantes da saúde e da necessidade de se construir um mundo com mais equidade (ANDRADE; BARRETO, 2002; WESTPHAL, 2007).

Após vinte anos da I Conferência Internacional de Promoção de Saúde, realizou-se a VI Conferência, em Bangkok, em 2005. Na ocasião, discutiu-se intensamente o tema da globalização como ampliadora de desigualdades e conflitos sociais, mas também de potencialidades que devem ser valorizadas pelos atores da Promoção da Saúde. A revolução tecnológica da informação é uma dessas potencialidades que tem possibilitado e ampliado continuamente 0 acesso e a troca de mensagens com muita rapidez, facilitando a universalização e o fortalecimento de novos movimentos sociais, como o feminista, o ecológico, o racial, entre outros, o que facilita e fortalece a advocacia por direitos e por políticas públicas saudáveis e equânimes. Várias estratégias foram discutidas no sentido de garantir a sustentabilidade ambiental e das ações de Promoção da Saúde, sendo que a busca e o estabelecimento de parcerias foram valorizados como importantes componentes, incluindo 0 setor privado, apesar das contradições que esse tipo de ação encerra.

A VII Conferência Internacional de Promoção da Saúde, ocorrida em Nairóbi, no Quênia, em outubro de 2009, identificou as estratégias-chave e os compromissos necessários para implementar e desenvolver ações de promoção de saúde. A discussão partiu do pressuposto de que tanto os países em desenvolvimento quanto os desenvolvidos enfrentam condições de saúde que comprometem o futuro e o desenvolvimento econômico dos países. Assim, foram elencadas responsabilidades a serem assumidas urgentemente pelos 
governos e tomadores de decisão: fortalecer as lideranças, tomar a promoção da saúde como política transversal, empoderar comunidades e indivíduos, fortalecer os processos participativos e construir e aplicar conhecimentos em torno da busca de evidências da efetividade da Promoção da Saúde.

A fim de contribuir na implementação da ação intersetorial em todas as políticas dos países, realizou-se, em 2013, a VIII Conferência Internacional de Promoção da Saúde, em Helsinque, na Finlândia. Com a denominação de Saúde em Todas as Políticas, pretendeu-se analisar o impacto e o progresso da Promoção da Saúde desde a Conferência de Ottawa; destacar o papel central da saúde na economia e sua relação com desenvolvimento humano e social, bem como apontar um conjunto de interconexões que já existem entre setores, e que demonstram o impacto sobre as condições de vida e saúde dos grupos populacionais.

A partir da análise das Conferências Globais de Promoção da Saúde, organizadas pela OMS, vê-se que, gradativamente, foram sendo reforçados e difundidos conceitos básicos como a equidade, a participação social e a intersetorialidade, que exigem o fortalecimento da saúde pública em torno do compromisso de "saúde para todos" (WESTPHAL, 2007). A proposta defendida a partir da Conferência de Ottawa e dos marcos legais do Sistema Único de Saúde no Brasil ampliou a responsabilidade do setor saúde, colocando-lhe outros campos de ação: 1) a defesa de políticas públicas saudáveis; 2) a articulação para criar ambientes de apoio à Promoção da Saúde - cidades, escolas, ambientes de trabalho, praças, parques ecológicos e outros; 3) o fortalecimento da ação comunitária; 4) o apoio ao desenvolvimento de habilidades e atitudes, especialmente em relação aos estilos de vida saudáveis; e 5) a reorientação da gestão dos serviços de saúde.

Também é relevante destacar a realização da Conferência Mundial sobre o Desenvolvimento Sustentável - Rio + 20, ocorrida em outubro de 2012, e que foi precedida pela Conferência Internacional de Saúde Urbana, pela Conferência Mundial sobre Determinantes Sociais da Saúde, em 2011, pelos Seminários Nacionais de Promoção da Saúde e pela Conferência Nacional de Saúde Ambiental. A Rio+20 colocou em destaque as relações entre 
Desenvolvimento Sustentável e Saúde na perspectiva da promoção da equidade, reafirmou os compromissos assumidos na Eco 92 e identificou os caminhos para fazer face aos desafios globais que se apresentam à humanidade, tendo como referência as dimensões econômicas, ambientais e sociais do desenvolvimento (NETTO, 2012).

A Conferência Mundial dos Determinantes Sociais de Saúde aprofundou a base conceitual de atuação sobre os determinantes de saúde a partir do modelo de Solar \& Irwin (2010; OMS, 2011).

Os vários elementos do modelo estão resumidos na Figura 2, que mostra como o contexto socioeconômico e político é um aspecto importante ao incluir elementos que podem afetar a saúde de forma mais decisiva: a governança, as políticas macroeconômicas, as políticas sociais e públicas (ou a ausência de tais políticas), a cultura e os valores sociais. Esses elementos dão origem a um conjunto de posições socioeconômicas que são estratificadas de acordo com a renda, educação, ocupação, sexo, raça/etnia e outros fatores. 


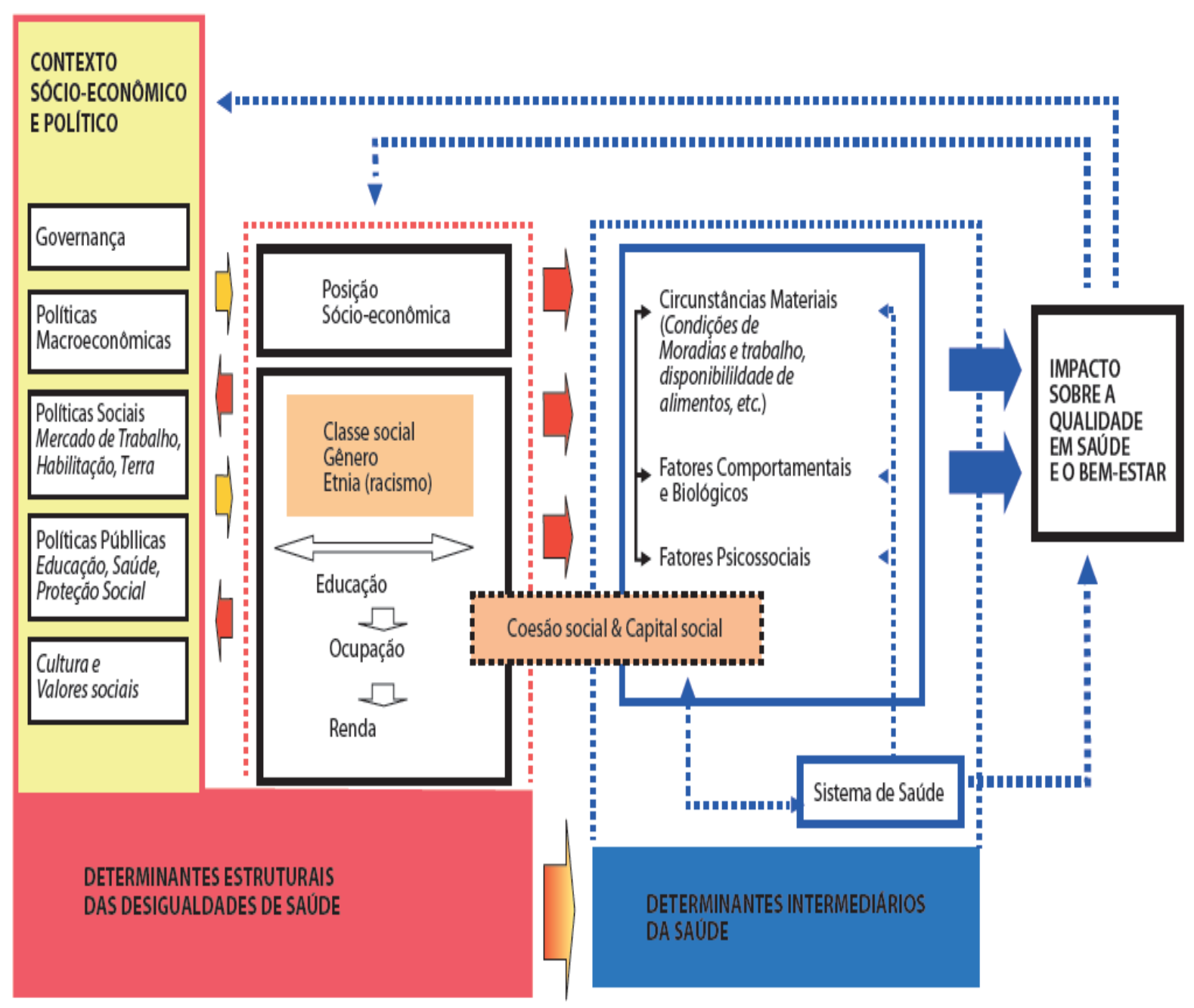

Figura 2. Modelo da determinação social da saúde de Solar \& Irwin (2010).

Dessa forma, o contexto, os mecanismos estruturais e a posição socioeconômica dos indivíduos são definidos como determinantes estruturais, ou como os determinantes sociais das desigualdades na saúde. Esses mecanismos estruturais - que alteram o posicionamento social dos indivíduos são a causa mais profunda das iniquidades em saúde - e deveriam ser prioridade na escolha da intervenção. Esses mecanismos impactam diretamente sobre os determinantes intermediários, como as circunstâncias materiais, os fatores comportamentais e/ou biológicos, fatores psicossociais e o próprio sistema de saúde.

As circunstâncias materiais incluem fatores como condições de moradia, trabalho e disponibilidade de alimentos. Já os fatores comportamentais e 
biológicos incluem a nutrição, atividade física, consumo de tabaco e álcool, além dos fatores genéticos, que são distribuídos de forma distinta entre os diferentes grupos sociais. As circunstâncias psicossociais incluem as formas de vida estressantes, os relacionamentos, os apoios sociais e as formas de enfrentamento dos problemas.

Nesse modelo, o papel do sistema de saúde torna-se relevante ao considerar e priorizar a questão do acesso, ao incorporar as diferenças de exposição e de vulnerabilidade dos grupos sociais, e por dar destaque à ação coordenada e intersetorial. O modelo aponta ainda a importância da coesão social e do capital social que articulam os determinantes estruturais e intermediários, e destaca a necessidade de implementação de intervenções coordenadas e coerentes entre si que influenciem os determinantes estruturais e impactem sobre a equidade em saúde e o bem-estar. Assim, reconhece-se que a boa saúde contribui para outras prioridades sociais como o bem-estar, a educação, a coesão social, a preservação do meio ambiente, o aumento da produtividade e o desenvolvimento econômico. Isso gera um "círculo virtuoso" no qual a saúde e os seus determinantes se retroalimentam e beneficiam-se mutuamente (OMS, 2011).

O compromisso em torno da equidade social e da saúde fortaleceu a atuação sobre os determinantes sociais da saúde como uma ampla abordagem intersetorial. A equidade em saúde foi considerada uma responsabilidade compartilhada que demanda 0 engajamento de todos os setores governamentais, dos diferentes segmentos da sociedade e de todos os membros da comunidade internacional, em uma ação global de "todos pela equidade" e "saúde para todos".

1.4 ORGANIZAÇÃO HISTÓRICA DA POLÍTICA DE SAÚDE NO BRASIL E A CONSTRUÇÃO DO SISTEMA ÚNICO DE SAÚDE - SUS

No contexto das transformações mundiais, no Brasil, desde o começo da década de 1970, muitos estudos e pesquisas já demonstravam que o modelo de desenvolvimento que o país tinha adotado (na época da ditadura) 
concentrava renda, não distribuía benefícios sociais e, com isso, prejudicava a saúde das pessoas. Da mesma forma, o sistema de saúde que vinha sendo implantado gastava mais que os benefícios que obtinha e não atendia adequadamente às necessidades da população. Não que antes a saúde da população fosse boa e o sistema de saúde adequado; mas, podendo fazer outras escolhas, o Governo optou pelo caminho mais perverso, ao priorizar os interesses particulares em relação aos públicos, alijando a população de qualquer participação nos seus destinos e criando um sistema de saúde de má qualidade, arraigado nas suas distorções e, por envolver muitos interesses escusos, resistente à mudança. Nesse contexto, surge o Movimento Sanitário Brasileiro que, utilizando aqueles estudos feitos nos anos anteriores, começou a denunciar os efeitos do modelo econômico sobre a saúde da população e a irracionalidade do sistema de saúde então implantado. Esse movimento, no entanto, se caracterizou não apenas por fazer denúncias contra a ditadura e os interesses econômicos com ela envolvidos, mas também por apresentar propostas construtivas, apresentando como alternativa um projeto de transformação do sistema de saúde vigente (RODRIGUEZ NETO, 1994).

Já em 1982, não suportando mais os gastos da Previdência Social com o Instituto Nacional de Assistência Médica e Previdência Social (Inamps), o governo brasileiro adotou algumas medidas de reorientação da sua política de assistência médica, mudando a forma de pagamento do setor privado contratado, pela introdução do pagamento por diagnósticos e não mais por atos e, por outro lado, celebrando convênios com as instituições dos estados e municípios para, repassando recursos, utilizar a capacidade pública instalada que, na época, estava extremamente ociosa. Essas propostas passaram a ser conhecidas, respectivamente, por Autorização de Internação Hospitalar (AIH) e Ações Integradas de Saúde (AIS).

As AIS, por seu lado, representaram, pela primeira vez, a possibilidade de que as instituições públicas de saúde se conhecessem mutuamente e começassem a fazer um planejamento mais articulado e até mesmo integrado. Propiciaram também a criação das Comissões Interinstitucionais de Saúde (CIS) e Comissões Interinstitucionais Municipais de Saúde (CIMS), que 
acabaram por se constituir na semente dos atuais Conselhos de Saúde, assim como foram a base para a implantação, mais à frente, dos Sistemas Unificados e Descentralizados de Saúde (SUDS), fase anterior à implantação do Sistema Único de Saúde (SUS). Com a superação do regime militar e o surgimento da Nova República em 1985, o movimento social se intensificou e foi possível uma discussão maior sobre os rumos que deveria tomar o sistema de saúde.

Prevista nos planos do novo governo e tendo em vista a realização da Assembleia Nacional Constituinte, em que seria discutida a nova ordem jurídico-institucional do país e celebrado um novo pacto entre os vários segmentos sociais, foi convocada a 8⿳ㅗ Conferência Nacional de Saúde, para discutir a nova proposta de estrutura e política de saúde para o país. Com uma ampla participação (cerca de 5.000 pessoas - dirigentes institucionais, técnicos, estudiosos, políticos e lideranças sindicais e populares), a $8^{\underline{a}}$ Conferência discutiu a situação de saúde do país e aprovou um relatório. As recomendações desse relatório passaram a constituir o projeto da Reforma Sanitária Brasileira, já então plenamente legitimado pelos segmentos sociais identificados com os interesses populares e que foi levado à Assembleia Nacional Constituinte em 1987, para disputar com outras propostas o que seria inscrito na Constituição sobre a Saúde.

Como destacado na perspectiva da determinação social, a construção da política de saúde como política social envolve diversos aspectos políticos, sociais, econômicos, institucionais, estratégicos, ideológicos, teóricos, técnicos, culturais, dentre outros, tornando-se muito difícil isolar a participação de cada um deles em um momento definido. Como atividade de proteção social, a política de saúde se coloca na fronteira das diversas formas de relação social, como a relação entre gestores e atores políticos, unidades governamentais e empresas, entre indivíduos e grupos sociais, entre cidadãos e os poderes públicos, entre consumidores e os provedores de bens e serviços. A ação da política de saúde sobre essas formas de relação é diferente em cada caso e envolve estratégias, planos, instrumentos e processos mediados por instituições e significados culturais. Portanto, a política de saúde se encontra na interface entre Estado, sociedade e mercado (FLEURY, 2009). 
De modo geral, a Reforma Sanitária foi uma proposta para a democratização da saúde brasileira. Primeiramente, inspirada nos movimentos internacionais, propôs que a saúde fosse entendida como resultado das condições de vida das pessoas. Isto é, que a saúde não é conseguida apenas com assistência médica, mas principalmente pelo acesso das pessoas ao emprego, com salário justo, à educação, a uma boa condição de habitação e saneamento do meio ambiente, ao transporte adequado, a uma boa alimentação, à cultura e ao lazer; além do acesso a um sistema de saúde digno, de qualidade e que resolvesse os problemas de atendimento das pessoas de acordo com suas necessidades. Isso significou a ratificação de que a conquista da saúde não poderia ser uma responsabilidade exclusiva da área da saúde, mas de todo o governo e da sociedade, por meio de suas políticas econômicas e sociais. Isso supunha uma necessidade de identificação do governo com as necessidades e aspirações da maioria da população e que a saúde fosse considerada uma finalidade do desenvolvimento econômico e social e não apenas um meio, como as demais políticas públicas (RODRIGUEZ NETO, 1994).

Para que isso se tornasse realidade, era necessário que, além das políticas gerais de governo que contribuíam para a melhoria da qualidade de vida, o setor saúde se organizasse de modo a zelar para que essas políticas fossem adequadas e produzissem os efeitos positivos sobre a saúde das pessoas e coletividades; assim como desenvolver as ações que visassem à promoção da saúde, à prevenção de doenças e ao atendimento adequado em situações de doenças e outros agravos à saúde.

A proposta que a Reforma Sanitária fez para o cumprimento dessas funções foi a implantação do Sistema Único de Saúde (SUS), que deveria atender a todos, de acordo com suas necessidades, independentemente de contribuição ou não à Previdência Social e sem cobrar pelo atendimento. Assim, segundo o Professor Eleutério Rodriguez Neto (1994), o SUS deveria atender as seguintes características:

- atuar de maneira integral, isto é, ver a pessoa não como partes, mas como um todo, que faz parte de uma sociedade, o que significa que as ações de saúde deveriam estar voltadas, ao mesmo tempo, para o indivíduo e para a 
comunidade, para a prevenção e para o tratamento, além de respeitar a dignidade humana.

- ser descentralizado, ou seja, o poder de decisão ser daqueles que são responsáveis pela execução das ações, pois, quanto mais perto do problema, mais chance se tem de acertar sobre a sua solução. Isso significava que as ações e serviços que atendem à população de um município deveriam ser municipais; as que servem e alcançam vários municípios deveriam ser estaduais; e aquelas que são dirigidas a todo o território nacional devem ser federais. Dessa forma, deveria haver uma inversão da situação à época, quando a maioria dos serviços de saúde estava vinculada ao nível federal, ao Inamps, e deveria passar para os níveis estadual e municipal, principalmente para este último, produzindo a chamada municipalização da saúde.

- ser racional, ou seja, o SUS deveria se organizar de maneira que as ações e os serviços fossem oferecidos de acordo com as necessidades da população. Para isso, o SUS deveria se organizar a partir de pequenas regiões e ser planejado para o atendimento específico dessas populações, de acordo com o que elas precisassem. É essencial, conforme o princípio da descentralização, que as decisões fossem tomadas pela autoridade de saúde no nível local, o que se convencionou chamar de Distrito Sanitário.

- ser eficaz e eficiente, isto é, deveria produzir resultados positivos quando as pessoas o procuram ou quando um problema se apresenta na comunidade. Para tanto, precisa ter qualidade e utilizar as técnicas mais adequadas de acordo com a realidade local e a disponibilidade de recursos, eliminando o desperdício e fazendo com que os recursos públicos sejam aplicados da melhor maneira possível, com a adoção de técnicas modernas de administração dos serviços de saúde.

- ser democrático, ou seja, deve assegurar o direito de participação de todos os segmentos envolvidos com o sistema - dirigentes institucionais, prestadores de serviços, trabalhadores de saúde e, principalmente, a comunidade, a população, os usuários dos serviços de saúde. Esse direito implica a participação de todos esses segmentos no processo de tomada de decisão sobre as políticas que são definidas no seu nível de atuação, assim como no controle sobre a execução das ações e serviços de saúde. Por isso, a 
ideia e a estratégia de organização dos Conselhos de Saúde - nacional, estaduais e municipais - para exercerem esse controle social sobre o SUS, com critério de composição paritária e poder de decisão (não ser apenas consultivo).

Em 1988 a Assembleia Nacional Constituinte aprovou a nova Constituição Brasileira, incluindo, pela primeira vez, uma seção sobre a Saúde. Essa seção sobre Saúde incorporou, em grande parte, os conceitos e propostas da 8a Conferência Nacional de Saúde, podendo-se dizer que, na essência, a Constituição adotou a proposta da Reforma Sanitária e do SUS.

Na Lei Orgânica da Saúde - Lei no 8.080/90 -, a descentralização político-administrativa foi enfatizada na forma da municipalização dos serviços e ações de saúde, que significou redistribuição de poder, competências e recursos em direção aos municípios. A organização dos Distritos Sanitários foi uma das estratégias propostas para mudar o modelo assistencial e as práticas de saúde, com efetiva participação social. A Lei ํo 8.142/90 dispôs sobre a participação da comunidade na gestão do SUS e condicionou o recebimento de recursos financeiros à existência de Conselho Municipal de Saúde funcionando de acordo com a legislação.

Assim, o SUS representou uma inovação, uma verdadeira reforma do Estado brasileiro, no sentido de recuperar sua função pública. Porém, ainda hoje enfrenta problemas em sua implantação, que se prendem ao fato de estar praticamente restrito ao setor da saúde e muito dependente da iniciativa governamental. Contudo, a Reforma Sanitária colocou em debate os princípios da política de saúde ao destacar seus determinantes e condicionantes sociais na relação saúde-doença, o que foi incorporado ao texto constitucional e ao SUS pela perspectiva de redução do risco de doenças e outros agravos e do acesso universal e igualitário às ações e serviços de promoção, proteção e recuperação da saúde (BRASIL, 1988). Todavia, somente em 2006 foi institucionalizada uma Política Nacional de Promoção da Saúde, com o propósito de promover a qualidade de vida e reduzir as vulnerabilidades sociais. 


\title{
1.5 PROMOÇÃO DA SAÚDE COMO ELEMENTO INDISSOCIÁVEL DA AGENDA DE DESENVOLVIMENTO SUSTENTÁVEL
}

\begin{abstract}
Reconhecemos que a saúde é uma condição prévia, um resultado e um indicador das três dimensões do desenvolvimento sustentável. Estamos convencidos de que as medidas sobre os determinantes sociais e ambientais da saúde, tanto para os pobres e vulneráveis como para toda a população, são importantes para criar sociedades inclusivas, equitativas, economicamente produtivas e saudáveis (OPAS, 2014).
\end{abstract}

As condições de vida e saúde têm melhorado de forma contínua e sustentada na maioria dos países do mundo, graças aos progressos políticos, econômicos, sociais e ambientais, assim como aos avanços na saúde pública e na medicina. Entretanto, ainda que tal melhoria seja incontestável, também o é a permanência de profundas desigualdades nas condições de vida e saúde entre os países e, dentro deles, entre as regiões e grupos sociais (BUSS, 2000). No campo das políticas públicas, essa contradição se expressa nas ambiguidades e incertezas que cercam a conformação das agendas estratégicas de crescimento econômico, desenvolvimento social e promoção da saúde.

A perspectiva de Desenvolvimento Sustentável trazida pela Agenda $21^{5}$, a partir da análise e da busca pela mensuração dos avanços compreendidos em suas três dimensões - social, econômica e ambiental - contribuiu para aprofundar as discussões sobre a integração dos aspectos econômicos e sociais relacionados ao desenvolvimento social e da saúde da população. $\mathrm{Na}$ declaração da Conferência Mundial sobre os Determinantes Sociais da Saúde, foi reconhecida a importância das políticas públicas para o alcance do desenvolvimento sustentável e da equidade sanitária por meio de intervenções focalizadas nos determinantes sociais (OMS, 2011). De acordo com a Organização Pan Americana para Saúde (OPAS), apesar de situada dentro da

\footnotetext{
${ }^{5}$ Em 1992, a Cúpula da Terra (Eco92) produziu um plano de ação - Agenda21 - para os governos, agências das Nações Unidas, grupos de interesse e sociedade em geral (ONU, 1992). Nessa ocasião, definiu-se o Desenvolvimento Sustentável como a satisfação das necessidades da atual geração sem comprometer a capacidade de satisfação das necessidades das gerações futuras.
} 
dimensão social, a saúde é determinada pelas condições sociais, ambientais e econômicas de uma sociedade e, por sua vez, determina em parte essas condições (OPAS, 2014). Em 2012, essa visão foi fortalecida no documento final da Conferência das Nações Unidas sobre Desenvolvimento Sustentável Rio+20, que reafirma a concepção de promoção da saúde na perspectiva do desenvolvimento sustentável.

As transformações sociais, demográficas e epidemiológicas ocorridas no decorrer do século passado estabeleceram um novo padrão de desenvolvimento socioeconômico rumo às sociedades industriais avançadas, tecendo, assim, novos desafios para o enfrentamento das desigualdades sociais, para a conformação das políticas governamentais e para o progresso científico e tecnológico da sociedade, diante da iminente diminuição da força de trabalho, do aumento dos gastos sociais, da globalização econômica e da necessidade de se estabelecer novos ideais para a qualidade de vida da população.

Contudo, desde o início da década de 1990 o advento da globalização tem lançado fortes críticas ao sistema de proteção social de caráter público. Discutiu-se muito sobre o fracasso do Estado de bem-estar social, ainda incompleto nos países "em desenvolvimento", e sobre as dificuldades para financiá-lo, já que o número de pessoas jovens e adultas vem diminuindo, a população idosa vive cada vez mais e a atenção à saúde é cada vez mais cara. Em uma economia globalizada, cada vez mais o conhecimento e a qualidade de vida são vistos como imprescindíveis para o aumento da produtividade e, portanto, da competitividade no mercado internacional (FLEURY, 2012).

Segundo Buss (2007), a globalização é um processo que ultrapassa a esfera econômica, sendo também social e cultural, que vem apresentando para o mundo elementos inéditos, como a consolidação de um mercado mundial; a transnacionalização das empresas e organizações; a eliminação das fronteiras para a circulação do capital, mercadorias e pessoas; a privatização da economia e o Estado mínimo; e o surgimento da "sociedade da informação", ampliando-se as possibilidades de comunicação, principalmente por meio da internet. $\mathrm{O}$ autor também faz uma crítica ao fenômeno em questão, relatando 
que a aproximação entre economias e culturas desiguais restringiu as políticas territoriais de Estado à resolução das dificuldades no âmbito das atividades transnacionais, e tem exacerbado os interesses de mercado e gerado ainda mais pobreza, o que é reconhecido por autores de diversas perspectivas teóricas (BUSS, 2007).

A pobreza, não obstante sua proximidade com noções como a qualidade de vida ou de bem-estar, foi principalmente estudada em seus aspectos materiais, usualmente relacionados com conceitos como o "nível ou padrão de vida, as "necessidades" ou a insuficiência de recursos", sendo os indicadores mais empregados: a satisfação de certas necessidades, o consumo de bens ou o rendimento disponível. Na perspectiva das necessidades, importa a privação dos bens materiais requeridos para funcionar minimamente como um membro da sociedade, com o qual se limitou atenção a uma lista predeterminada de artigos específicos. Por outro lado, no termo "padrão de vida", temos considerado o bem-estar privado de um modo de vida socialmente aceitável, com o qual $o$ interesse se dirige aos recursos econômicos que permitem às pessoas participarem deste estilo de vida (FERES; MANCERO, 2001).

Nessa direção, nos últimos anos, cobrou-se relevância na discussão acadêmica e, nas agendas políticas, cobrou-se a necessidade de avançar para um enfoque mais amplo para a medição da pobreza. A partir daí, os estudos passaram a considerar também dimensões não monetárias da pobreza, uma vez que as medidas baseadas exclusivamente na renda corrente são aproximações à capacidade de consumo privado através do mercado, e não captavam o acesso aos bens públicos, o que faz com que a correlação renda e bem-estar se desfaça (FERES; MANCERO, 2001). Propôs-se então que a pobreza, mais do que aludir a um baixo padrão de qualidade de vida, expressava-se na privação de capacidades no acesso aos direitos básicos e na negação da cidadania (SEN, 2000).

O Centro para a Investigação da Pobreza Crônica ${ }^{6}$ compreende que a pobreza pode ser analisada em três expressões fundamentais: alcance,

\footnotetext{
${ }^{6}$ The Chronic Poverty Research Centre (CPRC) foi uma parceria internacional de universidades, institutos de pesquisa e ONGs, que tratou de aprofundar a compreensão das causas da pobreza crônica, desde análises até a orientação política sobre a redução da
} 
profundidade e dinâmica. A noção de alcance alude às diferentes dimensões nas quais pode se manifestar a pobreza (por exemplo, aspectos monetários, de capital humano, sociopolíticos e psicossociais). Por sua vez, a profundidade alude à distância que os pobres estão em relação à linha de pobreza ${ }^{7}$. E a dinâmica inclui a duração de um estado de pobreza e os movimentos de entrada e saída desta situação. Essas perspectivas apoiaram-se em novos marcos conceituais, como o enfoque de direitos e a perspectiva de desenvolvimento social e humano.

Seguindo nesta trajetória, podemos entender por desenvolvimento social a ampliação das condições de qualidade de vida e do exercício dos direitos de uma dada população, com o objetivo de promover o compartilhamento da riqueza material e imaterial disponível em um grupo social (INOSOJA, 1998). O patamar material mínimo e universal de qualidade de vida diz respeito à satisfação das necessidades mais elementares da vida humana: alimentação, acesso à água potável, habitação, trabalho, educação, saúde e lazer; elementos materiais que têm como referência noções relativas de conforto, bem-estar, e realização individual e coletiva (MINAYO, 2000). Assim, as perspectivas de desenvolvimento social e qualidade de vida se reaproximam e se integram à noção de Promoção da Saúde.

Isso porque a diferença de riqueza material entre as pessoas se reflete nos indicadores de saúde da população. Em se tratando de Brasil, por exemplo, a mortalidade infantil está relacionada com a renda das famílias, o nível de educação da mãe, as condições do domicílio, o local em que vive e a situação social da família da criança (BUSS, 2007). Não obstante a tendência

pobreza crônica. O CPRC foi financiado pelo UK Department for International Development. Para maiores informações consulte: http://www.chronicpovertynetwork.org/ , o site do Chronic Poverty Advisory Network (CPAN).

${ }^{7}$ Sob este enfoque indireto, utiliza-se a renda (ou a capacidade de consumo) como uma aproximação do nível de vida das pessoas e emprega-se uma cesta básica de consumo composta por diversos bens e serviços, em que a linha de pobreza é o gasto necessário para adquirir essa cesta básica. Habitualmente, subdivide-se a cesta em dois grupos de bens, "alimentícios" e "outros", em que para os primeiros se considera uma cesta que cumpra os requerimentos nutricionais (FERES; MANCERO, 2001). 
de queda secular nas taxas de mortalidade infantil, as disparidades entre regiões, territórios e grupos sociais ainda são bastante expressivas no país.

De acordo com Buss, nas últimas décadas, tanto na literatura nacional, como internacional, também se observou um extraordinário avanço no estudo das relações entre a maneira como se organiza e se desenvolve uma determinada sociedade e a situação de saúde de sua população. Esse avanço é particularmente marcante no estudo das iniquidades em saúde, ou seja, daquelas desigualdades de saúde entre grupos populacionais que, além de sistemáticas e relevantes, são também evitáveis, injustas e desnecessárias. Segundo Buss (2007), citando Nancy Adler (2006), podemos identificar três gerações de estudos sobre as iniquidades em saúde. A primeira geração se dedicou a descrever as relações entre pobreza e saúde; a segunda, a descrever os gradientes de saúde de acordo com vários critérios de estratificação socioeconômica; e a terceira e atual geração está dedicada principalmente aos estudos dos mecanismos de (re)produção das iniquidades.

Neste contexto, pensar em promoção da saúde na nossa realidade concreta é pensar em políticas públicas voltadas para a diminuição das iniquidades existentes na sociedade, evidenciadas nas desigualdades em saúde, mas cujas raízes situam-se nas desigualdades de acesso às condições mínimas de cidadania. Implica, em primeiro lugar, ter como diretriz política a eliminação das múltiplas carências cotidianas da vida individual e coletiva, que passam pela pobreza, pela fome, pela exclusão social, inclusive de acesso aos serviços e práticas de saúde. Assim como situar esses objetivos no vértice da pirâmide de prioridades políticas, visto que são esses os verdadeiros determinantes do desequilíbrio social e sanitário forjado em nossa sociedade (VERDI, 2004).

Assim, as políticas públicas de Desenvolvimento Social e Promoção da Saúde se conectam à perspectiva do Desenvolvimento Sustentável a partir da concepção ampliada das condições e estilos de vida da população e de seus determinantes sociais, políticos, econômicos e ambientais, propondo a articulação de saberes técnicos e populares, e a mobilização de recursos institucionais e comunitários, públicos e privados, para a melhor compreensão 
e alcance das necessidades humanas e das diversidades sociais (BRASIL, 2006a).

No entanto, a relação entre políticas de saúde, com as demais políticas sociais e econômicas é, na maioria das vezes, uma relação tensa, pois os governos costumam ver as políticas sociais como áreas de gasto, e não de produção. Nos momentos de crise econômica e contenção de gastos governamentais, a área econômica do governo impõe limites aos gastos sociais para a preservação do equilíbrio financeiro. Contudo, as áreas de políticas sociais deveriam ser também vistas como áreas produtivas, pois são geradoras de empregos nas diferentes regiões do país, já que as redes de proteção social e saúde têm acentuada capilaridade no território nacional.

Além de geradoras de emprego, as políticas de saúde também contribuem para o desenvolvimento econômico ao promover a qualidade de vida, impedir a mortalidade precoce e desnecessária, e formar uma força de trabalho mais educada e em melhores condições sanitárias. Dessa forma, as políticas de saúde se tornam um ponto de convergência entre os interesses sociais e econômicos, entre trabalhadores e empresários, representando o consenso virtuoso da socialdemocracia, por meio do qual não só se amenizam os conflitos e as tensões sociais, mas também se promove um aumento da produtividade do trabalho (FLEURY, 2009).

Assim, cada vez mais, busca-se superar as limitações arbitrárias entre as políticas econômicas e sociais, ao introduzir, por exemplo, a noção de investimento em saúde como investimento produtivo, e não somente gasto social, e reconhecer a capacidade econômica destes na produção de empregos e consumo de bens industriais. Nesta direção, podemos entender que as políticas de saúde, suas estratégias, instrumentos e planos produzem uma ação que não se limita ao campo da saúde, uma vez que, podendo influir em diversos outros aspectos da dinâmica social, também podem, igualmente, cumprir vários outros papéis, ou funções, além de seu objetivo básico de resolver problemas por meio de assistência à saúde.

Neste contexto, ainda que ventiladas pelas ambiguidades e incertezas do debate acumulação versus equidade, advindos do final do século $X X$ e início do século XXI, as políticas públicas voltadas à Promoção da Saúde ganharam 
ênfase no Brasil com a Agenda do Desenvolvimento Social e Combate à Pobreza. Assim, a perspectiva de expansão dos direitos sociais e econômicos da população, a qualificação da oferta e prestação de serviços públicos às populações vulneráveis e a ampliação dos mecanismos de participação e controle social estiveram à frente das prioridades do "desenvolvimento sustentável" adotado pelo governo nas últimas décadas. Essas estratégias têm orientado o discurso e a agenda política federal na lógica de integração das políticas sociais com as políticas econômicas, e promovido a articulação dos setores de governo na formulação e implementação de políticas públicas sob a égide do enfrentamento à pobreza, combate à fome e erradicação da miséria.

Essa Agenda ampliou a atuação do governo federal sobre os condicionantes e determinantes sociais da saúde. Intensificaram-se as intervenções nas políticas econômicas para assegurar o controle inflacionário e o fortalecimento do salário mínimo, ao mesmo tempo em que se ampliaram as políticas de concessão de benefícios sociais e transferência de renda. De modo geral, cresceram os investimentos na estruturação e organização das redes de serviços essenciais, na qualificação profissional e no estimulo à geração de oportunidades de trabalho, como forma de promover a inclusão social e melhorar o acesso e o consumo de grupos vulneráveis a bens e serviços básicos. Dessa forma, intensificaram-se os esforços para integrar as melhores iniciativas das políticas sociais, por meio da expansão, coordenação e acompanhamento das ações dos diferentes setores de forma intersetorial.

Por tudo isso, a Agenda Política do governo federal tem estimulado uma reaproximação das políticas sociais como forma de qualificar a atuação do Estado sobre as demandas sociais e implicado a necessidade de aperfeiçoamento político, institucional e operacional das ações programáticas e setoriais das políticas públicas, por meio da instalação de processos de planejamento integrado e participativo das ações e serviços públicos, orientados para a construção de objetivos comuns e o alcance de resultados sinérgicos para o desenvolvimento sustentável. Portanto, a qualificação da oferta e o acesso aos serviços públicos de saúde a partir das concepções de desenvolvimento social e qualidade de vida parecem ter ganhado espaço na 
formação da agenda de prioridades do governo, principalmente a partir do anos 2000, abrindo-se uma "janela de oportunidade"8 para reflexão e consolidação da Política Nacional de Promoção da Saúde na agenda governamental.

${ }^{8}$ Dadas circunstâncias podem abrir oportunidades para uma questão entrar na agenda estratégica dos governos. Distintos fluxos (de problemas, de políticas públicas e de emergência política) caminham normalmente separados até que se cruzam, abrindo, então, a janela de oportunidades para mudanças (KINGDON, 1984, apud DAMASIO, 2011). Este é um ponto de diálogo aberto entre os modelos de políticas públicas e os institucionalistas. As janelas de oportunidades são condições similares às conjunturas críticas para mudanças de agenda política tanto quanto para introdução de inovações institucionais (DAMASIO, 2011). http://bibliotecadigital.fgv.br/dspace/bitstream/handle/10438/8547/DISSERT LEANDRO\%20DA MASIO.pdf?sequence $=1$ 


\section{REFERENCIAL TEÓRICO: ABORDAGEM DE POLÍTICAS PÚBLICAS E GESTÃO INTERSETORIAL}

\subsection{ESTRUTURAÇÃO DO APARATO GOVERNAMENTAL DAS POLÍTICAS SOCIAIS NO BRASIL}

Segundo Inosoja (1998), a conformação histórica do Estado brasileiro foi eivada por valores patrimonialistas e clientelistas presentes na sociedade, introduzindo a confusão entre o público e o privado. A concepção mecanicista, somada a esses valores, resultou num aparelho excludente tanto do ponto de vista da participação nas decisões quanto na contribuição para a redistribuição de riquezas. As políticas sociais gerenciadas por esse modelo de organização do governo configuraram-se como assistencialistas ${ }^{9}$, considerando os problemas sociais como carências e não como direitos. Essas políticas não visaram essencialmente à transformação da sociedade, mas à manutenção de seu equilíbrio para a própria preservação dos interesses hegemônicos (INOSOJA, 1998).

Dessa forma, as estruturas organizacionais do aparato governamental se constituíram em formato piramidal, composto de vários escalões hierárquicos e dividido por disciplinas ou áreas de especialização. A essas características somaram-se um conjunto de práticas de organização do trabalho, como: centralização decisória, planejamento normativo, dicotomia entre planejamento e execução, sigilo e ocultação de informações, formalização excessiva e distanciamento do cidadão e do usuário, dificultando o controle social. Do ponto de vista da modelagem, a organização pública do aparato governamental nos três níveis de governo no Brasil seguiu os antigos paradigmas da teoria clássica da administração.

Já a partir da década de 1990, com a formulação da proposta de desenvolvimento da Comissão Econômica para América Latina e Caribe

\footnotetext{
9 A noção assistencialista caracteriza o modo de fazer política social, que tem como consequência criar uma relação de submissão e não oferecer os instrumentos para superação das carências que estão sendo minoradas. Quando associadas ao clientelismo, as formas de assistência podem se transformar em fortes instrumentos de poder (CARDOSO, 2004). Ver http://www.scielo.br/scielo.php?pid=S0102-88392004000200005\&script=sci arttext .
} 
(CEPAL) e Organização Pan-Americana da Saúde (OPAS), denominada "transformação produtiva com equidade" ${ }^{10}$, colocou-se em pauta a adoção do enfoque integrado como perspectiva de análise para as políticas de Estado, tendo em vista que outras abordagens tratavam as políticas econômicas e sociais de forma fragmentada, e não beneficiavam nem o crescimento econômico nem a equidade social. Além disso, a proposta defendeu a integração das políticas por meio do apoio recíproco e complementação entre as medidas de fomento à competitividade e àquelas capazes de promover a coesão social (RIZOTTO, 2013).

Esse enfoque acolheu e fortaleceu a concepção de Estado voltado à Promoção da Saúde e apontou para a necessidade de mudança concreta na estrutura governamental, para capacitá-la a outro tipo de relação com a sociedade. Os governos orientados para a garantia dos mínimos sociais e da qualidade de vida a todos os cidadãos precisavam construir uma interferência intencional e monitorada nas questões que estão no seu espaço de governabilidade. Nesta direção, a discussão de modelos alternativos de gestão voltados à superação dos modelos hierárquicos e fragmentados ganhou importância impulsionada pelo fortalecimento dos processos de descentralização e intersetorialidade nas políticas públicas.

Entretanto, ainda que houvesse certa convergência quanto ao caráter virtuoso da aposta na descentralização, na intersetorialidade e em modelos de gestão alternativos (JUNQUEIRA, 1998), persistiram as dúvidas quanto às formas mais adequadas de planejar, organizar, conduzir, gerir e avaliar tais intervenções (VIANA, 1998). Nesse particular, ainda há divergências quanto à ênfase e à precedência de reformas gerenciais ${ }^{11}$ para compor novos arranjos organizacionais e institucionais, além de perplexidades em relação às práticas

${ }^{10}$ Salud, equidade y transformación produtiva em América Latina e Caribe; OPAS, CEPAL, 1997.

${ }^{11}$ O movimento das reformas gerenciais na década de 1990, inspirado na administração de empresas privadas, busca modernizar o Estado e tornar sua administração mais eficiente e voltada para o cidadão-cliente. Para tanto, prioriza a estratégia da gestão pela qualidade dos resultados, mas deixa claro que as formas de gestão podem assumir formatos variados. $O$ problema central da reforma não é escolher entre estratégias de gestão, mas criar instituições que viabilizem a adoção dessas estratégias (BRESSER-PEREIRA,2000). RAP Rio de Janeiro 34(4):7-26, Jul./Ago. 2000. Disponível em: http://www.bresserpereira.org.br/papers/2000/608RefGerencial 1995-RAP.pdf 
políticas necessárias à distribuição do poder e à reorganização dos processos de trabalho (PAIM, 1992; INOJOSA, 1998), sobretudo no que se refere à integração de políticas públicas para assegurar legitimidade e efetividade à atuação social do Estado.

De acordo com Inosoja, para se modelar uma organização governamental a partir da lógica intersetorial, em termos de desenho de estrutura, é preciso avançar na constituição de órgãos governamentais que sejam capazes de proporcionar a melhoria das condições de vida da população de forma integral. Essa dinâmica supõe um planejamento geral, com base territorial, acima das áreas setoriais, que articule os planos particulares de cada uma delas e as respectivas redes de serviço. De acordo com a autora, a configuração desse novo modelo de gestão entre políticas públicas visa introduzir práticas de planejamento e avaliação participativas e integradas, o compartilhamento de informações e a permeabilização ao controle social (INOSOJA, 1998). Entretanto, esses aspectos da dinâmica de cada uma das áreas da política social são complexos e de extrema importância no desenvolvimento dos sistemas e redes de proteção social, uma vez que é nesses aspectos que os sistemas adquirem forma concreta e agem diretamente sobre a realidade social.

2.2 ABORDAGEM DE POLÍTICAS PÚBLICAS: ATORES, INSTITUIÇÕES, DISPUTAS E CONFLITOS COMO OBJETOS INERENTES À GESTÃO INTERSETORIAL

No campo de análise das políticas públicas, os padrões de ação de atores governamentais, políticos e sociais envolvidos nos processos decisórios constituem elementos analíticos importantes desde as primeiras investigações nesse campo, desenvolvidas a partir da década de 1960. Inicialmente, os trabalhos produzidos identificavam exclusivamente os atores considerados politicamente relevantes para esse processo, os quais representavam, em maior ou menor grau, o Estado e os grupos de interesse vinculados à política pública em questão. 
Com o avanço dos debates e das investigações sobre políticas públicas nos anos 1970, em resposta, sobretudo, às mudanças políticas e socioeconômicas ocorridas nesse período, novas interpretações passaram a compor o leque de abordagens preocupadas em compreender e explicar os processos de formação e de mudanças das políticas. Dentre as mais proeminentes, estavam a abordagem institucional, de redes, da teoria da escolha racional e a abordagem baseada no papel das ideias ${ }^{12}$ (JOHN, 1999).

Nesta direção, a análise de políticas públicas exige enfoques multidisciplinares e tem comportado arranjos metodológicos variados que visam compreender as relações complexas que se instituem no lócus de organização social estabelecido entre Estado, Mercado e Sociedade. Como campo de estudo, a principal contribuição desse tipo de análise tem sido possibilitar maior transparência e reflexão sobre o padrão político, organizacional e decisório adotados pelos Estados Modernos (VIANA; BAPTISTA, 2012).

Assim, a orientação desta pesquisa procura trabalhar com a abordagem geral de análise de políticas públicas ("policy analysis"), que consiste na explanação das leis e princípios próprios das políticas específicas e pretende, assim, analisar a inter-relação entre as instituições políticas, o processo político e os conteúdos da política, buscando superar abordagens isoladas que priorizam ou a dimensão institucional ou a dimensão político-processual, mas pela confluência dessas dimensões a partir da dimensão material da política, ou as políticas públicas propriamente ditas, por meio de seus programas, ações e serviços (FREY, 2000).

A literatura sobre a análise de políticas públicas diferencia três dimensões da política:

- A dimensão material ('policy'), que se refere aos conteúdos concretos, isto é, à configuração dos programas políticos, aos problemas técnicos e ao

\footnotetext{
${ }^{12}$ A abordagem cognitiva na análise de políticas públicas ganha importância nos anos 19801990 insistindo sobre o papel do conhecimento, das ideias, das representações ou das crenças sociais nas políticas públicas. As políticas públicas são, aqui, analisadas como determinadas pelas crenças comuns de um conjunto de atores (públicos e privados), as quais definem a maneira como estes atores percebem os problemas públicos e concebem as respostas para esses problemas (GRICA, 2010).
} 
conteúdo material das decisões políticas, alcançando assim, a dimensão das ações, serviços e resultados das políticas públicas.

- A dimensão processual ('politics'), que tem em vista o processo político, frequentemente de caráter conflituoso, no que diz respeito à imposição de objetivos, aos conteúdos e às decisões de distribuição de poder. Esta dimensão procura investigar a participação dos atores políticos no processo de tomada de decisão acerca dos problemas, buscando identificar a representação de interesses dos atores envolvidos na formulação e implementação das políticas.

- A dimensão institucional ('polity'), que se refere à ordem do sistema político, delineada pelo sistema jurídico, e à estrutura institucional do sistema político-administrativo. Esta dimensão busca identificar a importância das instituições e setores de políticas públicas (histórico, cultura e aparato organizacional) na formulação dos preceitos legais e organizacionais estruturados para o alcance dos resultados propostos.

A partir desses referenciais, direcionamos nossa análise para o estudo de caso da Política Nacional de Promoção da Saúde (PNPS), a fim de verificar a organização institucional e os aspectos de intersetorialidade implementados para a gestão dessa política. Para tanto, procedemos a uma análise documental da PNPS considerando dois marcos temporais de sua construção: o momento de sua criação, em 2006; e seu processo de atualização, ocorrido em 2014. Com esse direcionamento, focamos prioritariamente o caráter político-institucional da PNPS, em que tornam-se importantes as interações entre os arranjos institucionais, as atitudes e objetivos dos atores políticos, os instrumentos de ação e as estratégias políticas constituídas para a conformação da Política Nacional de Promoção da Saúde.

O foco nos processos de elaboração de políticas e nas relações entre atores em um arranjo interativo enfrenta diversos desafios no que tange aos tipos de dados a serem coletados. Bogason e Zolner (2007) expressam essas dificuldades ao afirmar que dados sobre os resultados das políticas e os atores que participam não são suficientes, sendo necessárias informações sobre a interdependência dos atores em termos de recursos, processos ou ação e a natureza da interação entre eles. Boa parte dos processos interativos de 
interesse desse tipo de pesquisa é informal, ou, ainda que tenha aspectos formais, seu funcionamento real apresenta particularidades que não estão formalmente registradas e sobre as quais não se discute em público, tornando necessários métodos de coleta de dados que incluam maneiras de dar voz aos atores participantes, de forma que eles explicitem os aspectos relevantes.

De fato, a metodologia proposta neste estudo tem como limitação reconhecida o fato de não capturar os elementos informais da coordenação interorganizacional. Ainda que alguns instrumentos de gestão possam estar formalmente descritos no desenho do Política, a dinâmica da governança pode alterá-los, descartá-los ou ainda fazer surgir novos instrumentos. Ademais, as lógicas subjacentes a esses instrumentos dificilmente podem ser captadas por métodos de pesquisa formais. Como forma de superar essa limitação, seria importante, em análises futuras, que essas investigações pudessem combinar a análise de documentos relativos ao caso em estudo com a realização de entrevistas com atores-chave da PNPS nos diferentes setores e níveis de governo.

O tema da intersetorialidade vem ganhando visibilidade e adesão de boa parte dos atores envolvidos com a análise e produção de políticas públicas, especialmente daquelas direcionadas ao enfrentamento da pobreza e Promoção da Saúde. Entretanto, a literatura especializada vem demonstrando que na prática uma gestão intersetorial suscita altos níveis de conflito e disputa política entre as diferentes áreas e atores envolvidos no processo. Além da competição em torno das estruturas de poder, também se percebem as disputas corporativas que permeiam o aparelho do Estado.

No cenário de atuação das organizações governamentais, o poder sempre é dividido, com maior ou menor assimetria, entre os atores internos, as corporações profissionais, e outros atores provenientes da sociedade civil, que a elas se integram temporariamente ou que, de algum modo, participam do processo decisório (INOSOJA,1998). Entretanto, para Costa, Pontes e Rocha (2006), a faculdade de reconhecimento dos limites de poder e de atuação entre os setores não constitui propriamente uma facilidade para os atores envolvidos, especialmente para aqueles que gozam das condições oferecidas pelo poder 
institucional. Há uma distância significativa entre o discurso e as práticas envolvidas na organização das políticas públicas pelo Estado, e as configurações institucionais não mudam apenas pela vontade política expressa em lei. Para mudar as relações de poder e as práticas institucionais, são necessárias diversas mediações e diversas iniciativas capazes de viabilizar esse processo (JUNQUEIRA, 2000).

Tem-se, portanto, suficiente consenso de que as concepções de gestão intersetorial acenam para um conjunto de inovações de natureza conceitual e organizacional no âmbito da gestão pública, em um contexto no qual os sistemas técnicos especializados e as estruturas de poder fortemente hierarquizadas e verticais são confrontados com novos objetivos e demandas políticas e sociais, que exigem uma remodelagem das velhas estruturas organizacionais e novas respostas das quais a intersetorialidade e/ou a transetorialidade são alternativas possíveis (BRONZO, 2007).

Para Andrade (2006), o modelo setorial tem implementado políticas endógenas, "sempre de dentro pra fora". Tal característica leva as políticas públicas a atenderem à realidade de modo desarticulado. Como consequência, cada setor se desenvolve em razão de suas demandas e de suas próprias soluções, operando a reafirmação do setor, em si e para si (ANDRADE, 2006). Inosoja demarca três situações identificadas no aparato governamental que se tornam empecilhos à intersetorialidade. Tal aparato

\footnotetext{
é todo fatiado por conhecimentos, por saberes, por corporações [...] é uma hierarquia verticalizada, piramidal, em que os processos percorrem vários escalões, mas as decisões são tomadas apenas no topo [...] é objeto de loteamento político-partidário e de grupos de interesse (INOJOSA, 2001).
}

Portanto, compreendemos aqui que a intersetorialidade é uma decorrência lógica da compreensão de problemas no contexto da complexidade, que traz para a gestão pública a necessidade de modelar novas estratégias para o adequado tratamento das demandas sociais. Todavia, para se superar de forma sustentável os dilemas históricos e as barreiras culturais que corroboram as desigualdades sociais e as iniquidades em saúde, assim 
como promover o bem-estar e a qualidade de vida da população na perspectiva de Promoção da Saúde, é necessário que o Estado consiga desenvolver um conjunto de capacidades e ações diferenciadas e intersetorialmente articuladas, o que exige mais do que uma simples conexão ou agregação de setores isolados, com a efetiva interação, cooperação e colaboração entre eles.

\subsection{INTERSETORIALIDADE COMO MECANISMO DE INOVAÇÃO DAS POLÍTICAS PÚBLICAS}

O debate sobre desenvolvimento e saúde (BUSS, 2000) e a formulação de propostas de ação intersetorial voltadas para a melhoria da qualidade de vida de diversos grupos populacionais (MINAYO et al., 2000), especialmente em áreas urbanas, fazem parte do contexto da busca de alternativas à crise dos setores de proteção social, em especial da saúde, cujas raízes encontramse, parcialmente, na reprodução de concepções e práticas insuficientes e inadequadas às mudanças demográficas, epidemiológicas, políticas e culturais das sociedades contemporâneas (TEIXEIRA; PAIM, 2000).

No campo das políticas públicas, a intersetorialidade tem sido entendida como a articulação de saberes e experiências no planejamento, a realização e a avaliação de ações, com o objetivo de alcançar resultados integrados em situações complexas, visando a um efeito sinérgico no desenvolvimento social (JUNQUEIRA, 1998). Nesta direção, a intersetorialidade apresenta-se como elemento importante para o desenvolvimento social, tratado aqui como a repartição mais equânime das riquezas existentes na sociedade, buscando reduzir as desigualdades, reverter a exclusão social e promover a qualidade de vida da população. Essa é uma lógica que não se prende somente às necessidades das pessoas ou dos grupos populacionais, mas procura alcançar o lugar onde vivem, suas características socioeconômicas, políticas e culturais (INOSOJA, 1998). 
Assim, o que se tem com a emergência da gestão intersetorial na agenda pública é uma redefinição conceitual e operativa das políticas públicas, principalmente dos setores sociais, que passam a exigir a integralidade na formulação e a transversalidade como lógica de implementação, conferindo à abordagem integral e às políticas transversais maior capacidade de equacionar a complexidade das demandas sociais contemporâneas (GOMÁ, 2004). Para tanto, aponta-se para a utilização de métodos mais democráticos e participativos voltados à escuta, à mediação de conflitos e ao compartilhamento de conhecimentos e responsabilidades entre os atores sociais.

Neste contexto, as formas de se operacionalizar a intersetorialidade podem variar de acordo com o objetivo, a amplitude e a complexidade das ações pretendidas. De modo geral, costumam caracterizar-se como um conjunto de ações com diferentes participações, enfatizando as redes de compromisso, a corresponsabilidade e a cooperação de distintos setores. É muito comum a citação de espaços coletivos para a discussão, o compartilhamento de saberes e a integração de profissionais para o planejamento de ação em conjunto, articulado e contínuo durante os programas intersetoriais (GARCIA et al., 2014). Contudo, é importante considerar que a intersetorialidade ocorre em diferentes espaços e níveis de decisão, que os objetivos dos projetos se transformam durante o processo, que há dificuldades em se negociar e decidir quais questões são prioritárias - por incompatibilidades e diferenças nas visões e agendas entre os agentes - e que os resultados sofrem interferência em função de disputas políticas e eleitorais (MAGALHÃES; BODSTEIN, 2009).

Portanto, um dos desafios enfrentados pela gestão pública diz respeito à organização e ao gerenciamento da ação intersetorial, isto é, da conjugação desses esforços entre distintos setores, visando à racionalização dos recursos existentes e à transformação das atividades para que tenham maior sustentabilidade e impacto sobre as demandas sociais. De tal forma, a gestão intersetorial caracteriza-se como um mecanismo capaz de organizar informações, mobilizar esforços, criar sinergias e responsabilizar atores na busca de eficácia, eficiência e efetividade nas políticas públicas direcionadas à 
resolução de problemas complexos e prioritários. Contudo, práticas tradicionais como o "loteamento" de cargos do governo entre diferentes tendências e grupos políticos (INOJOSA, 1998), o aprisionamento da política pelos interesses das elites locais, o burocratismo, o corporativismo e os limites impostos pela atual política econômica (VIANA, 1998) representam constrangimentos que devem ser considerados no desenho estratégico deste modelo de gestão.

Neste contexto, enquanto instrumento direcionado à prospecção de resultados sinérgicos da ação governamental para a promoção da saúde, a gestão intersetorial tem apontado para questões paradigmáticas relacionadas ao projeto político de estruturação das políticas públicas; perpassa os padrões governamentais de planejamento setorial e descentralizado; e alcança os conflitos de interesse inerentes às relações de poder entre atores, instituições e corporações que permeiam o aparelho do Estado. Em última análise, remetem ainda às questões éticas e morais que têm orientado a conduta profissional e o progresso cientifico e tecnológico das 'sociedades modernas'.

Para aprofundarmos as análises dos processos de gestão intersetorial no campo das políticas públicas, procuramos discutir aqui quais os principais componentes políticos e institucionais que melhor configuram um modelo de gestão intersetorial no aparato governamental, assim como se constituem os arranjos organizacionais para o desenvolvimento de capacidades estatais desses modelos de gestão alternativos. Para tanto, buscamos organizar algumas dimensões que permitam avaliar o "nível de intersetorialidade", a partir da elaboração de um fluxo esquemático identificando os principais conteúdos, estruturas e processos consensuados na literatura, bem como as atividades e resultados esperados nesta perspectiva de gestão. Dessa forma, sem a pretensão de esgotar as possibilidades, abordaremos o tema a partir dos componentes de integralidade necessária à compreensão e análise dos problemas sociais, e intrinsecamente ligada à visão atual do conceito de Promoção da Saúde; e de transversalidade, exigida para a articulação e integração das políticas públicas. 


\subsection{ASPECTOS DA VISÃO INTEGRAL E DA GESTÃO TRANSVERSAL NOS ARRANJOS INSTITUCIONAIS DE POLÍTICAS PÚBLICAS: ELABORAÇÃO DE UM FLUXO ESQUEMÁTICO}

As principais discussões teóricas encontradas na literatura salientam basicamente o mesmo conjunto de questões sobre a gestão intersetorial. A estratégia da intersetorialidade pode permitir maior eficiência e resultados mais significativos quanto ao impacto e sustentabilidade das políticas públicas, evitando sobreposições de ações e garantindo maior organicidade à implementação. Permite, sobretudo, uma resposta integral e, dessa forma, mais adequada e pertinente aos problemas sociais identificados. Apesar de não existirem formatos predefinidos para a gestão de programas ou estratégias intersetoriais no campo das políticas sociais, ou de políticas mais específicas como a de promoção da saúde, pode-se dizer que, na origem de estratégias com esse formato, existe sempre a busca por um diagnóstico ampliado sobre o caráter multideterminado dos problemas sociais, bem como a perspectiva de planejamento estratégico, de gestão coletiva e de participação social.

Tendo em vista que não dispomos de um formato ideal para a conformação de políticas, programas ou ações intersetoriais, neste estudo pretendemos clarear algumas perspectivas de análises a partir da sugestão de um fluxo esquemático para orientar a análise da gestão intersetorial da Política Nacional de Promoção da Saúde. Dentro desta abordagem, trataremos a gestão intersetorial como a instituição de estruturas de governança direcionadas ao desenvolvimento de capacidades relacionais, técnicas e administrativas, com vistas a assegurar legitimidade política e representatividade social para a construção de agendas e objetivos comuns e para a definição de instâncias e mecanismos de pactuação e cooperação entre os setores sociais, visando promover ações integradas e um tratamento mais equânime das demandas sociais. Para tanto, propomos um desenho de gestão sustentado nos componentes de integralidade, para captar, compreender e analisar os problemas e demandas sociais, e de transversalidade, para planejar estratégias e organizar arranjos institucionais mais democráticos e participativos. 
O conceito de integralidade ganha relevância nos estudos atuais das políticas de saúde, pois, além de constituir-se como um dos princípios do SUS, surgiu da necessidade de superação das dicotomias históricas entre 0 preventivo e o curativo, o individual e o coletivo, expressas no campo da saúde coletiva, decorrente do conflito entre a saúde pública e a assistência médicohospitalar. A noção de integralidade, mais do que uma formulação teórica, implica repensar aspectos importantes da organização do trabalho, gestão, planejamento e principalmente da construção de novos saberes e práticas em saúde, buscadas nas necessidades reais de cada indivíduo, o que torna ampla a dimensão do conceito de integralidade.

A integralidade tem sido vivenciada no Brasil, em algumas experiências, seja na formulação das políticas de saúde ou nas práticas de alguns serviços. E, apesar de constituir-se como um dos princípios do SUS, sua incorporação às práticas continua sendo um grande desafio. No campo da saúde, a resposta integral extrapola a estrutura organizacional hierarquizada e regionalizada da assistência de saúde, se prolonga pela qualidade real da atenção individual e coletiva assegurada aos usuários do sistema, e requisita o compromisso com a prática multiprofissional e o aprendizado contínuo.

Assim, entende-se que a integralidade no cuidado de pessoas, grupos e coletividade busca perceber o usuário como sujeito histórico, social e político, articulado ao seu contexto familiar, ao meio ambiente e à sociedade na qual se insere. A noção de integralidade como princípio deve orientar para ouvir, compreender e, a partir daí, atender às demandas e necessidades das pessoas, grupos e comunidades num novo paradigma de atenção à saúde. $O$ princípio de integralidade, em um dos seus sentidos, corresponde exatamente a uma crítica da dissociação entre as práticas assistenciais, fomentadas através de distinções cristalizadas entre serviços de saúde pública e serviços assistenciais (MACHADO, 2007).

No âmbito deste estudo, a integralidade, não obstante sua polissemia conceitual, será abordada a partir da capacidade organizacional do SUS de promover a escuta e a participação social na conformação de diagnósticos diferenciados de situação, na relação institucional com os usuários, para o 
acolhimento de suas histórias, condições de vida e necessidades em saúde, que apontam, por um lado, para uma visão ampliada acerca dos determinantes sociais da saúde, e por outro, para aprendizagem organizacional e qualificação dos profissionais; que a conecta com a perspectiva multidimensional e interfederativa da atenção integral à saúde. Complementarmente, observamos o modo de organizar o sistema de saúde de forma a ampliar o acesso a todos os níveis de complexidade do serviço abrangendo ações de promoção, proteção, assistência e recuperação da saúde. Dessa forma, procuramos enfocar os modos de organização do sistema de saúde que visam a extrapolar o alcance dos serviços e apontam para a formulação e gestão de políticas destinadas à produção da saúde tomada em seu sentido mais amplo, o que buscamos enfatizar a partir da lógica intersetorial da promoção da saúde, tal como a afirmação de "saúde para todos".

Já a ideia de transversalidade está inserida em uma lógica de etapas do desenvolvimento. A transversalidade seria a última delas, em que seria necessária articulação de diferentes atores em busca de se entender as diversidades e especificidades das demandas sociais e construir melhores políticas públicas. Nesse sentido, uma política transversal buscará responder a problemas afastando-se das estruturas hierarquizadas e tradicionais, de modo a organizar um Estado Relacional envolvendo diferentes atores sociais (SERRA, 2004). Portanto, torna-se possível atingir melhores resultados com a definição de objetivos construídos em comum acordo, a partir de arranjos institucionais multissetoriais e horizontais, em contraponto às organizações tradicionais de gestão. Nesse sentido, Reinach (2013), ao analisar o tema, destaca o fato de a transversalidade dizer respeito à cultura organizacional e a novas formas de gestão. No campo da saúde essa perspectiva se conforma nas estratégias de 'saúde em todas as políticas'.

As tensões e ambiguidades presentes na lógica especialização versus integralidade, e na organização setorial versus transversalidade, originam-se a partir das dicotomias encrustadas no bojo da gestão pública tradicional. Assim, os modelos emergentes e alternativos pautados na intersetorialidade pretendem superar essas limitações históricas do aparato governamental 
através da busca por uma visão integral dos problemas sociais e por meio da implantação de gestão transversal, pautada na articulação estratégica de políticas e integração operacional programas e ações entre os diferentes atores sociais e níveis de governo. Nesta direção, aponta para o aprimoramento dos arranjos institucionais de modo a dotar o aparato governamental de capacidades mais condizentes com as relações societais estabelecidas no âmbito da democracia representativa, que exige tanto uma melhor captação e alcance das diversidades e especificidades sociais, por meio da representatividade como mecanismos que possam sensibilizar, mobilizar e promover uma atuação colaborativa dos atores envolvidos, o que confere a legitimidade às políticas intersetoriais.

Grande parte da literatura mais atual sobre gestão pública reconhece a ocorrência de mudanças substanciais expressas na tensão entre especialização, necessária para atender a demandas diferenciadas, e integralidade, necessária para possibilitar uma visão global sobre as pessoas atendidas e seus problemas. $O$ que permite abordar 0 tema da intersetorialidade a partir do registro da integralidade e da transversalidade baseia-se, de forma muito mais direta, na capacidadedas políticas públicas de serem responsivas aos problemas identificados, e de darem respostas que tenham aderência às necessidades da população ou do território, por meio do diálogo e integração entre demandas e ações sociais. (BRONZO, 2007).

Sob a perspectiva da transversalidade, procura-se destacar os aspectos relacionais de coordenação multilateral e multinível de redes interorganizacionais, a legitimidade técnica e a representatividade política dos arranjos institucionais constituídos. Quanto aos aspectos operativos, ressaltase a consistência dos processos administrativos e oferta de serviços, buscando identificar o desenvolvimento e a consolidação das capacidades estatais voltadas à visão estratégica e atuação relacional, que deveriam promover a transformação dos resultados programáticos e setoriais das diferentes políticas sociais implicadas em uma estratégia intersetorial.

Neste sentido, procuramos organizar de forma sintética os principais elementos teóricos e estruturais que melhor configuram os aspectos da gestão 
intersetorial entre políticas públicas, conforme esquema apresentado na Figura 3.

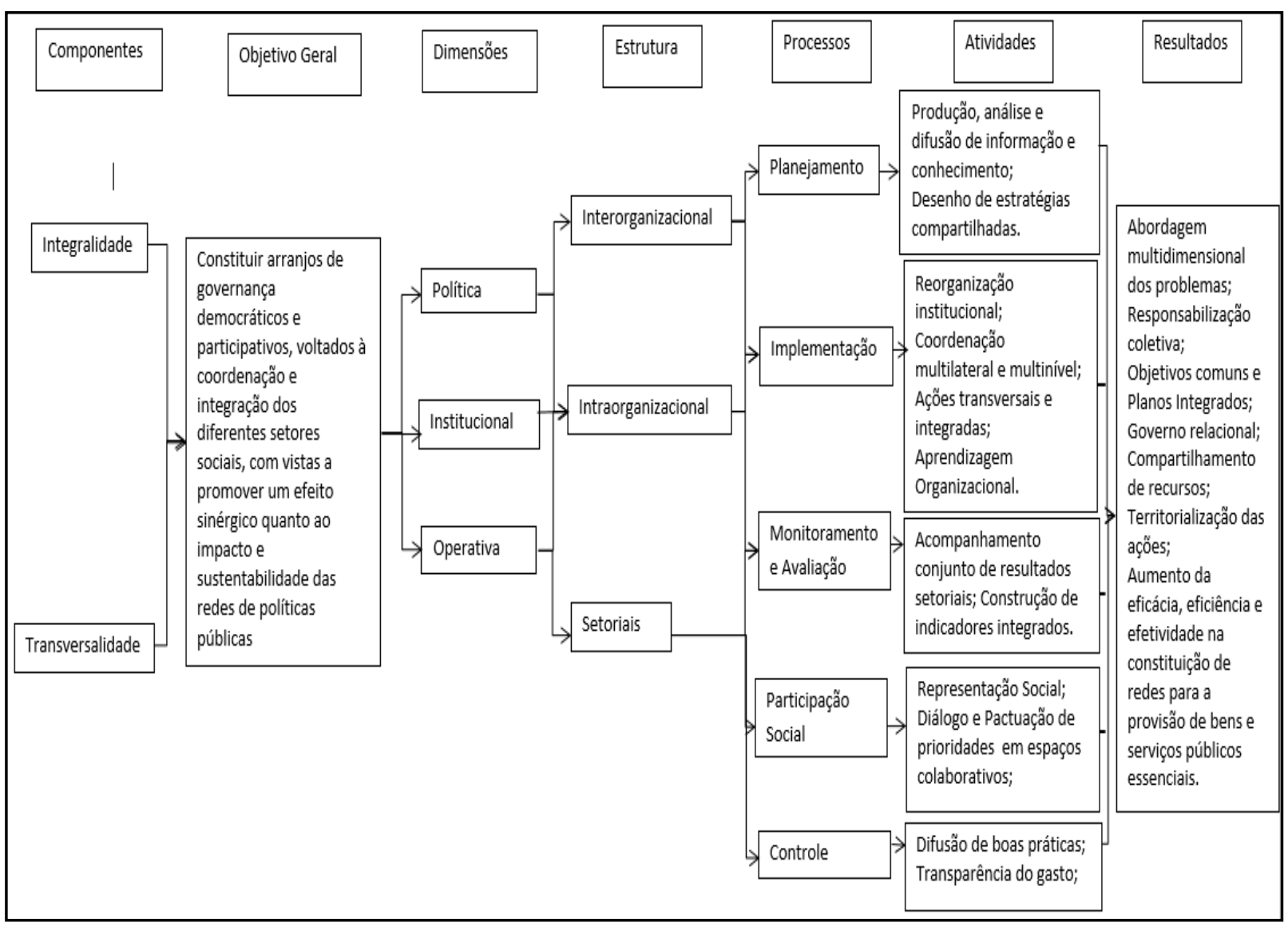

Figura 3. Representação esquemática para análise de gestão intersetorial nas políticas públicas (elaborada pelo autor).

A abordagem trabalhada no fluxo esquemático busca compreender a responsabilização, transparência e qualificação dos resultados gerenciais e sociais das políticas públicas, por meio de processos de comunicação, coordenação e cooperação entre setores e redes sociais. Para tanto, está pautada na necessidade de compartilhamento e análise de informações estratégicas, governança institucional e no aprimoramento dos processos de trabalho a partir de processos de aprendizado organizacional e de educação permanente. Pretende-se, assim, ampliar as possibilidades de análise a respeito da formulação e implementação da Política Nacional de Promoção da Saúde. 
A perspectiva de governança tem sido utilizada em alguns países da Europa e América Latina como sinônimo de intersetorialidade, para se referir à interação entre diversos setores - Estado, Mercado e Sociedade - em uma visão de governo relacional e multinível (BRONZO, 2007). O termo governança é utilizado para identificar e descrever um conjunto de procedimentos, atores e processos configurados para que uma sociedade alcance melhor qualidade de vida. O conceito de governança, segundo Querol (2004), "é um sistema de regras formais e informais (normas, procedimentos, costumes...) que estabelecem as pautas de interação entre atores no processo de tomada de decisões (considerando atores relevantes tanto dos poderes públicos como dos atores sociais e econômicos)". Adotar o conceito de governança significa investir em processos de mudança que sejam planejados e implementados em uma relação de corresponsabilidade em torno de um marco institucional formado por regras e procedimentos formais e informais, que devem garantir a democratização das relações, das informações e a articulação entre os diferentes setores sociais (BENTO, 2003; CALAME, 2004).

$O$ conceito de redes vem ganhando espaço e importância entre diversos atores sociais e políticos preocupados com a gestão pública. A ideia de rede tem se tornado uma referência central nas discussões em diversos campos para sinalizar a interconexão, a interdependência e a conformação necessárias para dar conta da complexidade dos processos e da realidade social. Essa noção de rede diz respeito a uma nova forma de organização e de ação, que decorre da associação de pessoas ou entidades para realizar determinado objetivo, tendo como ideário uma nova visão do processo de mudança social, que considera fundamental a participação cidadã, e a forma de organização dos atores sociais para conduzir esse processo (SCHERER-WARREN, 2008). A noção de redes multinível amplia a perspectiva de redes horizontais (multilaterais) e remete não apenas à articulação entre atores de um mesmo nível, mas à interdependência entre os níveis de governo (BLANCO; GOMÀ, 2003).

A gestão intersetorial situa-se em um contínuo que abrangeria desde a articulação e coordenação de estruturas setoriais já existentes até uma gestão 
transversal, perpassando setores internos e externos da organização, assim como diferentes níveis de gestão governamental, configurando novas formas intermediárias e arranjos organizativos que podem expressar a intersetorialidade de baixa ou alta densidade (SERRA, 2004). Assim, a gestão intersetorial deve evoluir gradualmente pela configuração de arranjos institucionais direcionados à coordenação entre os diferentes atores sociais e políticas públicas, por meio da estruturação de espaços interativos com caráter mais horizontal e colaborativo. Isso requer uma lógica de ação coletiva e mecanismos de coordenação social, que exigem, para tanto, a atuação de "empreendedores" dotados de competências técnicas e habilidades políticas. Dessa forma, uma gestão intersetorial poderá se constituir a partir de diferentes critérios prioritários: populacionais, territoriais, temáticos, etários, étnicos etc.

O termo "arranjos institucionais" pode ser entendido como o conjunto de regras, mecanismos e processos que definem a forma particular como se coordenam atores e interesses na implementação de uma política pública específica. São os arranjos institucionais que dotam o Estado de capacidade de execução de seus objetivos. Ou, em outras palavras, são os arranjos institucionais que determinam a capacidade do Estado de implementar políticas públicas (GOMIDE;PIRES, 2014).

No contexto democrático, entende-se que tal capacidade pode ser percebida a partir de dois componentes: o técnico-administrativo e o político. $O$ primeiro deriva do conceito weberiano de burocracia, contemplando as competências dos agentes do Estado para levar a efeito suas políticas, produzindo ações coordenadas e orientadas para a produção de resultados. $O$ segundo, associado à dimensão política, refere-se às habilidades da burocracia do Executivo em expandir os canais de interlocução, negociação com os diversos atores sociais, processando conflitos e prevenindo a captura por interesses específicos. Assim, entende-se que capacidades políticas estariam associadas à promoção da legitimidade da ação estatal em contextos democráticos, por meio da mobilização da sociedade e da articulação e compatibilização de interesses diversos em torno de plataformas comuns. 
Para Gomide e Pires (2014), são os arranjos institucionais que dotam o Estado das habilidades necessárias para implementar seus objetivos. Como demonstrado na Figura 3, as capacidades técnico-administrativas e políticas derivam das relações entre as burocracias do Poder Executivo com os atores dos sistemas representativo, participativo e de controles em cada setor específico. Dessa maneira, são as regras, processos e mecanismos instituídos pelos respectivos arranjos de implementação que vão explicar o resultado alcançado por cada política pública.

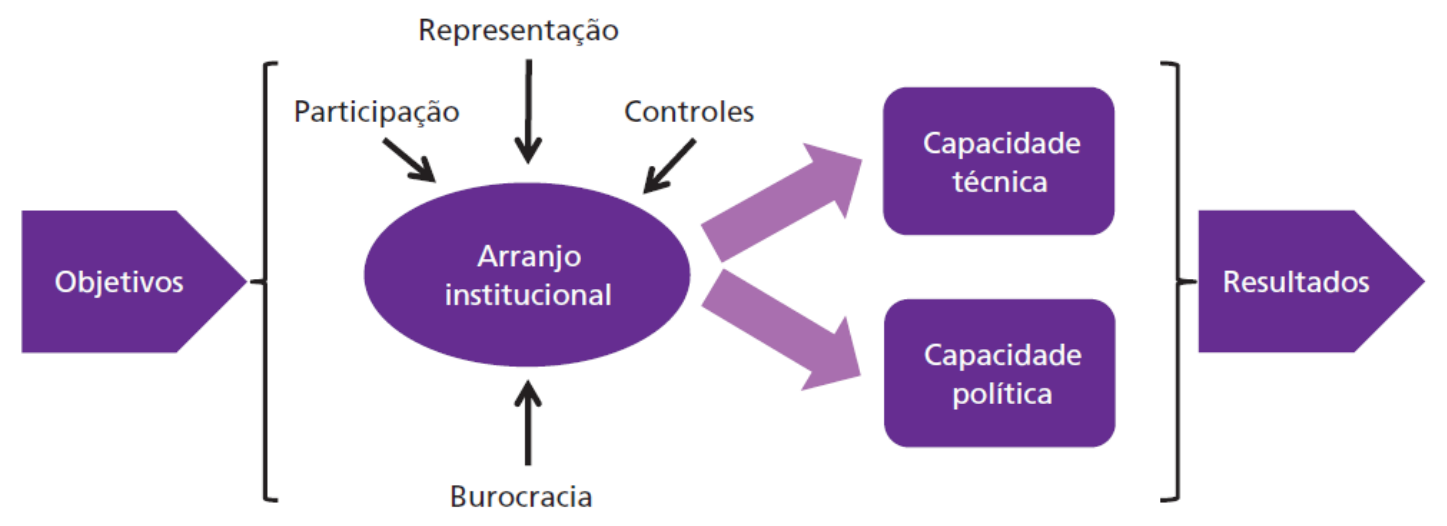

Figura 4. Modelo analítico de interação do arranjo institucional no desenvolvimento de capacidades estatais (GOMIDE;PIRES, 2014 p.21).

Para Serra, uma referência importante sobre 0 debate da intersetorialidade, do ponto de vista da gestão, adota a perspectiva de que tais arranjos, intersetoriais ou transversais, constituem uma parte soft da organização, enquanto dimensão complementar à estrutura organizativa básica ou hard (SERRA, 2004). Isso quer dizer que os arranjos de intersetorialidade ou da transversalidade não pretendem substituir as estruturas setoriais existentes, embora pressuponha a introdução de novos pontos de vista, novas linhas de trabalho e de objetivos em relação aos já existentes nos diversos setores (SERRA, 2004).

Portanto, o posicionamento das iniciativas e arranjos institucionais nesse contínuo vai depender do grau de legitimidade e da centralidade do tema na agenda pública e no plano decisório; da magnitude dos arranjos e alterações institucionais necessárias para viabilizar a gestão horizontal das políticas; das alterações nas rotinas, práticas de trabalho e metodologias de entrega dos 
bens e serviços. É importante, portanto, considerar que a construção de um arranjo de natureza intersetorial pode ocorrer em três dimensões: 1) no âmbito da decisão política, trata-se de construir e legitimar consensos e pactuações que enfrentem a excessiva setorialização e departamentalização da estrutura administrativa encarregada da produção de políticas públicas; 2) no âmbito institucional, situam-se as alterações nas estruturas e nos mecanismos e processos existentes, visando criar instrumentos necessários e suficientes para dar materialidade aos desdobramentos da decisão política. Dentre tais alterações, têm-se as reformas no aparato administrativo para a reestruturação de setores e competências (organogramas), com relevância para a capacidade de coordenação política e tecnicamente legitimada, capazes de estabelecer marcos e pautas comuns de ação, negociar interesses e neutralizar resistências às mudanças, fomentando ainda os processos de aprendizagem organizacional; c) no âmbito operativo das políticas, as mudanças ocorrem nos processos de trabalho, o que exige a adoção de posturas mais cooperativas, disposição para compartilhar informações e restabelecer fluxos, reorientar a forma de provisão dos serviços públicos de modo a ajustá-los às demandas e necessidades identificadas (VEIGA; BRONZO, 2005).

Para Serra, uma especificidade das estruturas transversais em relação às verticais é que as primeiras incluem análises ampliadas do problema e seu entorno (visão integral), priorizando o planejamento estratégico e o desenho de objetivos integrados que orientam o monitoramento e avaliação conjunto dos resultados (visão transversal), mas a capacidade de gestão e de produção pertence às estruturas verticais e setoriais. Isso quer dizer que os órgãos transversais são sistemas de relacionamento e de conhecimento e que alimentam as organizações de visões específicas e objetivos estratégicos de mudança social (SERRA, 2004). Embora não participem da gestão operativa do dia a dia, os órgãos transversais acompanham e monitoram o impacto da gestão transversal, o que os mantêm ligados ao processo operativo, ainda que não diretamente (BRONZO, 2007).

A transversalidade confere outro foco à organização, dirigindo a atenção para aspectos e temas considerados centrais e permitindo intensificar a 
atuação dos atores sobre eles. O gestor da transversalidade necessita operar com instrumentos de gestão estratégicos, com domínio dos instrumentos de análise e desenho, de gestão relacional, gestão política e avaliação. As atividades principais para o trabalho transversal, segundo Serra, residem: a) na produção, análise e difusão de informação e conhecimento, com a criação, gestão e suporte de expertise, experiências, técnicas e boas práticas para subsidiar a direção política e os órgãos verticais; b) no desenho e formulação de objetivos estratégicos, concepção e desenvolvimento de políticas e metodologias de trabalho e c) estruturação e gestão de redes relacionais internas e externas de tipo multilateral e multinível (SERRA, 2004). O trabalho transversal exige, sobretudo, recursos estruturados em torno de dois eixos: conhecimento (capacidade de análise e de formulação de estratégias a partir das diversidades sociais), que o conecta à perspectiva de integralidade; e capacidade relacional, que traz em si o conceito de transversalidade e governança.

Nesta direção, Querol (2004) apresenta alguns requisitos para demonstrar o estreito vínculo existente entre a discussão sobre a governança, os processos de democratização do espaço público e a valorização institucional de uma cultura política participativa, que são: (1) democratização da informação e dos conhecimentos adequados para participar de maneira informada dos processos de tomada de decisões; (2) coordenação intergovernamental no eixo local-global (integração vertical); (3) coordenação e integração entre as políticas setoriais, isto é, a intersetorialidade, ou seja, a integração horizontal; (4) criação de instrumentos políticos inovadores; (5) mudança na cultura administrativa por meio da transparência, prestação de contas, utilização de instrumentos de avaliação; (6) valorização de uma cultura política participativa; (7) disponibilidade de certo nível de capital social.

Assim, a sociedade também é convocada a dispor de capacidades de comunicação e liderança, ter confiança no governo, ser capaz de demonstrar reciprocidade, e colaborar com a definição das prioridades e dos processos de gestão das políticas públicas. Neste tipo de gestão, o papel de recursos econômicos convencionais (orçamento, pessoal ou infraestrutura), que são 
centrais nas estruturas verticais de gestão, aparecem como secundários para sua efetividade (BRONZO, 2007), sendo estes mais dependentes de legitimidade política, representação social e qualificação técnica.

Dessa forma, as atividades analíticas e transversais convergem para promover a interconexão entre as dimensões política, institucional e operacional da gestão, por meio de arranjos capazes de mobilizar os esforços técnicos e políticos e conduzir processos colaborativos em torno dos problemas prioritários. Esta atuação pode ser fortalecida pela ação sistemática de instâncias de articulação e integração intra e interorganizacionais, organizadas com base nas estruturas setoriais já existentes. Entretanto, as estratégias de mobilização interna e externa de atores sociais e grupos de interesse precisam ser permeadas e materializadas por processos participativos e democráticos de planejamento, implementação, avaliação e controle, que visem à comunicação dialógica ${ }^{13}$ e a coordenação de ações complementares e coincidentes na produção de resultados integrados diante das expectativas dos atores e dos resultados esperados, considerando ainda que a diminuição dos custos de transação $^{14}$ individualizados amplia as possibilidades de integração de saberes e recursos setoriais e programáticos.

Assim, de modo geral, os resultados esperados para as estratégias de gestão intersetorial apontam para uma visão multidimensional sobre os problemas complexos, de forma a sensibilizar e induzir a responsabilização coletiva dos atores, facilitando, assim, a construção de objetivos comuns e a elaboração de planos integrados para intervenção conjunta. Para tanto, os

\footnotetext{
${ }^{13}$ Termo cunhado por Paulo Freire na defesa pela comunicação com reciprocidade, nunca passividade, sendo o diálogo o que caracteriza a comunicação. Segundo Lima, 2010: "O próprio conhecimento gerado pelo diálogo comunicativo só será verdadeiro e autêntico quando comprometido com a justiça e a transformação social. A comunicação passa a ser, portanto, por definição, dialógica, vale dizer, de 'mão dupla', contemplando, ao mesmo tempo, o direito de ser informado e o direito à plena liberdade de expressão". LIMA, Venício. Paulo Freire, direito à comunicação e $\quad$ PNDH3. Disponível em http://www.cartamaior.com.br/templates/colunaMostrar.cfm?coluna id=4596.

${ }^{14} \mathrm{~A}$ reflexão a respeito da noção de custos de transação, aplicada à avaliação de políticas públicas, possibilita a identificação ou mapeamento dos diversos grupos e organizações envolvidos (stakeholders), bem como permite visualizar a distribuição (entre eles) dos encargos relativos à política. A realização dessa tarefa pode fornecer subsídios muito importantes para o desenvolvimento e estabelecimento de mecanismos e espaços de concertação e negociação assim como suas regras de funcionamento - entre os diversos atores envolvidos (ROCHA, 2004).
} 
processos de coordenação das ações intersetoriais devem dotar o Estado de capacidades técnicas e relacionais, voltadas à análise de situação, à negociação de interesses e a moderação de conflitos nos espaços de gestão e pactuação da política. Dessa forma, é possível planejar estratégias cooperativas com o compartilhamento de recursos e a territorialização das ações, buscando superar as lacunas e sincronizar as intervenções, com o objetivo de ampliar a efetividade dos resultados das políticas públicas voltadas ao tratamento dos determinantes sociais e das iniquidades em saúde.

\subsection{ASPECTOS GERAIS PARA A CLASSIFICAÇÃO DA GESTÃO INTERSETORIAL ENTRE POLITICAS PÚBLICAS}

Construir um fluxo esquemático para análise da gestão intersetorial consiste em uma escolha metodológica que nos auxilia na avaliação de fenômenos sociais complexos que apresentam singularidades que podem ou não ser encontradas em outros estudos de caso. É importante fundamentar que cada modelo de gestão intersetorial, independentemente da política estudada, tende a apresentar um caráter individual próprio, construído de maneira gradual e histórica. Neste sentido, a proposição de um esquema para a análise nos permite contrastar o caso concreto com um modelo ideal, ainda que utópico. Entender do que se trata a intersetorialidade abre espaço para a possibilidade de compreender a estrutura construída entre os setores para a implementação de uma política pública como um conjunto de múltiplas lógicas e diferentes perspectivas sobre um mesmo objeto (NAVARRO, 2011).

Portanto, o objetivo desta etapa é apresentar as categorias criadas para a compreensão de quais condições, segundo nossa perspectiva, podem fortalecer ou restringir a perspectiva de integralidade, na compreensão e análise dos problemas, e a gestão da transversalidade, na articulação e integração dos atores sociais para a formulação e implementação de políticas públicas; com vistas a superar os padrões tradicionais - hierárquicos e setoriais - da administração pública. 
Para o desenvolvimento e aplicação do esquema de forma mais apurada, desdobramos os componentes de análises em aspectos mais específicos relacionados às estruturas, aos processos e às atividades que podem aumentar ou diminuir as possibilidades de uma gestão ser mais ou menos integral, e mais ou menos transversal, sendo delimitados os seguintes fatores, conforme Tabela 1.

Tabela 1. Descrição dos aspectos de análise de gestão intersetorial.

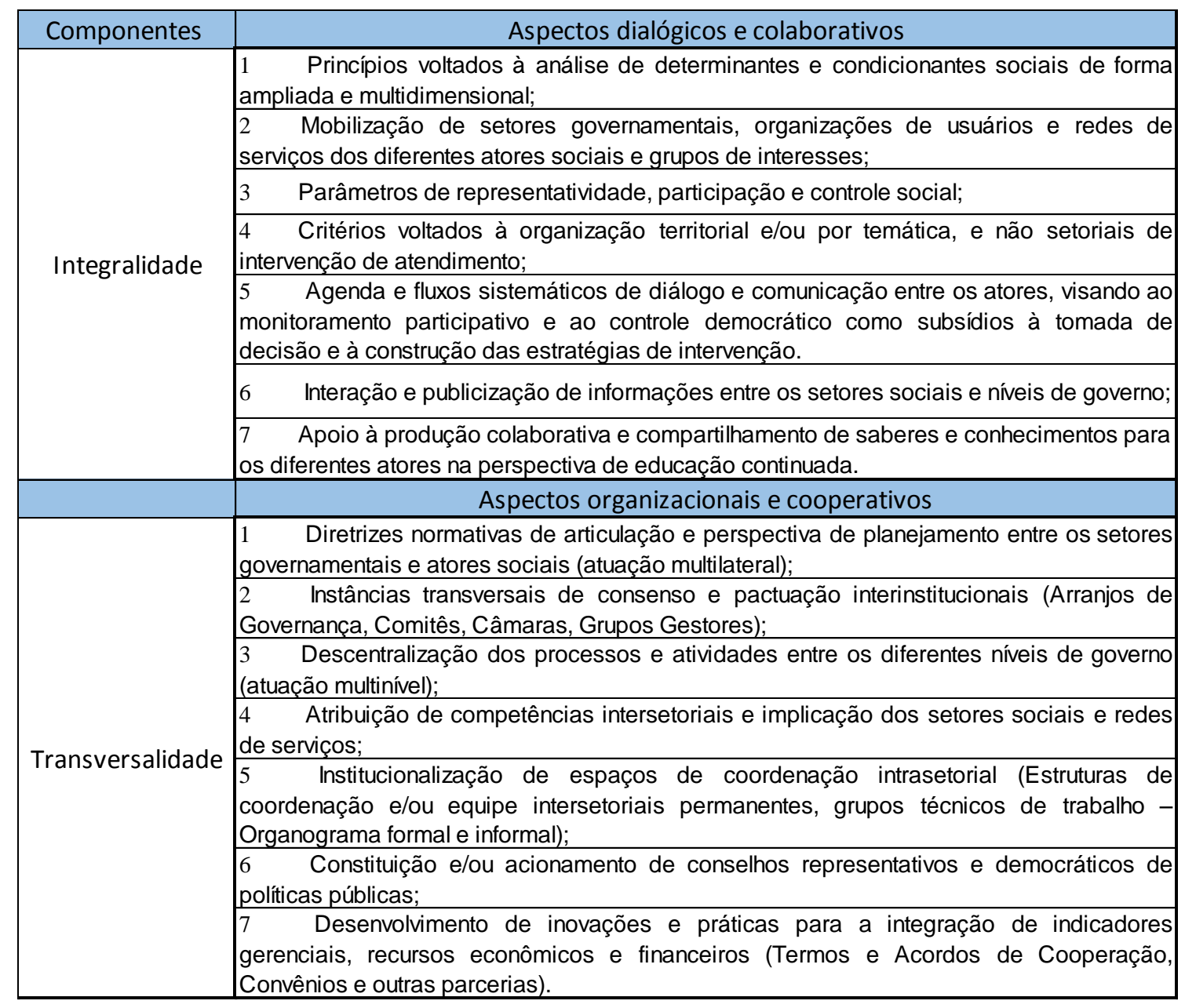

$\mathrm{Na}$ descrição dos aspectos apresentados, consideramos o componente da integralidade associado às questões mais dialógicas e colaborativas, direcionadas a fortalecer os processos de participação e construção coletiva de diagnósticos ampliados e multidimensionais para a definição de prioridades. Quanto ao componente da transversalidade, buscamos associá-lo às questões organizacionais e cooperativas, direcionadas à estruturação de mecanismos 
para a responsabilização dos distintos setores implicados a partir de suas hierarquias e competências institucionais. Neste sentido, os aspectos de colaboração buscam um envolvimento mútuo dos participantes em um esforço coordenado para juntos resolverem o problema delimitado. Já os aspectos de cooperação estão mais restritos à divisão do trabalho entre os participantes, em que cada setor está responsável por uma parte na resolução do problema, mas todos trabalham no sentido de atingir um objetivo comum. Somados, os aspectos colaborativos e cooperativos contribuem para uma melhor compreensão dos arranjos organizacionais orientados para o fazer intersetorial.

Autores como Fiorentini (2004) destacam que uma produção coletiva pode se dar de forma cooperativa ou colaborativa. $O$ autor distingue cooperação e colaboração a partir da etimologia das palavras em que "co" significa ação conjunta; operare, operar, executar, fazer funcionar; e laborare, trabalhar ou produzir em vista de um determinado fim. Afirma que na cooperação os membros de um grupo executam tarefas que não resultam de uma negociação conjunta do coletivo, podendo haver subserviência de uns em relação a outros, e relações desiguais e hierárquicas, enquanto que na colaboração todos trabalham conjuntamente e se apoiam mutuamente, tendendo, dessa forma, a um relacionamento não hierárquico. Assim como o referido autor, Kenski (2003) destaca que nos processos colaborativos todos dependem de todos para a realização de atividades, e essa interdependência exige aprendizados complexos de interação permanente, respeito ao pensamento alheio, superação das diferenças e busca de resultados que possam beneficiar a todos.

Buscando facilitar o estabelecimento de parcerias, 0 desenho intersetorial deve convocar os setores a partilhar informações, visando construir um processo cooperativo e colaborativo. Assim, as atividades dinamizadas em interfaces como os fóruns de pactuação, por exemplo, devem procurar sempre provocar a interação e o diálogo entre os atores, fazendo vir à tona as suas ideias, opiniões, reações, suas experiências e suas expectativas, ficando claro que para criar um contexto de construção coletiva de conhecimentos não basta 
colocar os sujeitos em contato, mas é essencial criar as condições para um confronto de experiências.

Para Lévy (1996), as pessoas aprendem a realidade por meio de uma rede de colaboração na qual cada um ajuda o outro a desenvolver-se, ao mesmo tempo em que também se desenvolve, e assim todos aprendem juntos e em colaboração, a partir de uma interação mútua, em um intercâmbio de ideias e pensamentos. Através da participação e da colaboração, o usuário contribui com a inteligência coletiva, agregando elementos e pontos de vista variados em determinada temática. Assim, pode-se exercitar a construção compartilhada e contribuir com a formação de coautores nesse processo coletivo. Além de ressaltar a importância no desenvolvimento de competências que geram a inclusão, pois à medida que os processos de inteligência coletiva se desenvolvem, "melhor a apropriação, por indivíduos e por grupos, das alterações técnicas, e menores são os efeitos de exclusão resultantes da aceleração do movimento tecnosocial” (LÉVY, 1999, p.29).

Foi possível constatar ainda que a probabilidade de um setor cooperar com outro setor aumenta na medida em que há a diminuição dos custos esperados com a cooperação (custos de transação), e crescem as possibilidades de atendimento de uma demanda ainda excluída, seja por falta de recursos, estrutura ou recursos humanos. Dessa forma, quanto menores os custos da cooperação em relação aos custos da não cooperação, tanto maior será a possibilidade de se estabelecer uma gestão intersetorial. Os custos de cooperação aqui referidos podem ser tanto financeiros, referentes ao compartilhamento e acesso a recursos, quanto estruturais, devido à baixa capacidade estrutural diante da grande demanda, ou ainda políticos, relativos a negociações e disputa por poder. Em linhas gerais, a análise das estratégias de cooperação entre os setores envolvidos na implementação da PNPS, passa pela compreensão da dinâmica de cada setor e dos mecanismos e incentivos oferecidos aos setores para que trabalhem intersetorialmente de forma colaborativa (NAVARRO, 2011).

Assim, esse esquema pretende facilitar a análise dos aspectos colaborativos e cooperativos de gestão intersetorial entre políticas públicas, em 
especial das áreas sociais, assim como permitir a comparação de gestões segundo as dimensões de integralidade e transversalidade. Com essa finalidade, são propostas quatro tipologias para classificação segundo os seguintes níveis de gestão:

(I) Gestão Intersetorial Restrita ou Normativa: com baixa integralidade e baixa transversalidade. Neste nível de gestão pretendemos classificar as políticas que, apesar de relacionadas a temas complexos e prioritários, seus aspectos de intersetorialidade estão restritos aos conteúdos e diretrizes nos marcos normativos, sendo considerados frágeis os

processos de diálogo e participação social, bem como a estruturação organizacional para a interação entre os setores. Possuem pouca legitimidade política e baixa representatividade social;

(II) Gestão Intersetorial Ampliada ou Política: com mais integralidade e pouca transversalidade. Neste caso, procuramos identificar as políticas que, além de disporem de um aparato normativo consistente na perspectiva da intersetorialidade, também conseguem convocar de forma sistemática a participação dos atores sociais para a formulação de estratégias, prevendo a constituição de instâncias intersetoriais de pactuação com ampla representação social. Entretanto, no plano organizacional não é possível observar uma atuação mais contundente junto aos demais setores, com vistas a induzir adequações institucionais, bem como a difusão e compartilhamento interno das estratégias intersetoriais. Geralmente possuem maior legitimidade e representatividade, mas não são capazes de promover mudanças significativas nas estruturas institucionais;

(III) Gestão Intersetorial Coordenada ou Organizacional: com pouca integralidade e mais transversalidade. Neste nível, esperamos classificar as políticas que dispõem de um aparato institucional consistente para a coordenação de estratégias intersetoriais, 
com atuação multilateral e multinível, mas que ainda carecem de espaços mais consistentes de representação e participação social. Essas políticas conseguem organizar estruturas institucionais mais consistentes para a articulação e integração entre os setores, mas precisam alcançar maior legitimidade política e representatividade.

(IV) Gestão Intersetorial Plena ou Operativa: identificada como de alta integralidade e alta transversalidade. Nesses casos, esperamos observar maior coerência entre os aspectos de integralidade e transversalidade, possivelmente respaldados por um amadurecimento histórico e institucional da temática. Portanto, deverão dispor de normativos, espaços de participação e instâncias de coordenação mais consistentes entre os setores e níveis de gestão, além de induzirem a mudanças institucionais e proporem ações integradas entre os partícipes. Nessa situação, pretendemos identificar um grande respaldo político e boa representatividade.

Para consolidar a disposição da análise em um gráfico de tipologias segundo os níveis elencados de gestão intersetorial, propõe-se uma pontuação dos aspectos apresentados considerando a apropriação dos conteúdos e a consistência de práticas organizacionais para estruturação e operacionalização da intersetorialidade. Neste sentido, busca-se analisar a coerência conceitual e a organização institucional dos aspectos de gestão da política como elementos de amplitude e intensidade do arranjo constituído, sendo estabelecidos os parâmetros de baixa $(0,25)$, média $(0,5)$ e alta $(1)$ intersetorialidade, para a pontuação de cada um dos aspectos elencados; cabendo a pontuação máxima de 7 (sete) pontos para cada um dos componentes analisados, ou seja, 7 pontos para integralidade e 7 pontos para transversalidade.

É interessante destacar que questões vinculadas à legitimidade e representatividade técnica e política da atuação intersetorial estão estreitamente relacionados à amplitude $e$ intensidade dos aspectos colaborativos e cooperativos que vão orientar a análise dos graus de 
apropriação de conteúdos e da aplicação de práticas intersetoriais na Política de Promoção da Saúde. No gráfico proposto (Figura 4), essa tendência pode estar representada por um deslocamento mais harmônico entre os componentes sugeridos nos eixos vertical (integralidade) e horizontal (transversalidade), quando pretendemos observar um desenvolvimento gradual e dialógico dos mecanismos de participação e análise situacional e de organização institucional e operativa apresentados nos documentos oficiais de institucionalização e gestão da Política em análise. Dessa maneira, o deslocamento do objeto de análise mais próximo ao eixo diagonal poderá representar uma melhor consistência e qualificação do arranjo institucional da política para a implementação de capacidades intersetoriais.

É claro para nós que os modelos de gestão intersetorial podem envolver mais dimensões, e que as categorias analíticas criadas não esgotam as possibilidades existentes. No entanto, trata-se de uma tentativa de elaboração de uma escala hipotética deste gênero, que tem como objetivo servir de base para avaliar o grau com que vários tipos de gestão de políticas, programas e ações se aproximam do esquema aqui proposto de gestão intersetorial.

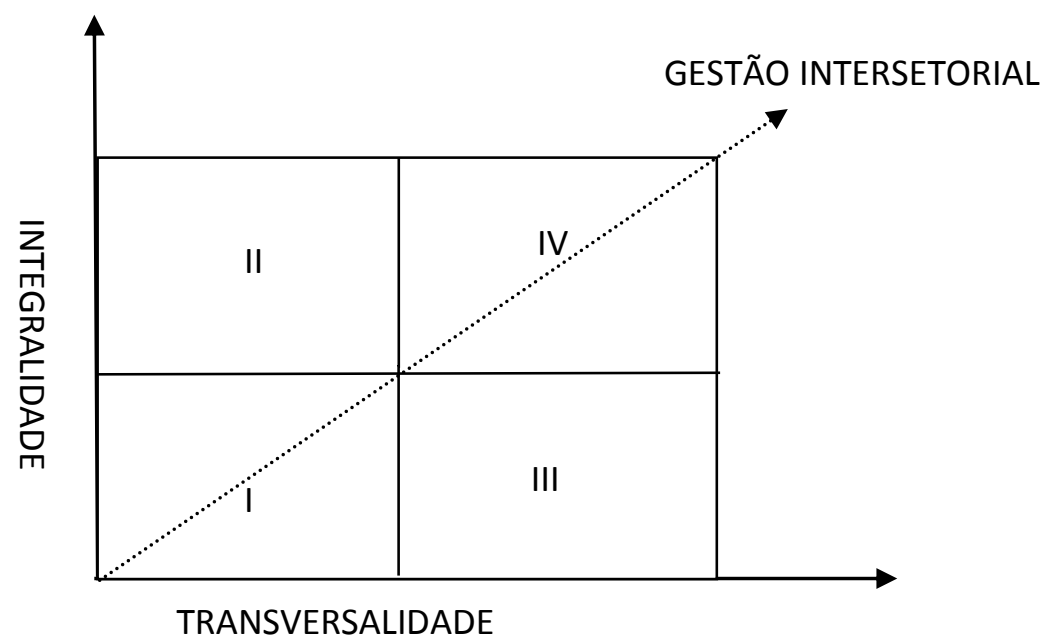

I - Gestão intersetorial restrita ou normativa;

II - Gestão intersetorial ampliada ou política;

III - Gestão intersetorial coordenada ou organizacional; 
IV-Gestão intersetorial plena ou operativa.

Figura 5. Gráfico de tipologia dos níveis de gestão intersetorial (adaptado pelo autor a partir de Navarro, 2011).

\subsection{A OPÇÃO METODOLÓGICA PELO ESTUDO DE CASO}

$O$ presente trabalho, conforme dito inicialmente, tem como objeto de estudo a implementação da Política Nacional de Promoção da Saúde (PNPS) em dois momentos distintos: o primeiro, por ocasião de sua implantação, em 2006, e o segundo quando de sua revisão, em 2014. O objetivo é realizar uma análise comparativa dos dois documentos - a Portaria no 687 MS/GM, de 30 de março de 2006, que aprova a Política Nacional de Promoção da Saúde, e a Portaria oㅡ 2.446 MS, de 11 de novembro de 2014, que redefine a Política, com vistas a compreender o arranjo institucional constituído para sua articulação e gestão intersetorial.

Entendemos que o estudo de caso constitui um eficiente método de pesquisa para investigação empírica de um fenômeno contemporâneo complexo em que os limites do objeto de pesquisa e o contexto não são muito claros. A análise de políticas públicas e os estudos de caso são tidos como complementares, tendo em vista a ampliação do poder explicativo quando aplicadas conjuntamente.

O estudo de caso exploratório foi adotado como estratégia de pesquisa, primeiramente porque esta metodologia contribui para a compreensão de fenômenos organizacionais, sociais e políticos, preservando as características complexas do objeto de pesquisa. De acordo com a proposta apresentada por Robert Yin em "Estudo de Caso: Planejamento e Método", a escolha pelo tipo de estudo de caso a ser adotado depende de três condições: (1) tipo de questão de pesquisa proposta, (2) extensão do controle que o pesquisador tem sobre os eventos comportamentais atuais e, (3) no grau de enfoque em acontecimentos contemporâneos em oposição a acontecimentos históricos. 
Diante disso, entendemos que o tipo de metodologia de pesquisa que melhor se adequa à proposta desta análise é a de estudo de caso. Já que (1) a forma de questão de pesquisa está disposta em como se organiza a PNPS, (2) neste estudo não dispomos de controle sobre os eventos comportamentais, (3) e, por fim, esta pesquisa tem como foco de análise os acontecimentos contemporâneos, mas não foram desconsiderados os elementos históricos que agregaram ou modificaram elementos na formulação e implementação da política. Ao contrário, a proposta da pesquisa buscou conectar esses elementos não como incidências, mas como fatores provenientes de uma trajetória interligada de ações. É importante ressaltar que esse fator histórico foi considerado nesta análise, mas não foi seu objetivo principal.

A escolha pelo estudo de caso único se justifica com base em três dos cinco fundamentos lógicos expostos por Robert Yin (2001). O primeiro referese à escolha de um caso "decisivo" de uma teoria significativa. No Brasil, a Política Nacional de Promoção da Saúde é indissociável da reflexão sobre a criação e a luta contínua pela melhoria do Sistema Único de Saúde (SUS) e qualidade de vida da população. Caracteriza-se como um campo teórico, prático e político, que traz em sua composição os conceitos e as posições delineadas pelo Movimento da Reforma Sanitária. Constituiu-se, assim, a partir de uma visão ampliada de saúde pautada pela necessidade de enfrentamento de uma realidade de iniquidades históricas de grandes proporções, que colocam desafios cotidianos não só ao setor saúde, mas a todos aqueles que participam da formulação e implementação de políticas públicas (CAMPOS et al., 2004). Neste sentido, apresenta-se como uma referência quanto à necessidade e importância da incorporação dos conceitos e práticas de intersetorialidade no SUS, contemplando diferentes dimensões do objeto de estudo desta dissertação, a gestão intersetorial.

O segundo fundamento lógico descrito por Yin (2001), o caso "representativo" ou "típico", também é contemplado no estudo, tendo em vista que a PNPS, ao adotar a definição de saúde como resultado dos modos de organização social da produção, como efeito da composição de múltiplos fatores, exige que o Estado assuma a responsabilidade por uma política de 
saúde integrada às demais políticas sociais e econômicas. O que ratifica 0 engajamento do setor saúde por condições de vida mais dignas e pelo pleno exercício da cidadania, tendo por base seus determinantes e condicionantes sociais como elo para promover uma abordagem ampliada e coletiva acerca dos riscos à saúde e às vulnerabilidades sociais. O desenho estrutural da PNPS aponta para uma política que deve percorrer o conjunto das ações e projetos de saúde, apresentando-se em todos os níveis de complexidade da gestão e da atenção do SUS. Assim, tal política exige uma atuação transversal, não só para a integração entre as áreas técnicas especializadas, os diferentes níveis de complexidade e as políticas específicas do setor saúde, mas também para a articulação com as demais políticas públicas e níveis de gestão que impactam nas condições e qualidade de vida da população.

O terceiro fundamento, que justifica a escolha pelo caso único, é o "caso longitudinal", ou, em outras palavras, uma análise que tem como objetivo $o$ estudo do mesmo caso em diferentes pontos no tempo. Essa perspectiva foi adotada visando compreender os avanços identificados no aprimoramento e qualificação da política rumo a uma gestão mais intersetorial, como forma de observar as transformações ocorridas no aparato conceitual e organizacional da PNPS ao longo de sua implementação.

Entendemos que o estudo de caso único apresenta algumas limitações, entre elas a impossibilidade de replicação dos resultados para outros casos, no entanto acreditamos ser adequado à compreensão dos mecanismos de gestão, da configuração dos atores e das redes de serviços mobilizadas ao longo dos oito anos de existência da PNPS.

As estratégias metodológicas para a captação dos dados foram: análise de documentos oficiais (portarias, normativas, planos e relatório de gestão) e a revisão de artigos publicados de avaliação da política desde o seu lançamento em 2006 até sua atualização em 2014, com vistas a empreender uma análise geral sobre os aspectos de institucionalização, implementação e qualificação da Política Nacional de Promoção da Saúde.

A análise documental consta como uma relevante etapa metodológica na medida em que a legislação foi analisada segundo os aspectos elencados 
na Tabela 1 - Descrição dos Aspectos de Análise da Gestão Intersetorial. Essa opção contempla a recomendação de Flick (2009) de que documentos não devem ser tratados como dados sem viés, mas como "dispositivos comunicativos produzidos, utilizados e reutilizados para objetivos práticos específicos". Por esse ponto de vista, pode-se identificar na legislação não apenas instrumentos de pesquisa explícita e objetivamente expressos, mas também, em alguns casos, a lógica de utilização desses instrumentos pelos atores do governo federal responsáveis pela elaboração desse tipo de documento, embora essa perspectiva possa ser considerada limitada.

Documentos são úteis para, dentre outras coisas, obter-se uma primeira impressão de um campo de política, como um ponto inicial a partir do qual se pode identificar os atores envolvidos, suas atribuições e alguns dos objetivos da política e formular questões mais detalhadas sobre processos, a serem aprofundadas por meio de outros métodos de pesquisa (BOGASON; ZOLNER, 2007). Os documentos analisados consistiram basicamente na legislação da PNPS - Portaria MS n 687 de 30/03/2006 e Portaria MS n 2.446 de 11/11/14, além dos planos de governo, relatórios de gestão e materiais relacionados à institucionalização e implementação da PNPS. A legislação e materiais escolhidos atendem aos critérios sugeridos por Scott (1990 apud FLICK, 2009) para utilização de documentos como dados em uma pesquisa: autenticidade, credibilidade, representatividade e significação.

Por fim, é importante lembrar que os métodos quantitativos e qualitativos quando abordados de forma complementar servem para qualificar a coleta de dados e ampliar as perspectivas de análise, sendo esta indicada com uma limitação deste estudo. Ressaltamos que a proposta inicial de pesquisa previa, para além da análise dos documentos oficiais, a realização de entrevistas junto aos atores envolvidos na implementação da PNPS, conjuntamente com a realização de visitas para a observação das rotinas de trabalho in loco, o que não pôde ser viabilizado. Neste ponto, vale destacar as dificuldades enfrentadas para obter autorização para a pesquisa junto aos órgãos e instituições envolvidas, e para o agendamento de entrevistas com os dirigentes estratégicos, corroboradas ainda pelas intempéries relativas à 
disputa eleitoral e a alternância de governo ocorridas durante o período do estudo. 


\section{O CASO DA POLÍTICA NACIONAL DE PROMOÇÃO DA SAÚDE}

\subsection{CONFORMAÇÃO CONCEITUAL DA POLÍTICA NACIONAL DE PROMOÇÃO DA SAÚDE}

A Promoção da Saúde tem como principal referencial teórico a Carta de Ottawa ${ }^{15} \mathrm{e}$ a busca da redução das iniquidades em saúde, visando 0 empoderamento dos indivíduos e da coletividade. As Conferências Internacionais de Promoção da Saúde contribuíram para o amadurecimento conceitual e inspiraram, no âmbito nacional, a ampliação do Movimento da Reforma Sanitária, a Constituição Federal de 1988 e a implantação do Sistema Único de Saúde (SUS), que ratificam tanto o conceito ampliado de saúde como a valorização das ações de Promoção da Saúde.

O desafio colocado para o gestor federal do SUS consistiu em implementar uma política transversal, integrada e intersetorial que fizesse dialogar as diversas áreas do setor sanitário, os demais setores do governo, os setores privados e não governamental e a sociedade, compondo redes de compromisso e corresponsabilidade quanto à qualidade de vida da população, de forma que todos fossem partícipes no cuidado com a saúde (BRASIL, 2009b).

Assim, consideramos a Promoção da Saúde como uma das estratégias do Desenvolvimento Sustentável que, articulada às demais estratégias e políticas econômicas e sociais, contribui para a construção de ações transversais que possibilitem superar as iniquidades sociais, tendo como principais características a abordagem integral do processo saúde-doença e o reconhecimento dos determinantes sociais da saúde. A noção da sustentabilidade relacionada às políticas de Promoção da Saúde é especialmente importante, tendo em vista que as iniciativas dessa área dirigem-se a questões de natureza complexa, envolvendo processos de transformação coletivos, com impactos a médio e longo prazo. Coerentemente

\footnotetext{
${ }^{15}$ World Health Organization (WHO). The Ottawa Charter for Health Promotion. Geneva: WHO; 1986
} 
com os outros princípios aqui enfocados, a sustentabilidade em Promoção da Saúde envolve também os aspectos econômicos, sociais, políticos, culturais e ambientais.

Nessa direção, para o desenvolvimento deste estudo de caso vale resgatarmos algumas bases conceituais da Política Nacional de Promoção da Saúde que orientam nossa análise. Assim, tendo por referência o arcabouço teórico=metodológico abordado no capítulo anterior, buscamos retomar os conceitos de intersetorialidade, integralidade e transversalidade, que compreendem o ideário temático da PNPS, agregando ainda a perspectiva de cogestão e governança que permeiam e integram esses conceitos no âmbito do SUS.

A intersetorialidade é aqui entendida como o modo de gestão desenvolvido por meio de um processo sistemático de articulação, planejamento e cooperação entre os distintos setores da sociedade e entre as diversas políticas públicas para intervir nos determinantes sociais. Tem como princípios a corresponsabilidade, a cogestão e a coparticipação entre os diversos setores e políticas em prol de um projeto comum. Portanto, caracteriza-se como uma prática social construída para enfrentar os limites da cultura organizacional, marcada historicamente por ações isoladas e setorializadas em que os serviços, produtos e ações são ofertados separadamente. Assim, a intersetorialidade constituiu-se por uma estratégia articulada entre saberes e práticas, que busca a convergência entre recursos humanos, financeiros, políticos e organizacionais; e implica no estabelecimento de relações de poder horizontais, exigindo processos de pactuação para 0 enfrentamento de conflitos e problemas sociais prioritários (BRASIL, 2012).

No que se refere à integralidade, para além do aspectos abordados na campo da gestão de políticas, temos como referênciao princípio constitucional do Sistema Único de Saúde que abrange três dimensões: a abordagem integral do ser humano visto em suas inseparáveis dimensões biopsicossocial; a ampliação da percepção dos profissionais e serviços de saúde na relação com os usuários para o acolhimento de suas histórias, condições de vida e necessidades em saúde; e, o modo de organizar a atenção à saúde de forma a ampliar o acesso a todos os níveis de complexidade abrangendo ações de 
assistência, promoção, proteção e recuperação da saúde. Essa forma de organizar o sistema de saúde extrapola o alcance dos serviços de saúde, tendo em vista a formulação de políticas destinadas à produção da saúde tomada em seu sentido mais amplo (BRASIL, 2012).

Quanto ao conceito de transversalidade, trata-se de uma característica da Promoção da Saúde que Ihe confere capacidade de produção e articulação de diferentes saberes e práticas, perpassando os diversos setores da saúde, como a atenção e a gestão, além de outros setores governamentais, não governamentais e a sociedade (BRASIL, 2012).

No que diz respeito à cogestão, é considerada neste estudo como um modo de gestão que pressupõe articulação, definição de prioridades e pactuação coletiva de soluções entre atores institucionais e sociais para a organização de uma rede de ações e serviços de atenção à saúde integral e resolutiva. Assim, trata de um arranjo institucional que tem como perspectiva ressignificar as relações entre gestores e sociedade, permitindo que desenvolvam, de forma solidária e cooperativa, as funções relativas ao planejamento, programação, orçamento, coordenação, execução, monitoramento e avaliação de ações, estratégias e serviços. Assim, também está relacionada à corresponsabilidade ou responsabilidade compartilhada entre gestores e atores sociais nas proposições e no acompanhamento de políticas públicas na lógica de governança (Brasil, 2012).

Como foco deste trabalho, as estruturas formais e informais de governança podem ser importantes causadoras de iniquidades em saúde, daí a opção de recorrermos aqui à ideia da "boa governança", para a qual o Programa das Nações Unidas para o Desenvolvimento (PNUD) recomenda a atenção a cinco princípios, quais sejam: dar legitimidade e voz a todas as partes; assumir uma visão estratégica que se preocupa com a sustentabilidade e que valoriza os processos; buscar a eficiência e eficácia das políticas; promover a corresponsabilização e transparência nas ações; buscar a redução das desigualdades e iniquidades.

A partir desses conceitos, entendemos ser possível observar a coerência com os aspectos elencados para avaliação dos componentes de integralidade e transversalidade, apresentados na Tabela 1, que foram propostos a partir do 
fluxo esquemático sugerido para análise e classificação dos níveis de gestão intersetorial de políticas públicas. Como destaque, consideramos importante observar que as definições conceituais convergem, de forma consistente, para as noções de participação, responsabilização e planejamento integrado entre atores sociais e governamentais, e apontam para a organização de arranjos institucionais mais democráticos e participativos para a gestão de demandas complexas e prioritárias para o desenvolvimento social e qualidade de vida da população.

Vale lembrar ainda que em nossa análise procuramos abordar 0 componente da integralidade associado às questões mais dialógicas e colaborativas, direcionadas a promover a construção coletiva, fortalecimento dos espaços de participação e a garantia dos direitos de cidadania, a partir da produção, análise e difusão de informações voltadas à conformação de diagnósticos ampliados capazes de alcançar as diversidades sociais e territoriais em saúde. Já o componente da transversalidade foi associado a questões mais organizacionais e cooperativas, direcionadas à constituição de estruturas e mecanismos para a mobilização e responsabilização dos distintos setores implicados, buscando o planejamento integrado de ações e serviços para atendimento das necessidades sociais. Neste sentido, trataremos a seguir de descrever alguns aspectos da institucionalização, implementação e qualificação da PNPS, buscando identificar a amplitude conceitual e a aplicação prática dos fatores considerados para a organização do seu arranjo de gestão intersetorial.

\subsection{INSTITUCIONALIZAÇÃO DA POLÍTICA NACIONAL DE PROMOÇÃO DA SAÚDE}

As transições epidemiológica, demográfica e nutricional, o agravamento dos efeitos sanitários dos grandes problemas sociais - miséria, fome, violências, destruição ambiental - e a interlocução contínua com organismos internacionais, como a OPAS e OMS, instâncias de controle social, Conass e Conasems, além de diversas instituições de ensino e pesquisa, brasileiras e internacionais, geraram as condições históricas necessárias à 
institucionalização da Promoção da Saúde no Brasil. Desde a década de 1990, múltiplos esforços foram sendo empreendidos no sentido de identificar e definir a contribuição que a Promoção da Saúde poderia oferecer ao processo de implantação e consolidação do SUS. Nos anos 2000, parte desses esforços foi contemplada no processo de reestruturação do Ministério da Saúde com a criação da Secretária de Vigilância em Saúde.

É importante frisar que a noção de vigilância em saúde abarca os vários níveis de atenção, tratando de articular o "enfoque populacional" (promoção) com o "enfoque de risco" (prevenção) e o enfoque clínico (assistência), constituindo, de fato, uma estratégia de organização de um conjunto heterogêneo de políticas e práticas que assumem configurações específicas de acordo com a situação de saúde das populações em cada país, estado, município ou territórios (TEIXEIRA; PAIM, 2000). É interessante observar que essa noção aponta para uma visão estratégica de desenvolvimento dos sistemas de saúde, a partir da análise de informações e da articulação das redes de serviços, visando dar suporte aos instrumentos de planejamento em saúde em todos os níveis de gestão do SUS, bem como impactar na implementação das demais políticas sociais. Abarca, ainda, a ideia de responsabilização da sociedade e dos usuários na construção das demandas e prioridades para a promoção da saúde.

No âmbito deste estudo, abordamos a Vigilância em Saúde em uma concepção ampliada, definida como um conjunto articulado de ações destinadas a controlar determinantes, riscos e danos à saúde de populações que vivem em determinados territórios, sob a ótica da integralidade do cuidado, o que inclui tanto a abordagem individual quanto coletiva dos problemas de saúde. As ações específicas de Vigilância Epidemiológica, Vigilância Sanitária e Vigilância Ambiental fazem parte do que aqui se denomina de Vigilância em Saúde, ao lado das ações de caráter individual organizadas sob a forma de consultas e procedimentos médicos (TEIXEIRA; PINTO; VILASBÔAS, 2004).

Nesta dimensão, coordenar a elaboração e implementação da Promoção da Saúde a partir da Secretaria de Vigilância em Saúde (SVS), em âmbito federal, requereu o fortalecimento da análise de situação e o planejamento de iniciativas de Promoção que exigiram a retomada dos marcos conceituais da 
Reforma Sanitária. O reconhecimento do impacto das Doenças e Agravos não Transmissíveis (DANT), na produtividade econômica e na qualidade de vida da população, reforçou o questionamento ao modelo hegemônico de atenção à saúde, a partir das prerrogativas saudáveis e sustentáveis de desenvolvimento social, de forma que coube ao órgão federal do SUS explicitar e institucionalizar as possíveis relações e congruências dos campos da promoção e da vigilância em saúde com foco na prevenção e controle das DANT, conforme demonstrado abaixo:

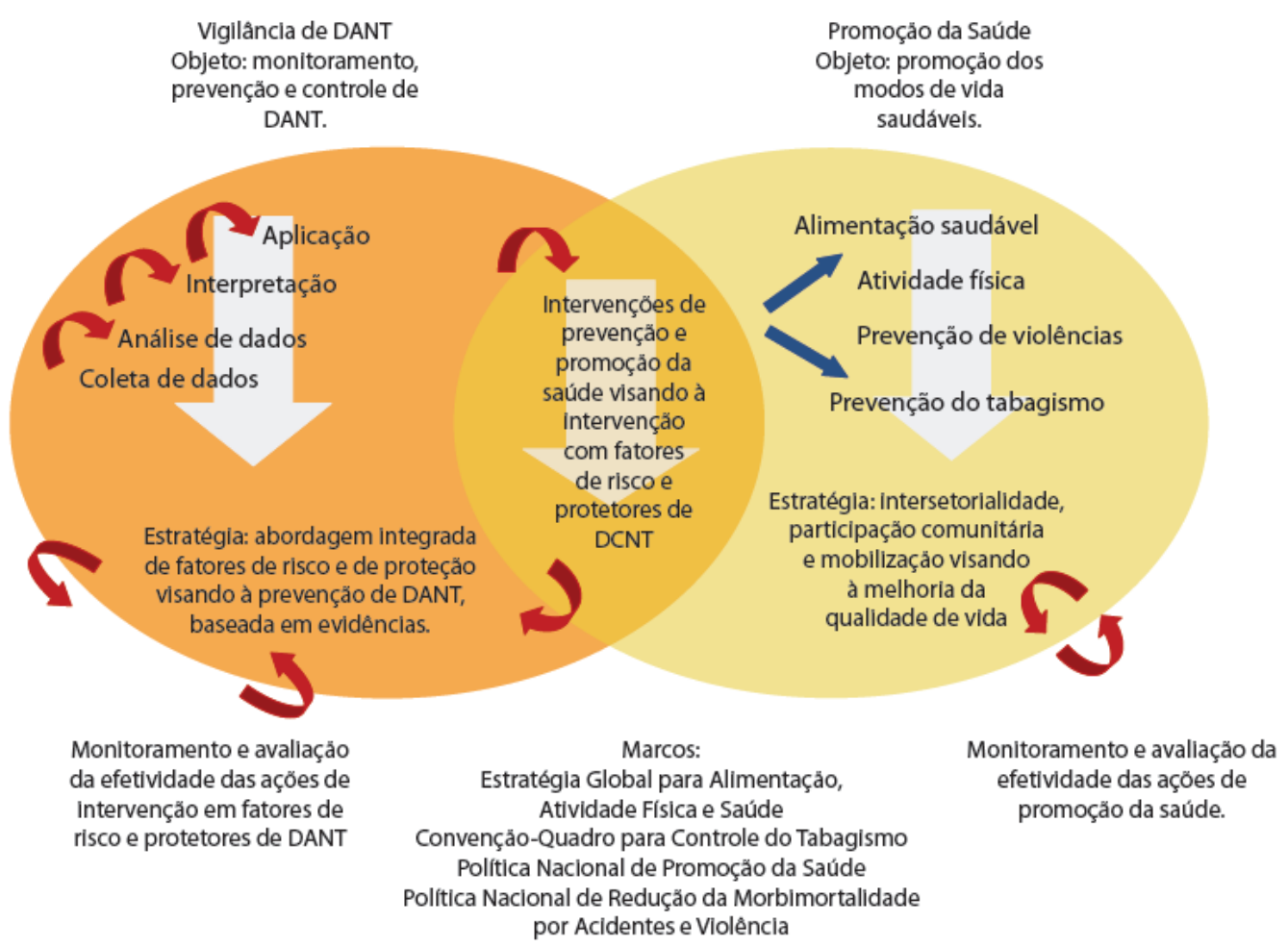

Figura 6. Relações e congruências dos campos da promoção e da vigilância em saúde (BRASIL, 2013).

Já a partir de 2004, coube à Coordenação Geral de Doenças e Agravos Não Transmissíveis (CGDANT/SVS) o papel de realizar a revisão dos documentos ministeriais e de governo a fim de fortalecer o caráter integrador e intersetorial da Promoção da Saúde, com ênfase no Plano Nacional de Saúde e nos materiais de outros setores de governos, como meio ambiente, educação, esporte e cidades (BRASIL, 2009b). Nesta direção, o primeiro passo para a institucionalização da Política de Promoção da Saúde ocorreu com a publicação da Portaria n¹.190 GAB/MS, em 14 de julho de 2005, que criou 0 
Comitê Gestor da Política Nacional de Promoção da Saúde (CGPNPS). Ao Comitê Gestor, formado por diferentes secretarias e órgãos do MS, atribuiu-se: consolidar a proposta da Política Nacional de Promoção da Saúde; coordenar a sua implantação e a articulação com os demais setores governamentais e não governamentais; incentivar estados e municípios a elaborarem Políticas de Promoção da Saúde; articular e integrar ações de Promoção da Saúde no SUS; monitorar e avaliar as estratégias de implementação da Política Nacional de Promoção da Saúde e seu impacto.

Entretanto, somente em 2006, houve a efetiva institucionalização da PNPS com a publicação da Portaria ํo 687 MS/GM, de 30 de março de 2006, após aprovação pela Comissão Intergestores Tripartite (CIT); e da Portaria MS № 23, de 18 de maio de 2006, que formalizou a constituição do CGPNPS. De modo geral, apesar da ênfase à integração intersetorial e da indicação estratégica do próprio MS quanto à importância dos setores de Meio Ambiente, Educação, Esporte e Cidades, a conformação institucional do CGPNPS deu-se apenas de forma intrassetorial, envolvendo somente as secretarias do MS e parte dos seus órgãos vinculados (SVS, SAS, SCITE, SGP, Funasa, INCA, Fiocruz e ANS), sem a participação de representantes da sociedade e outros setores de governo.

Não obstante as diretrizes para a convocação e participação de diferentes atores sociais, o processo de formulação e pactuação da PNPS concentrou-se no setor saúde, inicialmente no plano federal, salvo pela participação da CIT no processo de aprovação. Sob esse aspecto, é possível aventarmos certa limitação na representatividade social e legitimidade política da PNPS, ao considerarmos que a participação dos demais níveis de governo e atores sociais, no plano da gestão federal, se dá após a sua formulação, o que poderia remeter a uma forma de organização setorial e descendente, sem efetiva discussão das demandas a partir das diferentes realidades e necessidades sociais dos territórios.

Contudo, a publicação da PNPS representou um marco na consolidação do SUS ao reafirmar os ideais da Reforma Sanitária e ratificar o debate dos condicionantes e determinantes sociais da saúde no processo saúde-doença. A PNPS estabeleceu como objetivo promover a qualidade de vida e reduzir 
vulnerabilidades e riscos à saúde relacionados aos modos de viver, condições de trabalho, habitação, ambiente, educação, lazer, cultura, acesso a bens e serviços essenciais. Suas diretrizes preconizaram atitudes baseadas na cooperação e no respeito às singularidades, como: estímulo à intersetorialidade, compromisso com a integralidade do cuidado, fortalecimento da participação social e o estabelecimento de mecanismos de cogestão no processo de trabalho em equipe (MALTA et al., 2014). Assim, seus princípios e diretrizes conceituais alcançaram as noções de: autonomia; empoderamento, participação social, governança, território, equidade, intersetorialidade, sustentabilidade e integralidade.

Após a institucionalização da Política Nacional e instalação do seu Comitê Gestor, trabalhou-se pela garantia de recursos financeiros para a implementação da Política, o que foi garantido com a inclusão da Promoção da Saúde como programa orçamentário do Ministério da Saúde a partir de 2008. Entretanto, segundo o relatório de avaliação anual do PPA 2008-11, publicado pelo Ministério da Saúde em 2010, somente 50\% dos recursos previstos para a implementação da PNPS foram realizados. Entre as principais dificuldades destacou-se "a fragilidade de institucionalização da promoção da saúde na estrutura de gestão do MS" (BRASIL, 2010, pág. 5). Essa fragilidade de gestão poderia estar relacionada tanto à limitação organizacional e técnica para a indução da nova política, como pela ausência de mecanismos de incentivo e fomento à organização das ações de promoção em nível local.

Em relação ao processo de participação social, o CGPNPS coordenou, ainda em 2006, o I Seminário Nacional sobre a Política Nacional de Promoção da Saúde, que abordou a agenda de prioridades da PNPS e contou com a participação de gestores e profissionais de saúde das três esferas do SUS, representantes do governo de outros Ministérios (Esporte, Cidades, Meio Ambiente etc.), de instituições (Secretaria de Direitos da Mulher, Secretaria de Comunicação Institucional da Presidência da República etc.), de organizações governamentais e não governamentais, de organismos internacionais, estudiosos, pesquisadores, entre outros (BRASIL, 2009a). Todavia, é interessante observar que o formato de seminário parece apontar para uma abordagem mais positivista e menos dialógica do que a perspectiva de 
conferências, geralmente adotadas por outras políticas; remetendo a uma lógica mais expositiva e menos deliberativa.

Assim, a PNPS destacou sete áreas temáticas prioritárias: alimentação saudável; práticas corporais/atividade física; prevenção e controle do tabagismo; redução da morbimortalidade por uso abusivo de álcool e outras drogas; redução da morbimortalidade por acidentes de trânsito; prevenção da violência e estímulo à cultura de paz; e promoção do desenvolvimento sustentável. Um dos efeitos considerados do I Seminário foi a reconfiguração do CGPNPS, que passou a incluir representantes da Secretaria Executiva do Ministério da Saúde, da Anvisa e dos gestores estaduais - Conass e municipais de saúde - Conasems (Portaria GM/MS n¹.409, de 13 de junho de 2007), além do compromisso de organizar os processos de formação para os profissionais e gestores do SUS.

Neste ponto, cabe observar que a PNPS tem um ganho de legitimidade política, ao incorporar um órgão com maior potencial articulador e poder decisório no âmbito do Ministério da Saúde - a Secretaria Executiva -, assim como amplia sua representatividade multinível com a inclusão de gestores estaduais e municipais - Conass e Conasems no CGPNPS. Contudo, a participação no CGPNPS ainda permaneceu restrita à atuação de órgãos e gestores internos do setor saúde, sem abertura à participação de outros setores governamentais e de representantes da sociedade civil. Essa lacuna foi parcialmente atendida com a publicação da Portaria nำ1.571, de 19 de julho de 2012, que alterou a Portaria $n^{\circ}$. 1.409 de 2007, com a inclusão de um representante da sociedade civil, a Associação Brasileira de Pós-Graduação em Saúde Coletiva (Abrasco).

Portaria GM/MS no 1409/2007

(...)

Art. $2^{\circ}$ O CGPNPS terá a seguinte composição:

I - três representantes da Secretaria de Vigilância em Saúde/SVS;

II - três representantes da Secretaria de Atenção à Saúde - SAS;

III - um representante da Secretaria de Gestão Estratégica e Participativa - SGEP;

IV - um representante da Secretaria de Gestão do Trabalho e da Educação na Saúde - SGTES; 


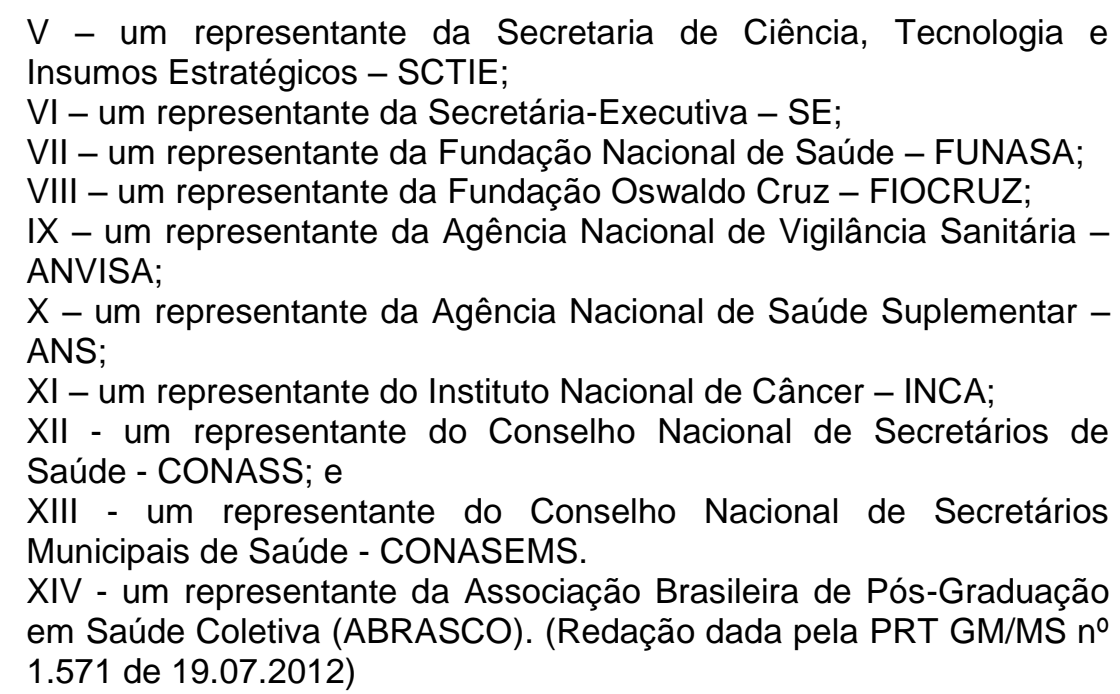

Podemos observar também que a definição dos sete eixos prioritários de atuação da PNPS ampliou ainda mais a perspectiva e necessidade de articulação com outras políticas sociais diretamente implicadas aos temas, para além dos setores já citados anteriormente, como as pastas de direitos humanos, desenvolvimento social, justiça, segurança alimentar e nutricional, cultura, entre outras políticas que emergiram na agenda estratégica do governo para enfrentar as desigualdades sociais nas últimas décadas.

Por outro lado, é possível observar que o CGPNPS parece se afastar de um modelo de arranjo intersetorial mais soft (SERRA, 2004), em que quanto maior a representatividade e poder decisório dos setores envolvidos em relação ao número de integrantes, maiores serão as facilidades para a mediação de interesses e conflitos para o estabelecimento conjunto de prioridades e o compartilhamento de recursos e responsabilidades. No mesmo sentido, a distinção entre o número de representantes dos órgãos do setor saúde também sugere certa hierarquia e assimetria na distribuição de poder no âmbito do Comitê, o que pode dificultar o desenvolvimento de relações mais horizontais entre os atores internos. Uma maneira de aprofundar a avaliação do grau de legitimidade do CGPNPS poderia ser obtida pela análise do perfil e qualificação dos seus membros e/ou participantes, principalmente a partir da avaliação do cargo e função ocupados na estrutura organizacional dos órgãos partícipes, e da formação ideológica e profissional dos seus integrantes. Isso poderia auxiliar na identificação das relações de poder no processo decisório, 
do nível de qualificação profissional de seus integrantes e na importância dada pelos órgãos à instância de coordenação da política, o que não foi possível ser verificado neste estudo.

Ressalta-se que a Portaria MS $n^{\circ} 23$, de 18 de maio de 2006, que nomeou parte dos componentes do Comitê, prevê um mandato de dois anos para a renovação dos seus membros, que poderiam ser reconduzidos à função. Entretanto, a única publicação posterior identificada para a nomeação dos membros do CGPNPS é a Portaria SVS/MS n 68 de 24/06/2008, a qual consideramos defasada. Ademais, neste estudo, não foram analisados registros de reuniões ou produtos de trabalho do CGPNPS, o que limita a análise de composição e funcionamento desta instância, assim como uma possível avaliação das pautas e regularidade da agenda, aspectos que poderiam contribuir para análise da organização funcional da PNPS e sua articulação junto a outros órgãos e instituições.

O MS considera que a atuação do CGPNPS produziu resultados importantes como, por exemplo, a pactuação dos principais indicadores da Promoção da Saúde - prevalência de sedentarismo e tabagismo - por estados e capitais, e de indicadores complementares - Núcleos de Prevenção das Violências e Promoção da Saúde -, que foram pactuados ou definidos como agenda prioritária por $100 \%$ dos estados e municípios prioritários, incluindo a PNPS na agenda dos gestores em todos os níveis do SUS (MALTA; CASTRO, 2009). No entanto, a definição desses indicadores parece restringir as dimensões e alcance da Promoção da Saúde e tornou evidente a escolha da política brasileira em priorizar a abordagem individual $\mathrm{e}$ aspectos comportamentais da promoção da saúde, em detrimento da abordagem coletiva e de estratégias mais integradas com as áreas sociais na lógica de indução de políticas públicas saudáveis.

Segundo Malta (2014), entre as ações intersetoriais da PNPS destacamse os marcos legais como: Plano de Ação para o Enfretamento da Violência Contra a Pessoa Idosa (2005); Política Nacional de Enfrentamento ao Tráfico de Pessoas (Decreto ํo 5.948, de 26/10/2006); Lei Maria da Penha (Lei oㅜ 11.340, de 7/8/2006), Política Nacional de Saúde Integral da População Negra (Portaria MS/GM no 992, de 13/5/2009); Política Nacional de Saúde Integral de 
Lésbicas, Gays, Bissexuais, Travestis e Transexuais - LGBT (2008), Política de Atenção Integral à Saúde da Mulher, Linha de Cuidado para a Atenção à Saúde de Crianças, Adolescentes e suas Famílias em Situação de Violências, entre outros.

Em 2010, foi realizado o II Seminário sobre a Política Nacional de Promoção da Saúde, que voltou a reunir o público de gestores e profissionais de saúde das três esferas do SUS, representantes de governo e organismos internacionais, estudiosos e pesquisadores. O momento foi de avaliação da PNPS, o que possibilitou a reflexão sobre a práxis nas três esferas de governo, buscando o aprimoramento das estratégias de implementação da política, o fortalecimento e a melhoria do SUS e, consequentemente, a melhoria da qualidade de vida da população.

\subsection{ASPECTOS DA IMPLEMENTAÇÃO DA POLÍTICA NACIONAL DE PROMOÇÃO DA SAÚDE}

O SUS é uma rede de organizações, de pessoas e de interesses que se inter-relacionam e interdependem. Para entender esta realidade institucional complexa, é interessante também incorporar a ideia de que os processos de mudanças não estão fora das organizações, mas embutidos em sua própria lógica. Ou seja, as relações criadas pelos diferentes atores organizacionais não surgem fora das organizações, mas nelas mesmas, como um meio de manter estáveis seus padrões de relações. São um processo de fechamento ou de autorreferência, através do qual a organização tenta concretizar e reproduzir sua identidade.

Para Buss (2000), com quem concordamos, a identidade da Promoção da Saúde trabalha com a ideia de "responsabilização múltipla", seja pelos problemas, seja pelas soluções propostas para eles, combinando "ações do Estado (políticas públicas saudáveis); da comunidade (reforço da ação comunitária); de indivíduos (responsabilização individual e desenvolvimento de habilidades pessoais); do sistema de saúde (reorientação dos serviços de saúde); e de parcerias intersetoriais" (BUSS, 2000, p. 165). 
Naido e Wills, citados por Westphal (2006), complementam essa identidade institucional quando classificam em cinco grupos as diferentes iniciativas de Promoção da Saúde: biomédicas - centradas na cura e reabilitação; comportamentais - voltadas aos estilos de vida individuais; educacionais - também voltadas ao estilo de vida, porém na perspectiva do empowerment $^{16}$ individual; o empowerment coletivo - associado ao desenvolvimento comunitário local, baseado no estímulo à participação social; e a transformação social - centrada na construção participativa de políticas públicas saudáveis, orientadas pelo princípio da equidade, para a mudança das relações de poder e implementação de ações sobre os determinantes sociais da saúde (WHESTPHAL, 2006).

No entanto, no que se refere à gestão intersetorial, a atuação da PNPS não contribuiu para o fortalecimento institucional e político da Promoção da Saúde na convocação e integração com as demais políticas de enfretamento às desigualdades sociais em ascensão nos últimos anos. Por outro lado, suas ações estiveram focadas na adoção de estratégias de descentralização de recursos para o financiamento de propostas de ação vinculadas à atividade física, à prevenção de violências, à promoção da cultura de paz, e para formação de profissionais e gestores de saúde, além de investimentos em ações para qualificar a informação para a gestão da Rede Nacional de Promoção da Saúde, conceitualmente vinculada à noção de Redes de Atenção à Saúde (RAS).

Assim, entendemos que, apesar do constrangimento político em nível federal, a promoção da saúde ganhou destaque nas RAS, a partir da sua institucionalização enquanto política, dada sua importância para a construção do cuidado integral no âmbito do SUS. A RAS apresenta-se como uma estratégia que visa superar a fragmentação da atenção e da gestão à saúde e aperfeiçoar o funcionamento do SUS, buscando assegurar o cuidado integral ao usuário. E é definida como arranjos organizativos formados por ações e serviços de saúde com diferentes configurações e densidades tecnológicas,

${ }^{16}$ Consideramos aqui a definição de Amartya Sen (2002) para empowerment como: a ampliação das possibilidades de controle, por um sujeito ou uma população, dos aspectos significativos relacionados à sua própria existência. 
que, integrados por meio de sistemas de apoio técnico, logístico e de gestão, buscam garantir a integralidade do cuidado (BRASIL, 2010). Dessa forma, ela objetiva promover a integração sistêmica, de ações e serviços de saúde pautados na atenção contínua, integral, de qualidade, responsável e humanizada, além de possibilitar o melhor desempenho do SUS em relação ao acesso, à equidade, à eficácia clínica e sanitária e à eficiência econômica.

A RAS caracteriza-se por (BRASIL, 2010; 2011a):

- Ações e serviços de saúde articulados de forma complementar e territorial, com formação de relações horizontais entre os pontos de atenção, considerando a Atenção Básica à Saúde (ABS) como o centro de comunicação;

- Centralidade nas necessidades de saúde da população;

- Responsabilização pela atenção contínua e integral;

- Cuidado interdisciplinar;

- Compartilhamento de objetivos e compromissos com resultados sanitários e econômicos pactuados.

A RAS fundamenta-se na compreensão da Atenção Básica como primeiro nível de atenção, a partir do qual se realiza e coordena o cuidado em todos os demais pontos da rede de atenção. A Atenção Básica, dessa forma, é primordial para o funcionamento das RAS, sendo o centro de comunicação, porta de entrada preferencial, coordenadora do cuidado e ordenadora da RAS (BRASIL, 2010, 2011a). Assim, no que se refere à implementação da PNPS, a organização operacional da Rede de Promoção da Saúde apresenta-se interconectada à RAS a partir da perspectiva do modelo de atenção, que é considerado o sistema lógico que organiza o funcionamento da RAS. Para isso, o modelo pretende articular as relações entre a população e os grupos estratificados por riscos; e o foco das intervenções do sistema de saúde e os diferentes tipos de intervenções sanitárias a serem realizadas, definidas pela situação demográfica e epidemiológica, e pelos determinantes sociais da saúde (BRASIL, 2010). Portanto, aponta para arranjos organizativos centrados na atenção básica como ordenadora das ações e serviços de saúde a partir do território e de forma ascendente, geridos por um sistema de governança 
interfederativo e transversal, as Comissões Intergestoras Regionais (CIR), Comissão Intergestora Bipartite (CIB) e Comissão Intergestora Tripartite (CIT).

Entendemos que essa organização impacta em pelo menos duas dimensões da gestão intersetorial da PNPS: a moderação intrassetorial das relações de poder entre Vigilância (SVS) e Atenção (SAS) na coordenação da PNPS em nível federal; e a observância do modelo de atenção na articulação estratégica do SUS com a Agenda Social do governo nos diferentes níveis de gestão.

O monitoramento da RAS tem sido realizado por meio da pesquisa telefônica - VIGITEL ${ }^{17}$. Segundo Malta, no período de outubro de 2010 a janeiro de 2011, foram entrevistados 991 municípios e nove estados que receberam financiamento em 2009 para organização da Rede de Promoção da Saúde, (MALTA; CASTRO, 2009). Entretanto, restam dúvidas quanto ao real universo de municípios prioritários para a implementação da PNPS, bem como dos efetivos indicadores para um possível "ranqueamento" para a priorização.

Vale observar que, não obstante a criação de um programa orçamentário para a promoção da saúde, o financiamento das políticas, programas e ações que contemplem os componentes de promoção da saúde são financiados por meio dos blocos de financiamento do SUS (BRASIL, 2015), ou por meio de incentivos que não têm caráter permanente (Portarias $n^{\circ} 79$, de 23 de setembro de 2008; $n^{\circ} 2.981$, de 9 de dezembro de 2008; e $n^{\circ} 139$, de 11 de agosto de 2009), podendo ainda responsabilizar recursos da atenção básica, por intermédio dos Núcleos de Apoio à Saúde da Família (Portaria no 154, de 24 de janeiro de 2008), como fora previsto no manual de gestão da vigilância em saúde (BRASIL, 2009b).

No que tange à perspectiva da Agenda Social e do Planejamento orçamentário em âmbito federal, o Plano Nacional de Saúde (PNS) 2012-15, reafirma que entre os principais problemas de saúde pública estão os agravos

\footnotetext{
${ }^{17}$ A Pesquisa de Vigilância de Fatores de Risco e Proteção para Doenças Crônicas por Inquérito Telefônico (Vigitel) é realizada anualmente desde 2006 nas 26 capitais e no Distrito Federal. O Vigitel mede a prevalência autorreferida de fatores de risco e proteção para doenças não transmissíveis na população brasileira, por meio de inquérito telefônico. São entrevistados adultos a partir de18 anos residentes nas capitais dos 26 estados brasileiros e do DF, em domicílios com pelo menos uma linha telefônica fixa. Em 2011 e 2012, foram entrevistados 54.144 e 45.400 pessoas, respectivamente (BRASIL, 2014).
} 
e vulnerabilidades relacionados às precárias condições de vida da população em situação de pobreza, que compreendem a maior exposição a fatores de risco ambiental, exposição a doenças infectocontagiosas e crônicas não transmissíveis, pior estado nutricional, maior taxa de fecundidade, maior prevalência de edêntulos, dificuldade de acesso a consultas oftalmológicas e óculos, além da dificuldade de acesso aos serviços de saúde e a medicamentos. Com destaque, entre outras questões, para a influência dos cuidados de saúde no desempenho escolar, na inserção e no desempenho no mercado de trabalho, bem como o potencial do setor de gerar oportunidades profissionais nas equipes de saúde da atenção básica, nas obras e na formação técnica, além da economia da saúde e do complexo industrial a ela relacionado (BRASIL, 2012).

Neste sentido, reconhecemos que o PNS 2012-15 volta a se reaproximar da dimensão social da Promoção da Saúde, quando considera que promover a saúde e contribuir com a erradicação da extrema pobreza são diretrizes transversais que alcançam todos os órgãos e programas do setor saúde. Portanto, são previstas ações para a atenção básica, como a construção, reforma e ampliação de unidades básicas de saúde, ampliação de equipes de saúde da família, de agentes comunitários de saúde, de núcleos de apoio à saúde da família, de consultórios de rua, de academias de saúde e de equipes de saúde bucal. Também estão previstas ações das Redes Cegonha e de Atenção à Saúde Mental, do Programa Farmácia Popular, do Projeto Olhar Brasil e o enfretamento das doenças relacionadas à pobreza (tuberculose, hanseníase, tracoma, helmintíase e esquistossomose).

Assim, a amplitude e o alcance da PNPS permeia o SUS nos seus diferentes níveis de atenção, organização e estruturação dos serviços de saúde e apresenta-se interligada às diferentes políticas públicas que determinam as estratégias de desenvolvimento social e econômico da sociedade e os padrões de qualidade de vida da população.

Nessa direção, entre as referências na atuação intersetorial da PNPS destaca-se o Projeto Vida no Trânsito (PVT), que conta com ampla parceria envolvendo instituições nacionais, internacionais e locais, visando reduzir o quadro de morbimortalidade relacionada aos acidentes de trânsito por meio da 
elaboração de um plano de ações integradas e intersetoriais de segurança no trânsito.

O PVT foi implantado em 2010 em cinco capitais brasileiras: Belo Horizonte, Curitiba, Teresina, Palmas, Campo Grande, e, após 2012, expandido para todas as capitais e cidades acima de um milhão de habitantes. O PVT utiliza como ferramenta as informações obtidas a partir das análises feitas pelas Comissões Locais de Dados, que orientam as intervenções integradas e intersetoriais nos territórios de maior necessidade. São articuladas ações integradas de educação, engenharia de trânsito, fiscalização, pesquisa e comunicação social. As intervenções são definidas em parceria e as ações executadas segundo as responsabilidades e especificidades de cada instituição.

$\mathrm{Na}$ área de desenvolvimento sustentável, são destacadas parcerias com os Ministérios do Meio Ambiente, Integração, Cidades, Casa Civil, Secretarias Estaduais de Saúde e Secretarias Municipais de Saúde, para a realização de Planos de Desenvolvimento Sustentável em áreas como a Região Turística do Meio-Norte (Piauí, Maranhão e Ceará); Plano de Desenvolvimento Regional Sustentável do Xingu, dentre outros. Cita-se ainda a criação da Câmara Técnica de Saúde em Apoio à Política Nacional de Desenvolvimento Regional (Portaria MS № 1.987, de 12 de setembro de 2012), a Criação do Grupo Técnico Saúde e Licenciamento Ambiental (Portaria GM № 2.241 de 25 de setembro de 2009), bem como o desenvolvimento do Programa Cidades Sustentáveis - Brasil + 20 - com a integração de políticas públicas voltadas à gestão ambiental urbana.

Outro destaque evidenciado pela PNPS refere-se à Política Nacional de Controle do Tabaco, que conta com a atuação da Comissão, criada por Decreto Presidencial, com caráter interministerial e atuação de fórum governamental responsável por implementar as medidas da ConvençãoQuadro no país. Esta Comissão é integrada hoje por 18 áreas do governo. A presidência da CONICQ cabe ao ministro da Saúde, e o INCA é responsável pela sua Secretaria-Executiva. Destacam-se ainda as parcerias com 0 Ministério da Educação, na implementação de ações do Programa Saúde na 
Escola, e com o Ministério do Esporte, apoiando o Programa Academia da Saúde.

Por fim, outra iniciativa que merece destaque na PNPS refere-se ao Plano de Ações Estratégicas para o Enfrentamento das Doenças Crônicas Não Transmissíveis (DCNT's) no Brasil, 2011-2022 (BRASIL, 2011b), principalmente por contemplar um planejamento que pretende alcançar diferentes setores e ciclos de gestão governamental. As doenças crônicas não transmissíveis, que constituem um grande problema de saúde pública no mundo e no Brasil, compõem um grupo de enfermidades que são de etiologia multifatorial, longa duração, de progressão geralmente lenta e que não são transmitidas de pessoa para pessoa (WHO, 2011).

Segundo a Organização Mundial de Saúde (OMS), no ano de 2008, as DCNT foram responsáveis por $63,0 \%$ dos 57,0 milhões de óbitos no mundo, sendo que $80,0 \%$ dessas mortes ocorreram em países em desenvolvimento (WHO, 2011). No Brasil, as DCNT foram responsáveis, em 2009, por $72,4 \%$ dos óbitos, destes, 80,5\% foram causados por doenças cardiovasculares, câncer, doença respiratória e diabetes mellitus. Ressalta-se ainda que, em 2008 , as doenças cardiovasculares e as neoplasias foram as principais causas de anos potenciais de vida perdidos em ambos os sexos (BRASIL, 2011a). Como determinantes sociais das DCNT, são apontadas as desigualdades sociais, as diferenças no acesso a bens e serviços, a baixa escolaridade e as desigualdades no acesso à informação. Por outro lado, elas também estão relacionadas a fatores de risco não modificáveis como idade, sexo e raça; e modificáveis, com destaque para o tabagismo, o consumo excessivo de bebidas alcoólicas, o excesso de peso, a alimentação não saudável e a inatividade física (BRASIL, 2011a, b; MALTA et al., 2011).

No Brasil, como consequência deste quadro epidemiológico, as DCNT exercem importante pressão orçamentária sobre o sistema de saúde, e impactam na perda de produtividade no trabalho e consequente redução da renda familiar. Assim, o Plano objetiva promover o desenvolvimento e a implementação de políticas públicas efetivas, integradas, sustentáveis e baseadas em evidências para a prevenção e o controle das DCNT e seus fatores de risco, bem como fortalecer os serviços de saúde para a assistência 
aos usuários com DCNT. Para o alcance de suas metas, o Plano foi eleito como prioridade de governo, e se destaca pela sua articulação intersetorial, incluindo a participação de todas as Secretarias e diversas áreas técnicas do Ministério da Saúde, abrangendo políticas e programas como a Política Nacional de Promoção da Saúde, Política Nacional de Alimentação e Nutrição, Programa Academia da Saúde, Programa Saúde na Escola, Rede Cegonha, Rede de Urgência e Emergência, luta contra o tabaco, entre outros.

A mobilização da sociedade civil, setor privado, Organizações não Governamentais (ONGs) e Conselhos de Saúde, com a efetiva participação popular, é igualmente apontada para o sucesso do Plano em promover a prevenção e o controle das DCNT. Acreditamos que esta articulação interdisciplinar e intersetorial é essencial, visto que as DCNTs possuem origem multifatorial, podendo um mesmo indivíduo estar exposto a vários fatores de risco, bem como apresentar distintas morbidades, necessitando de múltiplas abordagens de tratamento e prevenção, mas principalmente de promoção da saúde. Ressalta-se ainda que, para alcançar seus objetivos, o Plano interliga diferentes Políticas de Saúde, propondo ações em três eixos estratégicos com

diretrizes e ações definidas, sendo estes eixos: Vigilância, Informação, Avaliação e Monitoramento, Promoção da Saúde e Cuidado Integral (BRASIL, 2011a).

\subsection{QUALIFICAÇÃO DO MODELO DE GESTÃO DA PNPS}

Em relação ao processo de qualificação do modelo de gestão da PNPS no âmbito da SVS, o atual ciclo de planejamento governamental e de saúde reforçou a importância da atuação intersetorial para o enfrentamento das desigualdades sociais e iniquidades em saúde. Neste sentido, a construção da Agenda da Vigilância em Saúde está focada no aperfeiçoamento da gestão pautando-se em ações de planejamento e desenvolvimento organizacional e de participação social em articulação com a Agenda Social do governo federal.

De modo geral, o foco desta agenda está orientado para promover um processo de envelhecimento saudável pelo incentivo à prática de atividade 
física na dimensão comportamental e no apoio à erradicação da pobreza na dimensão social. A esperança de vida aumentou, vive-se melhor e a tecnologia biomédica nunca se desenvolveu de modo tão acelerado. Mas envelhecer com saúde se tornou um grande desafio para o sistema de saúde, que precisa recriar seus modelos de atenção; e para as pessoas, que precisam reconhecer sua corresponsabilidade na prevenção e promoção do seu próprio bem-estar. Assim, tornou-se ainda mais evidente a necessidade de construção de modelos mais integrados, com novas tecnologias de conhecimento, processos, equipamentos e medicamentos; e com usuários mais conscientes fazendo escolhas adequadas e com inclusão dos grupos vulneráveis (BRASIL, 2015).

Em janeiro de 2011, a SVS iniciou o planejamento da Agenda Estratégica 2011-2015, redefinindo prioridades, resultados e indicadores. Essa iniciativa foi ao encontro do terceiro ciclo de Planejamento Estratégico do MS para o quadriênio 2012-2015, para uma gestão centrada em resultados e no acompanhamento sistemático das metas estabelecidas. A Agenda do MS, alinhada ao Plano Nacional de Saúde (PNS) e ao Plano Plurianual do MS (PPA-MS) 2012-2015, resultou em diretrizes únicas para a realização do Programa de Aperfeiçoamento do Sistema Único de Saúde (SUS). Nesse contexto, coube à SVS coordenar ações para o alcance de dois objetivos estratégicos do MS: i) reduzir os riscos e agravos à saúde da população, por meio de ações de promoção e vigilância em saúde; e ii) promover a atenção integral à saúde da pessoa idosa e dos portadores de doenças crônicas, estimulando o envelhecimento ativo e saudável, fortalecendo as ações de promoção e prevenção da saúde. Coube ainda à SVS, contribuir para erradicar a extrema pobreza no país, objetivo comum a todos os órgãos do governo federal, no qual foram inseridas as ações para o controle de doenças que afetam particularmente as populações que vivem em precárias condições de vida e saúde.

No ano de 2014, a Agenda Estratégica (AE) da Vigilância em Saúde foi composta por 75 resultados. Ela contemplou parte da AE do MS e resultados relacionados ao Programa de Qualificação das Ações de vigilância em Saúde (PQA-VS), ao Contrato Organizativo da Ação Pública (COAP), ao PPA, ao PNS e aos Objetivos do Milênio (ODM). Portanto, apresentou um direcionamento 
voltado à integração dos instrumentos de planejamento entre diferentes níveis de gestão e setores governamentais.

Neste sentido, conforme o Relatório Anual de Gestão da saúde de 2014 (RAG 2014), entre as prioridades que reforçam a visão ampliada e intersetorial da Promoção da Saúde e a importância de fortalecimento de políticas públicas saudáveis na perspectiva de alcance da integralidade, destacam-se as seguintes diretrizes:

- Diretriz 7 - Reduzir os riscos e agravos à saúde da população, por meio das ações de promoção e vigilância em saúde;

- Diretriz 15 - Implementar ações de saneamento básico e saúde ambiental, de forma sustentável, para a promoção da saúde e redução das desigualdades sociais;

- Diretriz 16 - Contribuir para erradicar a extrema pobreza no país.

Assim, dentro das ações de promoção da saúde, incluem-se a promoção da alimentação saudável operacionalizada por meio do desenvolvimento de ações e abordagens para a prevenção de doenças relacionadas à alimentação e nutrição e a prática de atividade física, por meio da Política Nacional de Alimentação e Nutrição e do Programa Academia da Saúde, que visam contribuir para a melhor qualidade de vida da população. Também estão previstas metas para a estruturação de medidas de saneamento com o objetivo de reduzir a ocorrência de doenças relacionadas ao meio ambiente (BRASIL, 2015).

De modo geral, essas diretrizes alcançam os resultados programados e executados no ano de 2014 para 35 metas relacionadas a saneamento básico e qualidade da água, controle sanitário de culturas agrícolas e resíduos sólidos, além de melhorias estruturais e tecnológicas para o controle e prevenção de doenças transmissíveis e vigilância alimentar e nutricional, com destaque para populações vulneráveis, grupos e regiões específicas, como os remanescentes de quilombo, áreas rurais e territórios da Amazônia Legal.

Em relação à perspectiva do componente de transversalidade, é importante destacar outras diretrizes prioritárias tratadas no RAG 2014, que impactam diretamente na organização e operacionalização da PNPS e 
reforçam a importância de arranjos intersetoriais que possam alcançar as dimensões política, institucional e operativa da Promoção da Saúde:

- Diretriz 9 - Aprimorar a regulação e a fiscalização da saúde suplementar, articulando a relação público-privada, gerando maior racionalidade e qualidade no setor saúde;

- Diretriz 10 - Fortalecer o complexo industrial e de ciência, tecnologia e inovação em saúde como vetor estruturante da agenda nacional de desenvolvimento econômico, social e sustentável, reduzindo a vulnerabilidade do acesso à saúde e da assistência farmacêutica no âmbito do SUS;

- Diretriz 11 - Contribuir para a adequada formação, alocação, qualificação, valorização e democratização das relações do trabalho dos profissionais e trabalhadores de saúde;

- Diretriz 12 - Implementar novo modelo de gestão e instrumentos de relação federativa, com centralidade na garantia do acesso, gestão participativa com foco em resultados, participação social e financiamento estável;

- Diretriz 13 - Qualificar instrumentos de execução direta, gerando ganhos de produtividade e eficiência para o SUS.

Essas Diretrizes prioritárias visam conjugar interesses públicos e privados com objetivo de promover a geração da saúde e contribuir para que 0 desenvolvimento nacional alcance a sustentabilidade buscada, com base na construção de conhecimentos técnicos e científicos ajustados às necessidades econômicas, sociais, culturais e políticas do país. Elas reforçam a competência do MS para orientar o processo de aperfeiçoamento da gestão do SUS e a incorporação de novos arranjos administrativos de caráter federativo e intergovernamental, sendo a mais recente a construção do Contrato Organizativo de Ação Pública (COAP). Também reforçam a importância da geração e disponibilização de informações estratégicas, em tempo oportuno, para subsidiar a tomada de decisão a partir da identificação de problemas; e o apoio aos entes federados para intensificar a qualificação de sua força de trabalho, em especial da educação profissional em saúde (BRASIL, 2015). 
Neste contexto, podemos enfatizar que, além da convocatória do setor saúde para atuação multilateral e multinível junto aos demais setores sociais e níveis de governo na perspectiva de promoção e vigilância em saúde, percebese a necessidade de se ampliar a integração intrassetorial entre as agendas de vigilância e atenção, diante de suas responsabilidades na PNPS. Portanto, vale destacarmos esse movimento de aproximação conceitual entre atenção, vigilância e promoção da saúde, a partir da lógica de promover a atenção integral à saúde. Para tanto, referendamos o conceito de vigilância em saúde como o "conjunto articulado de ações destinadas a controlar determinantes, riscos e danos à saúde de populações que vivem em determinados territórios, sob a ótica da integralidade do cuidado - abordagem individual e coletiva dos problemas de saúde"; e de atenção básica, enquanto o "conjunto de ações de saúde no âmbito individual e coletivo, que abrangem a promoção e a proteção da saúde, a prevenção de agravos, o diagnóstico, o tratamento, a reabilitação e a manutenção da saúde", como afirmam Teixeira, Pinto e Vilasboas (2004).

Portanto, é possível observar a convergência da Promoção da Saúde entre as ações de vigilância e atenção, o que exigiu um arranjo institucional especialmente voltado à articulação intrassetorial entre SVS, SAS, e suas respectivas redes de serviços. Não obstante, os objetivos transversais de erradicar a pobreza e combater as desigualdades sociais também remetem à responsabilidade do setor saúde na composição de arranjos de integração intersetorial, buscando tanto competências técnicas para subsidiar uma gestão adequada das ações de promoção da saúde, como habilidade política para articular a centralidade da saúde na indução de políticas públicas que visem à proteção dos direitos de cidadania e à melhoria das condições de vida da população.

Essa tendência de atuação interna e externa para ampliar a intervenção sobre os determinantes sociais aponta, portanto, para a necessidade de compartilhamento e análise conjunta de informações epidemiológicas, qualificação dos profissionais para atuação multidisciplinar e intersetorial, bem como para a capacidade de interconexão e integração dos equipamentos públicos e redes de serviços essenciais relacionados à qualidade de vida da população. É por meio desses elementos que se poderá conformar uma efetiva 
rede nacional de Promoção da Saúde, com a definição de estrutura, pessoal, recursos, fluxos e, principalmente, indicadores orientados para um fazer colaborativo entre os setores sociais e os níveis de gestão e atenção à saúde. Para que essa integração se efetive, alguns pressupostos já exaustivamente destacados tornam-se indispensáveis, como, por exemplo, o foco nas pessoas e no território, o envolvimento da população na identificação de problemas e características das comunidades, o planejamento voltado às necessidades, o trabalho em equipe e, principalmente, a Promoção da Saúde como ação transversal e estratégica para o desenvolvimento sustentável.

\title{
3.5 ORGANIZAÇÃO DA ESTRUTURA DE GOVERNANÇA E COORDENAÇÃO DA PNPS
}

A OMS vincula estrategicamente a discussão da governança ao enfrentamento das iniquidades em saúde ao considerar que

\begin{abstract}
a implantação de respostas políticas dedicadas à redução de iniquidades em saúde demanda uma governança que explicite as responsabilidades individuais e conjuntas dos diferentes atores e setores (...) na melhoria da saúde e do bem-estar enquanto metas coletivas relacionadas a outras prioridades da sociedade (OMS, 2011, p. 3).
\end{abstract}

Nesta discussão, referendamos ainda o pensamento de Navarro (2011), quando observa que, em uma política pública que tem como modelo de gestão a intersetorialidade, os fatores políticos e institucionais podem aparecer de forma mais ou menos acentuada, tendo em vista primeiramente o número de atores envolvidos e, em segundo lugar, a grande quantidade de arenas de discussão, negociação, barganha e ainda da inevitável interdependência das ações entre os setores e níveis de gestão. Assim, para avançarmos nossa análise sobre a PNPS é importante retomarmos a atuação da CGPNPS na formulação e implementação da PNPS, buscando identificar sua articulação e interdependência com outras instâncias de articulação intersetorial tendo por referência a SVS como seu lócus institucional de governança em nível federal. 
Portanto, a partir da Secretaria de Vigilância em Saúde (SVS), como coordenadora do Sistema Nacional de Vigilância em Saúde (SNVS), coube à gestão federal desenvolver um modelo de gestão voltado ao alcance de resultados e ao fortalecimento dos processos de gestão compartilhada e participativa no SUS, envolvendo os atores sociais no processo decisório e na execução das ações. Ao analisarmos seu planejamento estratégico, pode-se observar que a SVS tem como premissas: a pactuação de políticas entre as esferas gestoras do Sistema Único de Saúde (SUS); o fortalecimento da articulação com outros órgãos de governo e com instâncias de controle social; o desenvolvimento de ações articuladas com o setor privado, com entidades científicas e com a sociedade civil, para a realização de ações conjuntas de vigilância em saúde, e o monitoramento permanente dos resultados pactuados para o alcance dos objetivos propostos; além de coordenar a mobilização de esforços para promover a sustentabilidade das políticas de vigilância em saúde, a equidade, a inclusão de grupos mais vulneráveis e a garantia universal dos direitos sociais (BRASIL, 2015).

Assim, o modelo de gestão da SVS procura privilegiar a gestão colegiada e participativa; o acompanhamento sistemático e tempestivo dos resultados; a pactuação de ações e a articulação com outros atores. A Agenda da SVS, e consequentemente da PNPS, é acompanhada pelos Colegiados Executivo e Ampliado $^{18}$ em reuniões deliberativas coordenadas pelo secretário. A análise das ações e dos processos em curso e dos resultados pactuados apoia-se nas informações registradas no programa de Controle, Acompanhamento e Avaliação de Resultados (e-Car). Também participam do debate, da formulação e do acompanhamento das ações de vigilância os órgãos consultivos de gestores e de controle social - Grupo de Trabalho de Vigilância em Saúde (GT-VS), Comissão Intergestores Tripartite (CIT) e Conselho Nacional de Saúde (CNS), assim como Comitês Técnicos

\footnotetext{
${ }^{18} \mathrm{O}$ Colegiado Executivo de Gestão da SVS é formado pelo secretário e pelos diretores, pela coordenação de Planejamento e Orçamento, pela coordenação de Epidemiologia em Serviços e pelos assessores. O Colegiado Ampliado da SVS é formado pelo secretário e pelos diretores, por todos os coordenadores-gerais e pelos assessores.
} 
Assessores (CTA), criados para ampliar o envolvimento da comunidade científica e da sociedade civil nesse processo.

O GT-VS é um fórum consultivo coordenado pela SVS que participa do planejamento e da avaliação das ações de vigilância em saúde que envolvem a descentralização para estados e municípios. O GT-VS é um grupo paritário vinculado à Comissão Intergestores Tripartite (CIT), composto por três representantes do MS (dois da SVS e um da Anvisa) e três do Conselho Nacional de Secretários de Saúde (Conass) e do Conselho Nacional de Secretários Municipais de Saúde (Conasems). Previamente às reuniões da CIT, o GT-VS reúne-se com a finalidade de realizar a avaliação técnica das políticas propostas pela SVS, pelo Conass e pelo Conasems, em que se inclui a análise de cenários e análises técnicas e operacionais para implantação das políticas, em especial aquelas que implicam a reorganização de serviços ou o impacto financeiro, como no caso da PNPS. O GT-VS é responsável pela produção de consensos com relação aos assuntos de interesse das três esferas de governo, pela qualificação de instrumentos normativos referentes aos aspectos comuns do trabalho dessas esferas, assim como pela proposição de pautas que exigem pactuação na CIT.

A Portaria MS/SVS oㅡ 224, de 15 de julho de 2011, institui os Comitês Técnicos Assessores (CTA) da SVS e define os procedimentos inerentes às suas atividades. Os CTAs são compostos por especialistas, gestores, representantes do Conass, Conasems e da sociedade civil e têm como objetivo fortalecer as políticas de vigilância em saúde, prestando assessoria técnica e científica à SVS em áreas estratégicas: vigilância da malária, dengue, hanseníase, doenças transmissíveis e imunopreveníveis, doenças crônicas não transmissíveis e fatores de risco e vigilância em saúde ambiental. Áreas que compõem o ideário ampliado de Promoção da Saúde, uma vez que estão diretamente relacionadas com aspectos regionais, culturais, econômicos e ambientais, que impactam na saúde dos indivíduos e da coletividade a partir dos seus determinantes e condicionantes sociais de saúde.

O MS reconhece ainda a existência da Comissão Externa de Monitoramento e Avaliação que, segundo o órgão, reúne pessoas de notório saber das áreas integrantes do Sistema Nacional de Vigilância em Saúde 
(SNVS). Ela foi constituída com o objetivo de contribuir com o aperfeiçoamento permanente do SNVS e para a sustentabilidade e a institucionalização dos avanços obtidos na vigilância em saúde. Suas principais atribuições são: monitorar e avaliar o desempenho do SNVS e elaborar recomendações à SVS para corrigir insuficiências detectadas e proteger os avanços obtidos. Na última gestão, há o indicativo de realização de duas reuniões, a primeira em 2011 e a segunda em novembro de 2014.

Conforme as Diretrizes Nacionais de Vigilância em Saúde, o Sistema Nacional de Vigilância em Saúde (SNVS) é integrado pelos seguintes subsistemas: i) subsistema nacional de vigilância epidemiológica, de doenças transmissíveis e de agravos e doenças não transmissíveis; ii) e subsistema nacional de vigilância em saúde ambiental, incluindo ambiente de trabalho. Além disso, são integrantes do SNVS o Sistema Nacional de Laboratórios de Saúde Pública, nos aspectos pertinentes à vigilância epidemiológica e saúde ambiental; os sistemas de informações de vigilância em saúde; programas de prevenção e controle de doenças de relevância em saúde pública, incluindo o Programa Nacional de Imunizações, e ainda a Política Nacional de Saúde do Trabalhador e Política Nacional de Promoção da Saúde.

Cabe destacar, ainda, a existência do seu homônimo, o Sistema Nacional de Vigilância Sanitária (SNVS), coordenado pela Anvisa no âmbito nacional e integrado pela Anvisa, Vigilâncias Sanitárias Estaduais, Vigilâncias Sanitárias Municipais; e Sistema Nacional de Laboratórios de Saúde Pública, no aspecto pertinente à vigilância sanitária e sistemas de informação de vigilância sanitária

Contudo, o referido SNVS ainda carece de melhor definição de suas estruturas organizacionais e fluxos de integração entre as diferentes áreas técnicas envolvidas, bem como de melhor institucionalização dos processos de coordenação de seus subsistemas com outras políticas, uma vez que não dispõe de um marco normativo específico. Também há dúvidas quanto à articulação e funcionamento dos citados subsistemas que o compõem. De modo geral, o que observamos é uma sobreposição de políticas e programas específicos e da fragmentação das estruturas institucionais e instâncias de coordenação, além da dispersão de esforços e mecanismos irregulares de 
incentivos à articulação interfederativa e interinstitucional entre as diferentes temáticas do SNVS.

Sob esse aspecto, é importante destacar a multiplicidade de agendas intersetoriais que permeiam a gestão do SUS e da SVS em nível federal, sem consideramos, contudo, a possível reprodução e funcionamento dessas agendas na orientação de arranjos e instâncias descentralizadas. Atualmente, foi possível identificar a existência de pelo menos 47 instâncias intersetoriais permanentes, com diferentes temáticas e níveis de institucionalização, cuja normalização pode variar de ofícios e portarias setoriais até normativos interministeriais e decretos presidenciais; de forma que, para uma análise mais apurada em relação a representação social e legitimidade técnica e política desses espaços de cogestão, seria necessário um maior aprofundamento quanto à composição e funcionamento dessas instâncias, o que não é objeto deste estudo. Ainda assim, podemos verificar que boa parte dessas instâncias e agendas estão imbricadas com as prioridades relacionadas à PNPS e remetem à implicação em nível ministerial, conforme apresentado nas Tabelas $2 \mathrm{a}, 2 \mathrm{~b}$ e 2c. Na mesma direção, também foi possível identificar outras 10 instâncias intersetoriais de atuação temporária, ou seja, cuja organização se pauta em agendas específicas e determinadas no tempo, conforme a Tabela 3. 
Tabela 2a. Identificação de instâncias permanentes e intersetoriais do MS. Fonte: SVS/MS (2015).

\begin{tabular}{|c|c|c|c|}
\hline $\begin{array}{c}\text { ESTRUTURA } \\
\text { (comissão/ Câmara Técnica/ Grupo de Trabalho / Rede / Comissão Especial/ Grupo Executivo / Comitê } \\
\text { de Orientação / Conselho / Missão) }\end{array}$ & $\begin{array}{l}\text { UNIDADE } \\
\text { (Ministério/Secretaria/ } \\
\text { Coordenação) }\end{array}$ & PORTARIA & $\begin{array}{l}\text { CARÁTER } \\
\text { (Permanente / Temporário / } \\
\text { Ministerial / Interministerial) }\end{array}$ \\
\hline Câmara Inteministerial de Agroecologia e Produção Orgânica - CIAPO & Ministério & Portaria MDA no 182 de 15 de junho de 2015 & Permanente e Interministerial \\
\hline Câmara Técnica da Saúde em apoio à Política Nacional de Desenvolvimento Regional & Secretaria & Portaria MS no 1987 de 12 de setembro de 2012. & Permanente e Intraministerial \\
\hline Câmara Técnica de Ciência e Tecnologia do Conselho Nacional de Recursos Hídricos - CNRH & Ministério & Resolução CNRH no 11, de 21 de junho de 2000 & Permanente e Interministerial \\
\hline Câmara Técnica de Saneamento Ambiental do Conselho das Cidades & Ministério & Decreto Presidencial $n^{0} 5790$ de 25 de maio de 2006 & Permanente e Interministerial \\
\hline $\begin{array}{c}\text { Comissão de Acompanhamento e Avaliação do Programa de Controle da Poluição do Ar por veículos } \\
\text { Automotores - PROCONVE }\end{array}$ & Ministério & PORTARIA MMA de 31 de OUTUBRO de 2014. & Permanente e Interministerial \\
\hline Comissão de Coordenação da Proteção ao Programa Nuclear Brasileiro - COPRON & Ministério & & Permanente e Interministerial \\
\hline Comissão Gestora do Plano Setorial da Saúde de Mitigação e de Adaptação às Mudanças Climáticas. & Secretaria & Portaria MS no $3.244 / 2011$. & Permanente e Intraministerial \\
\hline Comissão Intergovernamental "Saúde Ambiental e do Trabalhador" - CISAT Mercosul & Ministério & & Permanente e Interministerial \\
\hline $\begin{array}{c}\text { Comissão Intergovernamental de Gestão de Riscos e Redução de Vulnerabilidades (CIGRRV) do } \\
\text { Mercosul }\end{array}$ & Ministério & & Permanente e Interministerial \\
\hline $\begin{array}{c}\text { Comissão Intersetorial de Saneamento e Meio Ambiente - CISAMA do Conselho Nacional de Saúde - } \\
\text { CNS }\end{array}$ & Ministério & & Permanente e Interministerial \\
\hline Comissão intersetorial de Saúde do Trabalhador - CIST do Conselho Nacional de Saúde - CNS & Ministério & RESOLUÇÃO CNS № 482, DE 7 DE AGOSTO DE 2013. & Permanente e Interministerial \\
\hline Comissão Nacional de Agroecologia e Produção Orgânica - CNAPO & Ministério & Portaria SG-PR no 331 de 9 de novembro de 2012. & Permanente e Interministerial \\
\hline Comissão Nacional de Biodiversidade - CONABIO & Ministério & Aviso no 725/GM/MS de 11 de novembro de 2014. & Permanente e Interministerial \\
\hline Comissão Nacional de Diálogo e Avaliação do Trabalho na Cana-de-açúcar & Ministério & & Permanente e Interministerial \\
\hline Comissão Nacional de Erradicação do Trabalho Infantil - CONAETI & Ministério & $\begin{array}{c}\begin{array}{c}\text { Portarias MTE } n^{\circ} \text { 952, de } 08 \text { de julho de 2003, e no } \\
\text { de } 1^{\circ} \text { - de dezembro de } 2008 .\end{array} \\
\end{array}$ & Permanente e Interministerial \\
\hline Comissão Nacional de Segurança Química - CONASQ & Ministério & & Permanente e Interministerial \\
\hline COMISSÃO NACIONAL DOS TRABALHADORES RURAIS EMPREGADOS - CNATRE & Ministério & Portaria MTE № 880, de 24 de Junho de 2014. & Permanente e Interministerial \\
\hline Comissão Nacional Permanente do Benzeno & Ministério & Portaria SIT/MTE nº 191 de 19 de novembro de 2010. & Permanente e Interministerial \\
\hline Comissão Tripartite de Saúde e Segurança no Trabalho - CT-SST & Ministério & $\begin{array}{c}\text { Portarias MPS № } 153 \text {, de } 16 \text { de abril de } 2015 \text { e № } 183, \\
\text { de } 11 \text { maio de } 2015 .\end{array}$ & Permanente e Interministerial \\
\hline Comissão Tripartite Paritária Permanente - CTPP & Ministério & Portaria MTE nº 230 de 27 de maio de 2011. & Permanente e Interministerial \\
\hline
\end{tabular}


Tabela 2b. Identificação de instâncias permanentes e intersetoriais do MS. Fonte: SVS/MS (2015).

\begin{tabular}{|c|c|c|c|}
\hline $\begin{array}{c}\text { ESTRUTURA } \\
\text { (comissão/ Câmara Técnica/ Grupo de Trabalho / Rede / Comissão Especial/ Grupo Executivo / Comitê } \\
\text { de Orientação / Conselho / Missão) }\end{array}$ & $\begin{array}{l}\text { UNIDADE } \\
\text { (Ministério/Secretaria/ } \\
\text { Coordenação) }\end{array}$ & PORTARIA & $\begin{array}{l}\text { CARÁTER } \\
\text { (Permanente / Temporário / } \\
\text { Ministerial / Interministerial) }\end{array}$ \\
\hline Comitê Consultivo do Projeto Brasil 2040: cenários e alternativas para adaptação à mudança do clima. & Ministério & Aviso no 438/GM/MS, de 14 de julho de 2014. & Temporário e Interministerial \\
\hline Comitê de Articulação nas Áreas de Segurança e Logística do Sistema Nuclear Brasileiro - CASLON & Ministério & & Permanente e Interministerial \\
\hline Comitê de Suporte do Plano Nacional de Contingência - PNC/MMA & Ministério & & Permanente e Interministerial \\
\hline Comitê Executivo do Plano Setorial da Saúde de Mitigação e de Adaptação às Mudanças Climáticas. & Secretaria & Portaria MS n. 3.244/2011 & Permanente e Intraministerial \\
\hline Comitê Executivo Interministerial para Proteção da Camada de Ozônio (PROZON) & Ministério & Portaria MMA no 211 , de 23.07.2008. & Permanente e Interministerial \\
\hline Comitê Gestor da Política Nacional de Promoção da Saúde (CGPNPS) & Departamento & & Permanente e Intraministerial \\
\hline Comitê Gestor do Acordo de Cooperação № 07 - MS e CONTAG & Secretaria & & Permanente e Intraministerial \\
\hline Comitê Interinstitucional do Programa Trabalho Seguro - Tribunal Superior do Trabalho & Ministério & & Permanente e Interministerial \\
\hline Comitê Interministerial da Política Nacional de Resíduos Sólidos - PNRS & Ministério & & Permanente e Interministerial \\
\hline Comitê Interministerial de Atenção Integral à Saúde dos Pescadores e Agricultores & Secretaria & $\begin{array}{c}\text { PORTARIA INTERMINISTERIAL MS/MPA № 1.073, DE } \\
4 \text { DE JUNHO DE 2013. }\end{array}$ & Temporário e Interministerial \\
\hline Comitê Interministerial de Inclusão Social e Econômica dos Catadores de Materiais Recicláveis - CIISC & Ministério & Portaria Interministerial MDS/MMA ํo 265 de 20/07/2011. & Permanente e Interministerial \\
\hline Comitê Interministerial sobre Mudanças do Clima - CIM & Ministério & $\begin{array}{c}\text { Decreto n. 6.263/2007 / Portaria Casa Civil no } 30 \text { de } \\
17 / 01 / 2008\end{array}$ & Permanente e Interministerial \\
\hline Comitê Nacional de Promoção da Saúde do Trabalhador do SUS & Secretaria & Portaria MS nº 2.871 de 19 de novembro de 2009. & Permanente e Interministerial \\
\hline Comitê Técnico Assessor de Vigilância em Saúde Ambiental - CTA VSA/MS & Secretaria & PORTARIA SVS № 9, DE 2 DE MAIO 2012. & Permanente e Intraministerial \\
\hline Comitê Técnico de Saneamento Ambiental - CONCIDADES & Ministério & & Permanente e Interministerial \\
\hline $\begin{array}{l}\text { Comitê Técnico Interdisciplinar de Saúde e Ambiente (CTI-AS), do COMITÊ DE GESTÃO DE } \\
\text { INDICADORES DE MORBIDADE E FATORES DE RISCO DA RIPSA) }\end{array}$ & Departamento & & Permanente e Intraministerial \\
\hline Conselho Curador da Fundacentro/MTE & Ministério & & Permanente e Interministerial \\
\hline Conselho Diretor da Rede Brasileira de Pesquisas sobre Mudanças Climáticas Globais - REDE CLIMA & Ministério & $\begin{array}{c}\begin{array}{c}\text { Portaria MCTI } n^{0} \text { 728/2007, e alterada pelas Portarias } n^{\circ} \\
\text { 262/2011 e } n^{\circ} \text { 1295/2013 }\end{array} \\
\end{array}$ & Permanente e Interministerial \\
\hline Conselho Diretor Nacional da Cruz Vermelha & Ministério & Aviso no 228-GM, 17/04/2015 & Permanente e Interministerial \\
\hline Conselho Nacional de Proteção e Defesa Civil (CONPDEC) & SEDEC/MI & Lei no 12.608 , de 10 de abril de 2012 & Permanente e Interministerial \\
\hline Conselho Nacional de Recursos Hídricos - CNRH/Plenária & Ministério & & Permanente e Interministerial \\
\hline Conselho Nacional de Trânsito (CONTRAN) & Ministério & $\begin{array}{l}\text { Portaria Ministério das Cidades № 317, de } 10 \text { de junho } \\
\text { de } 2015 .\end{array}$ & Permanente e Interministerial \\
\hline CONSELHO NACIONAL DO MEIO AMBIENTE (CONAMA) & Ministério & & Permanente e Interministerial \\
\hline
\end{tabular}


Tabela 2c. Identificação de instâncias permanentes e intersetoriais do MS. Fonte: SVS/MS (2015),

\begin{tabular}{|c|c|c|c|}
\hline $\begin{array}{c}\text { ESTRUTURA } \\
\text { (comissão/ Câmara Técnica/ Grupo de Trabalho / Rede / Comissão Especial/ Grupo Executivo / Comitê } \\
\text { de Orientação / Conselho / Missão) }\end{array}$ & $\begin{array}{l}\text { UNIDADE } \\
\text { (Ministério/Secretaria/ } \\
\text { Coordenação) }\end{array}$ & PORTARIA & $\begin{array}{l}\text { CARÁTER } \\
\text { (Permanente / Temporário / } \\
\text { Ministerial / Interministerial) }\end{array}$ \\
\hline $\begin{array}{c}\text { CONSELHO NACIONAL DO MEIO AMBIENTE (CONAMA) - Câmara Técnica de Qualidade Ambiental e } \\
\text { Gestão de Resíduos }\end{array}$ & Ministério & & Permanente e Interministerial \\
\hline $\begin{array}{c}\text { CONSELHO NACIONAL DO MEIO AMBIENTE (CONAMA) - Comitê de Integração de Políticas } \\
\text { Ambientais (CIPAM) }\end{array}$ & Ministério & & Permanente e Interministerial \\
\hline CONSELHO NACIONAL DO MEIO AMBIENTE (CONAMA)- Câmara Técnica de Controle Ambiental & Ministério & & Permanente e Interministerial \\
\hline Fórum Brasileiro de Mudanças Climáticas & Ministério & DECRETO DE 28 DE AGOSTO DE 2000 & Permanente e Interministerial \\
\hline Fórum Nacional de Aprendizagem Profissional & Ministério & Portaria MTE № 751 , de 10 de junho de 2015. & Permanente e Interministerial \\
\hline Grupo da Terra & Secretaria & & Permanente e Intraministerial \\
\hline Grupo de Segurança de Infraestruturas Críticas - Abastecimento Urbano de Água - GTSIC & Ministério & & Temporário e Interministerial \\
\hline $\begin{array}{l}\text { Grupo de Trabalho Interinstitucional de acompanhamento da Implementação do Plano Nacional de } \\
\text { Saneamento Básico - GTI PLANSAB }\end{array}$ & Ministério & $\begin{array}{l}\text { Portaria Ministério das Cidades № } 171 \text { de } 9 \text { de abril de } \\
2014 .\end{array}$ & Permanente e Interministerial \\
\hline $\begin{array}{l}\begin{array}{l}\text { Grupo de Trabalho Interinstitucional do Relatório sobre o desenvolvimento urbano sustentável (HABITAT III) } \\
\text { - CONCIDADES }\end{array} \\
\end{array}$ & Ministério & & Temporário e Interministerial \\
\hline $\begin{array}{c}\text { Grupo de Trabalho Interministerial GTI para desenvolvimento de iniciativas da região de Tapajós (GT } \\
\text { TAPAJÓS) }\end{array}$ & Ministério & & Temporário e Interministerial \\
\hline Grupo de Trabalho para Assuntos Internacionais em Saúde e Ambiente - GT S\&A & Secretaria & & Permanente e Intraministerial \\
\hline $\begin{array}{c}\text { Grupo de Trabalho responsável pela avaliação e preposição de Políticas de Saúde e Segurança no } \\
\text { Trabalho - GTSST }\end{array}$ & Ministério & Portaria MPS № 353 de 01 de agosto de 2012. & Temporário e Interministerial \\
\hline Grupo de Trabalho sobre Mercúrio da Comissão Nacional de Segurança Química (CONASQ) GT-Mercúrio & Ministério & & Temporário e Interministerial \\
\hline Grupo Executivo sobre Mudança do Clima - GEx & Ministério & $\begin{array}{l}\text { Ofício no 1854/2015/GAB/SVS/MS de } 3 \text { de junho de } \\
2015 .\end{array}$ & Permanente e Interministerial \\
\hline \begin{tabular}{|l} 
Grupo Nacional Coordenador do Projeto/Plano Nacional de implementação da Convenção de Estocolmo \\
(POPs)
\end{tabular} & Ministério & & Permanente e Interministerial \\
\hline Plano Brasil Sem Miséria - Programa "ÁGUA PARA TODOS" (Cômite Gestor e Comitê Operacional) & Ministério & & Permanente e Interministerial \\
\hline Subcomitê de Promoção da Igualdade Racial - Agenda Nacional do Trabalho Decente & Ministério & Portaria MTE no 2511 de 21 de outubro de 2010. & Permanente e Interministerial \\
\hline $\begin{array}{c}\text { Subcomitê de Promoção do Trabalho Decente nos Grandes Eventos - Agenda Nacional do Trabalho } \\
\text { Decente }\end{array}$ & Ministério & Ofício no 66/2015/GAB/SE/MS de 9 de março de 2015. & Temporário e Interministerial \\
\hline $\begin{array}{l}\text { Comitê de Planejamento de Resposta a Situações de Emergência Nuclear no Município de Angra dos } \\
\text { Reis - COPREN/AR }\end{array}$ & Ministério & & Permanente e Interministerial \\
\hline $\begin{array}{c}\text { Grupo de Trabalho interministerial para a Elaboração do Plano de Assistência em Saúde a } \\
\text { Radioacidentados }\end{array}$ & Ministério & & Temporário e Interministerial \\
\hline Câmara Técnica de Água Subterrânea do CNRH & Ministério & & Permanente e Interministerial \\
\hline Seção Brasil do Conselho Mundial da Água & Ministério & & Permanente e Interministerial \\
\hline
\end{tabular}


Tabela 3. Identificação de instâncias temporárias e intersetoriais do MS. Fonte: SVS/MS (2015).

\begin{tabular}{|c|c|c|c|}
\hline $\begin{array}{c}\text { ESTRUTURA } \\
\text { (comissão/ Câmara Técnica/ Grupo de Trabalho / Rede / Comissão Especial/ Grupo Executivo / Comitê } \\
\text { de Orientação / Conselho / Missão) }\end{array}$ & $\begin{array}{l}\text { UNIDADE } \\
\text { (Ministério/Secretaria/ } \\
\text { Coordenação) }\end{array}$ & PORTARIA & $\begin{array}{c}\text { CARÁTER } \\
\text { (Permanente / Temporário / } \\
\text { Ministerial / Interministerial) } \\
\end{array}$ \\
\hline Comitê Consultivo do Projeto Brasil 2040: cenários e alternativas para adaptação à mudança do clima. & Ministério & Aviso no 438/GM/MS, de 14 de julho de 2014 . & Temporário e Interministerial \\
\hline Comitê Interministerial de Atenção Integral à Saúde dos Pescadores e Agricultores & Secretaria & $\begin{array}{l}\text { PORTARIA INTERMINISTERIAL MS/MPA № 1.073, DE } \\
\text { 4 DE JUNHO DE 2013. }\end{array}$ & Temporário e Interministerial \\
\hline Grupo de Segurança de Infraestruturas Críticas - Abastecimento Urbano de Água - GTSIC & Ministério & & Temporário e Interministerial \\
\hline $\begin{array}{c}\begin{array}{c}\text { Grupo de Trabalho Interinstitucional do Relatório sobre o desenvolvimento urbano sustentável (HABITAT III) } \\
\text { - CONCIDADES }\end{array} \\
\end{array}$ & Ministério & & Temporário e Interministerial \\
\hline $\begin{array}{l}\text { Grupo de Trabalho Interministerial GTI para desenvolvimento de iniciativas da região de Tapajós (GT } \\
\text { TAPAJÓS) }\end{array}$ & Ministério & & Temporário e Interministerial \\
\hline $\begin{array}{c}\text { Grupo de Trabalho responsável pela avaliação e preposição de Políticas de Saúde e Segurança no } \\
\text { Trabalho - GTSST }\end{array}$ & Ministério & Portaria MPS № 353 de 01 de agosto de 2012. & Temporário e Interministerial \\
\hline Grupo de Trabalho sobre Mercúrio da Comissão Nacional de Segurança Química (CONASQ) GT-Mercúrio & Ministério & & Temporário e Interministerial \\
\hline $\begin{array}{c}\text { Subcomitê de Promoção do Trabalho Decente nos Grandes Eventos - Agenda Nacional do Trabalho } \\
\text { Decente }\end{array}$ & Ministério & Ofício no 66/2015/GAB/SE/MS de 9 de março de 2015. & Temporário e Interministerial \\
\hline $\begin{array}{c}\text { Grupo de Trabalho interministerial para a Elaboração do Plano de Assistência em Saúde a } \\
\text { Radioacidentados }\end{array}$ & Ministério & & Temporário e Interministerial \\
\hline
\end{tabular}


Não obstante as possíveis dificuldades de se coordenar uma atuação ministerial para a indução de políticas públicas saudáveis pelos diferentes setores sociais e governamentais diante da multiplicidade de agendas intersetoriais, também foram identificadas outras oito instâncias direcionadas às atividades de coordenação e articulação intrassetorial, entre elas o próprio Comitê Gestor da Política Nacional de Promoção da Saúde, com implicação em nível de Departamento, conforme demonstrado na Tabela 4. 
Tabela 4. Identificação de instâncias permanentes e intrassetoriais do MS. (Fonte SVS/MS, 2015).

\begin{tabular}{|c|c|c|c|}
\hline $\begin{array}{c}\text { ESTRUTURA } \\
\text { (comissão/ Câmara Técnica/ Grupo de Trabalho / Rede / Comissão Especial/ Grupo Executivo / Comitê } \\
\text { de Orientação / Conselho / Missão) }\end{array}$ & $\begin{array}{l}\text { UNIDADE } \\
\text { (Ministério/Secretaria/ } \\
\text { Coordenação) }\end{array}$ & PORTARIA & $\begin{array}{l}\text { CARÁTER } \\
\text { (Permanente / Temporário / } \\
\text { Ministerial / Interministerial) }\end{array}$ \\
\hline Câmara Técnica da Saúde em apoio à Política Nacional de Desenvolvimento Regional & Secretaria & Portaria MS no 1987 de 12 de setembro de 2012. & Permanente e Intraministerial \\
\hline Comissão Gestora do Plano Setorial da Saúde de Mitigação e de Adaptação às Mudanças Climáticas. & Secretaria & Portaria MS no $3.244 / 2011$. & Permanente e Intraministerial \\
\hline Comitê Executivo do Plano Setorial da Saúde de Mitigação e de Adaptação às Mudanças Climáticas. & Secretaria & Portaria MS n. 3.244/2011 & Permanente e Intraministerial \\
\hline Comitê Gestor da Política Nacional de Promoção da Saúde (CGPNPS) & Departamento & & Permanente e Intraministerial \\
\hline Comitê Gestor do Acordo de Cooperação № 07 - MS e CONTAG & Secretaria & & Permanente e Intraministerial \\
\hline Comitê Técnico Assessor de Vigilância em Saúde Ambiental - CTA VSA/MS & Secretaria & PORTARIA SVS № 9, DE 2 DE MAIO 2012. & Permanente e Intraministerial \\
\hline $\begin{array}{l}\text { Comitê Técnico Interdisciplinar de Saúde e Ambiente (CTI-AS), do COMITÊ DE GESTÃO DE } \\
\text { INDICADORES DE MORBIDADE E FATORES DE RISCO DA RIPSA) }\end{array}$ & Departamento & & Permanente e Intraministerial \\
\hline Grupo da Terra & Secretaria & & Permanente e Intraministerial \\
\hline Grupo de Trabalho para Assuntos Internacionais em Saúde e Ambiente - GT S\&A & Secretaria & & Permanente e Intraministerial \\
\hline
\end{tabular}


Assim sendo, diante da amplitude e diversidade das instâncias intra e intersetoriais que permeiam as agendas prioritárias do MS e da SVS, é possível compreender a fragilidade institucional e ausência de protagonismo político da PNPS para organizar uma atuação intersetorial mais consistente e coletiva na perspectiva de superação das iniquidades em saúde e promoção do desenvolvimento sustentável. Essa fragilidade parece ter origem na forma de organização do setor saúde em nível federal, que tem conduzido sua atuação intersetorial de forma fragmentada, em contraponto à possibilidade de organização de estruturas mais customizadas e direcionadas à construção de sinergias entre as agendas prioritárias de promoção da saúde e as demais políticas públicas vinculadas aos determinantes sociais.

Por conseguinte, a PNPS tem apontado mais para uma estratégia de orientação de temas e comportamentos direcionados à melhoria do estilo de vida, do que para uma Política Nacional destinada a convocar o diálogo e a integração entre os diferentes atores sociais para a construção de ações e serviços voltados à qualidade de vida da população e ao desenvolvimento sustentável do país.

Em 2013, sete anos após sua implementação, o CGPNPS do Ministério da Saúde propôs uma ação de atualização e reflexão da PNPS diante dos compromissos assumidos pelo governo brasileiro nos últimos anos, relativos a novas demandas, políticas e agendas internacionais e nacionais decorrentes de eventos e momentos estratégicos, como a discussão de "Cidades/Municípios Saudáveis", Estratégia Global da Organização Mundial de Saúde e as demandas sistematizadas pela Comissão Nacional de Determinantes Sociais da Saúde que configuraram um cenário e induziram uma agenda que promoveu um debate permanente entre as visões de promoção da saúde comportamental e a promoção da saúde voltada para enfrentamento da determinação social do processo saúde-doença. (ROCHA et al., 2014) Neste sentido, destacaram-se como marcos do cenário deste processo de revisão: 
- O Plano Nacional de Ações Estratégicas para Enfrentamento de Doenças Crônicas Não Transmissíveis do Ministério da Saúde;

- O Decreto no 7.508, de 28 de junho de 2011.

- A Regulamentação da Lei № 8.080/1990, na perspectiva da articulação interfederativa e regionalização da saúde;

- A Conferência de Alto Nível da Organização das Nações Unidas Doenças Crônicas não Transmissíveis;

- A Declaração da Conferência Mundial dos Determinantes Sociais da Saúde;

- A Declaração da Conferência Rio + 20; e

- A Declaração da 8ª Conferência Mundial de Promoção da Saúde, Saúde em todas as Políticas.

Os debates e documentos oriundos dessas agendas, assim como sua necessária articulação, impulsionaram a revisão da PNPS, considerando os avanços e desafios das transformações sociais.

\subsection{ANÁLISE COMPARATIVA DOS MARCOS NORMATIVOS DE IMPLANTAÇÃO E ATUALIZAÇÃO DA POLÍTICA NACIONAL DE PROMOÇÃO DA SAÚDE}

A partir das visões de institucionalização, implementação e qualificação da PNPS destacadas nos itens anteriores e dos fatores analíticos propostos no capítulo 2, tratamos a seguir da avaliação normativa da Política Nacional de Promoção da Saúde, tendo por base as Portarias de criação - MS n687 MS/GM, de 30 de março de 2006 - e de atualização - MS nº 2.446 de 11 de novembro de 2014 -, buscando identificar as transformações ocorridas na conformação do arranjo institucional para a gestão intersetorial da PNPS.

Entretanto, cabe observar que, apesar de alguns estudos de avaliação da PNPS considerarem outros instrumentos normativos como produtos ou resultados da PNPS, em especial decretos e leis relacionados a outros programas intersetoriais conduzidos pelo governo federal com a participação e/ou coordenação do setor saúde, neste estudo buscamos analisar apenas a 
constituição do arranjo institucional específico da PNPS para a operacionalização de uma gestão mais ou menos intersetorial. Essa opção procura compreender a capacidade política da PNPS de compreender e analisar a diversidade das demandas sociais de saúde, assim como mobilizar e responsabilizar os demais setores sociais e níveis de governos em um processo dialógico de planejamento, a partir do seu arcabouço normativo e institucional voltado à coordenação de processos integrados de formulação, planejamento e implementação de ações conjuntas sobre os determinantes sociais.

De forma a compreender as transformações ocorridas desde 0 lançamento até o atual estágio de implementação da PNPS, procuramos organizar o contexto histórico e político de estruturação e organização da PNPS e realizar uma análise comparativa dos instrumentos normativos e elementos materiais nos diferentes momentos de institucionalização. Para a composição no gráfico proposto de tipologia dos níveis de gestão intersetorial, os fatores foram pontuados segundo uma escala de apropriação dos conteúdos e a aplicação de práticas organizacionais para estruturação e operacionalização da intersetorialidade. Para este fim, procuramos analisar a coerência conceitual dos normativos e a estruturação institucional dos processos e atividades de gestão intersetorial como aspectos da amplitude e intensidade do arranjo organizacional constituído.

A proposta é fazer uma comparação entre as versões normativas e o aparato organizacional da Política Nacional de Promoção da Saúde nos dois momentos distintos de sua institucionalização, para comparação a partir dos resultados dos níveis de gestão intersetorial nos dois momentos. Nesta direção, procuramos observar as transformações ocorridas durante o processo de implementação e qualificação da política, a partir dos componentes e aspectos organizacionais já destacados para a análise dos arranjos de gestão intersetorial. 
3.6.1 Portaria MS Nº67 MS/GM, de 30 de março de 2006

Em relação à Portaria de lançamento em 2006, no que se refere ao componente de Integralidade, representado no eixo vertical do modelo proposto, observamos um deslocamento um pouco acima da média $(3,75)$. O destaque está nos aspectos 1 e 4, voltados à análise dos determinantes sociais, a organização por temas prioritários e o direcionamento para atuação descentralizada e territorial, que foram definidos como de alta consistência, considerando a amplitude e intensidade conceitual apresentada no aparato normativo da PNPS.

Já 0 aspecto 7 , relativo- ao apoio à produção colaborativa e compartilhamento de saberes entre os diferentes atores foram considerados de alcance médio, uma vez que os espaços de formulação e coordenação da política situam-se prioritariamente no âmbito do setor saúde e estão voltados, prioritariamente, para o diálogo e qualificação de gestores e profissionais da saúde, que puderam contar com diferentes iniciativas de capacitação e formação.

Os demais aspectos observados 2, 35 e 6 - mobilização de setores governamentais e sociais; representatividade, participação e controle social; agendas e fluxos de diálogo e comunicação, assim como a interação e publicização de informações - foram considerados de baixa relevância. Apesar de os normativos e materiais publicados destacarem o papel intersetorial da PNPS, e seus indicadores prioritários, não foi possível identificar uma agenda de participação efetiva de outros setores no processo de formulação e planejamento da política, sendo observada uma incoerência na lógica integrativa entre a redação da política e sua estrutura de governança institucional. Logo, o compartilhamento e análise de informações estratégicas para a construção de objetivos comuns e planejamento de ações conjuntas não aparece com uma prioridade para a legitimação da PNPS em âmbito federal, salvo em algumas iniciativas pontuais com o setor de educação, como o PSE. Ademais, o escopo geral dos materiais orientativos para a implantação e gestão da política está direcionado ao processo de descentralização 
interfederativa e articulação dos níveis de vigilância e atenção por meio da atuação das RAS.

Nesse aspecto, pode-se observar certo distanciamento da PNPS em relação à organização da agenda estratégica da PNS 2012-2015 e da Agenda Social de Combate à Pobreza, quando esperamos identificar uma interlocução mais direta junto aos Programas do Ministério de Desenvolvimento Social (MDS), em especial, o Programa Bolsa Família (PBF) e, posteriormente, do Programa Brasil Sem Miséria (BSM). Ambos direcionados para atuar sobre os determinantes sociais e situações de iniquidades, por meio da transferência de renda às populações em situação de pobreza, considerando as condicionalidades de saúde e educação como indicadores para o atendimento e acompanhamento das famílias beneficiadas. No entanto, não identificamos a existência de fluxos orientados a trocas de informações, articulação e de atuação da PNPS nesses programas governamentais, bem como da participação do CGPNPS na análise e discussão da situação de saúde dessas populações.

Entre as publicações utilizadas para a publicização e divulgação de prioridades e indicadores da PNPS, vale destacar os Anais do I Seminário sobre a Política Nacional de Promoção da Saúde (2006) e o Painel de Indicadores do SUS no6 - Temático - Promoção da Saúde V. IV (2009), que foram considerados como documentos instrumentais para o diálogo e discussão das demandas sociais da promoção da saúde entre os diferentes atores sociais. No entanto, apesar de tais documentos não estarem mais disponíveis no âmbito do MS, eles foram consultados nesta pesquisa pelo potencial de publicização de informações e difusão de conhecimentos, práticas e inovações para a implementação da PNPS nos diversos setores e níveis de atuação.

De modo geral, os indicadores apresentados apontam para 0 aprimoramento da democracia participativa e controle social do SUS; destacam a importância de práticas educativas e enfatizam as temáticas a serem articuladas por meio de políticas especificas - Alimentação Saudável; Práticas Corporais e Atividade Física; Prevenção e Controle do Tabaco; Saúde Mental, Álcool e outras drogas; Promoção da Saúde na Assistência Privada; Prevenção 
de Violência e Promoção da Cultura de Paz; Promoção e Desenvolvimento Sustentável; Direitos Sexuais e Reprodutivos de Adolescente e Jovens -, tendo por base as Estratégias de Saúde da Família e seus espaços de concertação e operacionalização. Por isso, a PNPS ratificou ainda o compromisso brasileiro para o cumprimento das metas e objetivos de desenvolvimento do milênio programados para 2015, quais sejam: erradicar a extrema pobreza e a fome, atingir o ensino básico universal, promover a igualdade entre os sexos e a autonomia das mulheres, reduzir a mortalidade infantil, melhorar a saúde materna, combater o HIV/Aids, a malária e outras doenças, garantir a sustentabilidade ambiental e estabelecer uma parceria mundial para 0 desenvolvimento.

Contudo, apesar das limitações de governança institucional da PNPS junto aos demais setores implicados na resposta e alcance dos ODM, houve avanços na articulação e integração de temáticas e políticas específicas da promoção da saúde junto a outros atores governamentais, como da Política Nacional de Alimentação e Nutrição (PNAN), que registra atuação em diferentes setores: Educação (PSE, Programa Nacional de Alimentação Escolar-PNAE); Desenvolvimento Social (Sistema de Segurança Alimentar e Nutricional-SISAN, Política Nacional de Assistência Social, Programa Bolsa Família-PBF); Desenvolvimento Agrário e Meio Ambiente (Programa de Aquisição de Agricultura Familiar - PAA, Política Nacional de Agroecologia e Produção Orgânica PNAPO, Programa Nacional de Redução de Agrotóxicos Pronara), entre outras. Vale observar aqui, no que se refere à PNPS, que não tratamos de uma ausência do setor saúde na discussão de agendas estratégicas e intersetoriais vinculadas a promoção da saúde, mas sim de uma atuação fragmentada e específica do setor sem ênfase à participação e centralidade da Promoção da Saúde como indutora de políticas públicas saudáveis.

No mesmo sentido, também não foi possível identificar aspectos de integração entre os sistemas de informação em saúde e outros sistemas relacionados aos condicionantes e determinantes sociais nos diferentes setores e níveis governamentais, como já destacado em relação às condicionalidades de saúde do PBF. Isso reforça uma atuação isolada de áreas especializadas do 
Ministério sem que haja uma participação da PNPS na coordenação dos setores internos e externos implicados nos conteúdos e indicadores da política, - que a afasta da abordagem multifatorial e da análise conjunta dos determinantes e condicionantes sociais da saúde, restringindo o protagonismo internacional das discussões de Promoção da Saúde na indução de políticas públicas saudáveis e promoção da atenção integral à saúde.

Por conseguinte, o componente de integralidade, apesar de apresentar forte composição conceitual, ainda carece de mecanismos institucionais que possam fortalecer a representação social e construção dialógica de ações colaborativas voltadas ao tratamento das diversidades populacionais e territoriais, de modo a alcançar a saúde integral dos indivíduos, comunidades e povos das distintas realidades e regiões do país. Vale lembrar, ainda, que existe um esforço organizacional do SUS direcionado ao fortalecimento da análise situacional e do Planejamento Regional Sustentável, a partir da lógica de integração entre regiões de saúde e do "novo" Contrato de Organização da Ação Pública da Saúde, os COAP. Todavia, os COAP ainda não passaram de estratégias de mobilização organizacional e gerencial para a consolidação de peças de planejamento estratégico e operacional de forma regionalizada.

Em relação ao componente de transversalidade, não obstante sua aproximação e interconexão com alguns aspectos abordados no componente da integralidade, foi observado um resultado mais significativo no eixo horizontal do gráfico proposto que apresentou deslocamento acima da média (4). Nesta perspectiva, o destaque ficou por conta dos aspectos 1 e 5 , relativos às diretrizes normativas para a articulação e planejamento multilateral, e insititucionalização de espaços de coordenação intrassetorial, considerados de alta amplitude e densidade. Logo, o arcabouço conceitual de articulação e integração intersetorial da PNPS é literalmente uma convocatória para a organização de processos de gestão horizontalizados, democráticos e participativos, dentro da lógica de cooperação e responsabilização de diferentes atores sociais e níveis de governo, conforme reforçam os seguintes dispositivos: 
Portaria MS 386/2006

(...) Dessa maneira, é tarefa do setor Saúde nas várias esferas de decisão convocar os outros setores a considerar a avaliação e os parâmetros sanitários quanto à melhoria da qualidade de vida da população quando forem construir suas políticas específicas.

(...)

Objetivos Estratégicos:

IX - Ampliar os processos de integração baseados na cooperação, solidariedade e gestão democrática;

XII - Valorizar e ampliar a cooperação do setor Saúde com outras áreas de governos, setores e atores sociais para a gestão de políticas públicas e a criação e/ou o fortalecimento de iniciativas que signifiquem redução das situações de desigualdade.

(...)

Diretrizes:

IV - Promover mudanças na cultura organizacional, com vistas à adoção de práticas horizontais de gestão e estabelecimento de redes de cooperação intersetoriais;

(...)

Estratégias de Implementação:

VIII - Criação e divulgação da Rede de Cooperação Técnica para Promoção da Saúde;"

(...)

Responsabilidades das esferas de gestão:

Federal

X - Buscar parcerias governamentais e não-governamentais para potencializar a implementação das ações de promoção da saúde no âmbito do SUS;

XI - Definir ações de promoção da saúde intersetoriais e pluriinstitucionais de abrangência nacional que possam impactar positivamente nos indicadores de saúde da população;

(...)

Gestor Estadua/ Municipal:

$X V$ - Ênfase ao planejamento participativo envolvendo todos os setores do governo municipal e representantes da sociedade civil, no qual os determinantes e condicionantes da saúde sejam instrumentos para formulação das ações de intervenção; (...)

A constituição do CGPNPS abordada nos aspectos de institucionalização e governança ratifica a forte conotação intrassetorial da política. No entanto, inicialmente, essa tendência não foi acompanhada pela institucionalização, no âmbito da PNPS, de espaços de diálogo e concertação intersetorial entre os diferentes setores de governo e atores sociais, conforme questões já destacadas na composição do CGPNPS. Nesta direção, os aspectos 3,4 e 7, relacionados à descentralização de processos e atividades, à atribuição de competências e implicação de setores e redes de serviços e ao desenvolvimento de inovações e práticas para a integração de indicadores e recursos foram considerados de amplitude e intensidade média. Sob esse aspecto, é importante ressaltar que apesar do arranjo central de governança da 
PNPS instituir-se estritamente de forma intrassetorial, há uma gradativa ampliação do escopo normativo da PNPS, que ganha fôlego com a atribuição de competências aos demais níveis de governo e com a responsabilização das redes de atenção à saúde. Entretanto, sua estrutura de governança ou arranjo organizativo, além de não contar com a participação efetiva de outros setores, também não menciona instrumentos e mecanismos gerenciais para coordenação e apoio institucional de forma multinível e regionalizada. Observase que, no que se refere ao processo de apoio institucional para atuação multilateral no diferentes níveis de gestão, ele nos parece imprescindível, uma vez que a centralidade da promoção se desloca da vigilância - no nível federal - para a atenção à saúde - no nível do território - na medida em que se intensifica o processo de descentralização, o que pode contribuir com a fragilização institucional e fragmentação da PNPS no âmbito dos territórios, onde as ações de integração e atendimento efetivamente se materializam.

Em relação aos aspectos menos desenvolvidos da PNPS no componente da transversalidade, foram considerados de baixo potencial e intensidade os aspectos 2 e 5, relativos à constituição de instâncias de pactuação interinstitucional; e acionamento de conselhos representativos de políticas públicas. Em relação às instâncias interinstitucionais, apesar da PNPS considerar a atuação de estruturas de governança intersetorial vinculadas a outros programas e políticas, seu arranjo institucional formal restringe-se a uma composição intrassetorial, como já abordado anteriormente. Também não foram identificados na PNPS mecanismos diferenciais de acionamento e compartilhamento de demandas e prioridades junto a conselhos representativos de políticas públicas em âmbito federal, a não ser pelas possíveis relações e fluxos já estabelecidos para as instâncias de participação social do SUS.

Entretanto, o arranjo institucional da PNPS tem sua institucionalização complementada pela publicação de normativos interministeriais entre Educação e Saúde, como a PI n 1.010/2006 - que Institui as diretrizes para a Promoção da Alimentação Saudável nas Escolas em âmbito nacional; e a PI no 675/2008 - que Institui a Comissão Intersetorial de Educação e Saúde na Escola; para 
além da criação do Programa Integrado entre os setores por meio de Decreto presidencial oㅜ 6.286/ 2007, o PSE.

O Programa Saúde na Escola constitui-se como estratégia para a integração e a articulação permanente entre as políticas e ações de educação e de saúde, com a participação da comunidade escolar, envolvendo as equipes de saúde da família e da educação básica, com finalidade de contribuir para a formação integral dos estudantes da rede pública de educação básica por meio de ações de prevenção, promoção e atenção à saúde (Brasil, 2007). Posteriormente, de forma paralela ao CGPNPS, a Comissão Intersetorial se constitui com representação das diferentes secretarias e conselhos gestores de ambos os setores, dispondo ainda de um marco institucional de maior legitimidade política, ao considerarmos o Decreto Presidencial,

$\mathrm{Na}$ mesma direção, conforme já abordado nos aspectos de implementação da PNPS, outras instâncias intersetoriais vão sendo constituídas para apoiar o desenvolvimento de inovações e práticas de integração com outros setores governamentais, por meio de parcerias e da formalização de acordos e termos de cooperação, além de novos instrumentos normativos que vão sendo considerados como produtos da atuação da PNPS. Contudo, no escopo deste estudo não foi possível identificar elementos contundentes de interconexão, interdependência e coordenação entres esses arranjos de governança intersetorial e a PNPS, para a conformação das Redes de Atenção e Promoção da Saúde.

Outra articulação pouco abordada no âmbito da PNPS se relaciona às atribuições pactuadas para o setor Saúde por meio da Portaria Interministerial (MDS, ME e MS) № 2 /2009, que institui o Fórum Intergovernamental e Intersetorial de Gestão de Condicionalidades do Programa Bolsa Família, entre elas as condicionalidades de saúde que constituem um de seus elementos principais, ao contribuir para o combate à pobreza intergeracional. Ressaltando-se que o PBF também constitui-se como uma política intersetorial e requer, para a sua efetividade, cooperação interfederativa e coordenação das ações dos entes públicos envolvidos em sua gestão e execução (Brasil, 2009). Entre os trabalhos desenvolvidos pelo Fórum Intergovernamental pode-se destacar a publicação das instruções operacionais conjuntas entre os 
Ministérios do Desenvolvimento Social, Saúde e Educação para a operacionalização dos calendários de acompanhamento das condicionalidades, que em regra vão recair sobre as agendas de trabalho das equipes das Rede de Atenção à Saúde.

Todavia, não foi possível avançar na análise de conformação das Redes de Cooperação Técnica para Promoção da Saúde, suas estruturas, orçamentos e planos nas múltiplas instâncias e níveis de governo.

Contudo, é importante reiterar que não há modelos de referência plenamente constituídos para a operacionalização da gestão intersetorial, o que restringe nossa análise dos níveis de intensidade das relações transversais e da legitimidade política das prioridades elencadas em torno da PNPS. Assim, torna-se importante considerar a composição e interconexão das instâncias intersetorias, bem como a avaliação do perfil profissional dos seus integrantes e gestores para o empreendimento da política nos processos decisórios de governo, o que pode clarear a qualificação e acúmulo de capacidades técnicas e habilidades políticas para uma gestão intersetorial. Consideramos que este aspecto, já mencionado anteriormente, poderia ser melhor explorado se complementado com as visões dos diferentes atores envolvidos.

De modo geral, o avanço de arranjos de gestão intersetorial é evidenciado a partir da ampliação da abordagem de problemas transversais pelos diferentes setores, bem como pelos esforços de aprimoramento dos processos de institucionalização de instâncias de consenso e pactuação intra e intersetoriais, que visam qualificar a atuação social do Estado. Essa qualificação é parcialmente observada na atuação do setor saúde e da PNPS, e tem sido explicitada pela melhora dos indicadores sociais ao longo da última década, mesmo que ainda persistam disparidades significativas entre territórios e grupos populacionais. Há de se considerar ainda que, em boa parte, os objetivos e metas do milênio pactuadas para o ano de 2015 foram perseguidas e alcançadas no decorrer dos últimos anos, e a perspectiva de gestão 
intersetorial para a superação de iniquidades sociais ainda figura como uma agenda estratégica do governo ${ }^{19}$.

Entretanto, quando avaliados alguns aspectos materiais necessários à operacionalização de capacidades institucionais e relacionais do setor saúde a partir da lógica de gestão intersetorial, na tentativa de identificar a disposição da PNPS no organograma do MS, pode-se constatar inconsistências quanto à constituição do seu arranjo formal. A competência de coordenar a implementação da PNPS é responsabilidade da Coordenação de Vigilância de Agravos e Doenças não transmissíveis, o que sugere redução da concepção da política e volta aos paradigmas tradicionais de especialização e fragmentação do aparato governamental, mesmo que ela esteja hierarquicamente subordinada ao Departamento de Análises de Situação de Saúde da Secretária de Vigilância em Saúde (SVS), o que poderia sugerir um posicionamento estratégico no que se refere à produção e compartilhamento de informações, mas que restringe a capacidade de mobilização política junto a outras secretarias e, principalmente, junto a outros ministérios.

\footnotetext{
${ }^{19}$ Para maior conhecimento sobre a Agenda Social e Plano de Governo intersetorial para a superação da pobreza, visite o Brasil sem miséria: http://www.brasilsemmiseria.gov.br/acessoservicos
} 


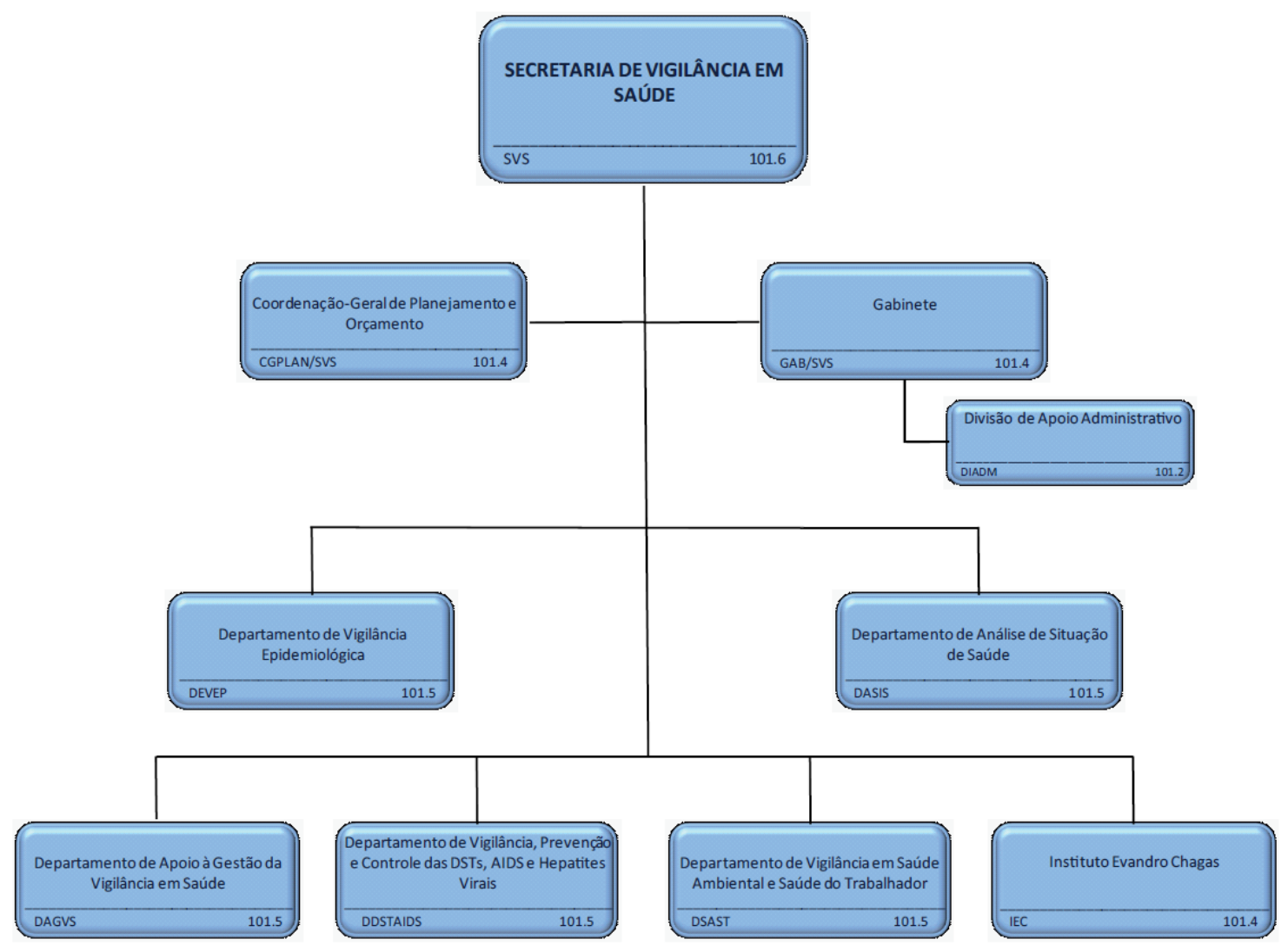

Figura 7. Organograma da SVS/MS ( MS, 2010).

Vale observar que no Organograma da SVS/MS, a noção de promoção da saúde não é formalmente explicitada na estrutura institucional do MS, o que compromete a legitimidade política e a conformação organizacional da PNPS nos demais níveis de governo, uma vez que, em boa medida, os arranjos institucionais das políticas no âmbito de estados e municípios tendem a se espelhar não apenas por normas regulamentadoras, mas também pela configuração do aparato governamental das políticas no plano federal. Neste sentido, por tratar-se de uma política intersetorial implicada nas agendas estratégicas do governo federal, articulada entre órgãos e instituições intrasetoriais e pautada em outras instâncias de análise e concertação interministerial e internacional, quando considerada a adesão a pactos e tratados internacionais de saúde e desenvolvimento sustentável, caberia à Promoção da Saúde um posicionamento mais relevante no desenho estratégico do arranjo institucional do órgão central do SUS em nível federal. 
Cabe relembrar também que a concepção de Promoção da Saúde e das responsabilidades estatais acerca da proteção e prevenção dos riscos e agravos à saúde e às vulnerabilidades sociais, dentro de uma abordagem ampliada e coletiva dos setores públicos e societais foi amplamente defendida pelo Movimento da Reforma Sanitária e encontra-se legalmente registrado e legitimado no texto constitucional.

Contudo, ainda em relação à transversalidade foram considerados visíveis os avanços logrados na implementação da PNPS, assim como nas demais políticas sociais em nível federal, inclusive sendo essa noção reforçada pela identificação de Agendas Transversais no atual Plano Plurianual do Governo Federal (PPA) 2012-15 $5^{20}$, que incluiu Políticas para os Objetivos do Milênio; para Prevenção, Atenção e Reinserção Social de Usuários de Crack, Álcool e outras Drogas; para os Povos Indígenas e para o Meio Ambiente, que estão refletidas no Plano Estratégico do Ministério da Saúde e apresentam-se relacionadas às temáticas da Promoção da Saúde.

Portanto, não restam dúvidas de que a PNPS experimentou transformações significativas na lógica da intersetorialidade durante seu processo de estruturação nos diferentes níveis de gestão do SUS, o que também é reconhecido por diversos estudos de avaliação voltados às temáticas prioritárias da PNPS a partir de iniciativas locais de operacionalização da PNPS em articulação com diferentes setores.

Assim, considerando o gráfico proposto para a classificação dos níveis de gestão intersetorial, pôde-se identificar que a PNPS/2006 situa-se no plano do Nível III - Gestão Intersetorial Coordenada ou Organizacional, em que observamos as políticas que dispõem de um aparato institucional mais estruturado para a coordenação de estratégias intersetoriais, com atuação multilateral e multinível, mas que ainda carecem de espaços mais consistentes de representação e participação social. Ou seja, a PNPS tem conseguido

\footnotetext{
${ }^{20}$ Plano Mais Brasil ( Mais Desenvolvimento, Mais Igualdade, Mais Participação), disponível em:

http://www.planejamento.gov.br/secretarias/upload/Arquivos/spi/PPA/2012/111206 agendas tr ansversais.pdf
} 
estruturar espaços de governança intersetorial, mas ainda carece de maior coordenação, legitimidade política e representatividade. Entretanto, cabe observar ademais que a multiplicidade de instâncias intersetoriais consideradas no âmbito da PNPS, o baixo poder de mobilização política de sua estrutura formal de coordenação na hierarquia ministerial, e o foco intraministerial de seu comitê de governança institucional, dificultam uma atuação mais integrada da Promoção da Saúde na coordenação do diálogo e responsabilização dos diferentes atores societais e governamentais, na lógica interinstitucional, para a construção de políticas públicas saudáveis direcionadas à superação das iniquidades sociais e ao desenvolvimento sustentável do país.

Tabela 5. Pontuação dos aspectos para classificação do arranjo intersetorial da PNPS/2006.

\begin{tabular}{|c|c|c|c|c|}
\hline Componentes & Aspectos dialógicos e colaborativos & Baixa & Média & Alta \\
\hline \multirow{8}{*}{ Integralidade } & $\begin{array}{l}1 \text { Princípios voltados à análise de determinantes e condicionartes sociais de forma } \\
\text { ampliada e multidimensional: }\end{array}$ & & & 1 \\
\hline & $\begin{array}{l}2 \quad \text { Mobilização de setores govemamentais, organizações de usuários e redes de } \\
\text { servicos dos diferertes atores sociais e qrupos de interesses; }\end{array}$ & 0,25 & & \\
\hline & 3 Parâmetros de representatividade, participação e controle social; & 0,25 & & \\
\hline & $\begin{array}{ll}4 & \text { Critérios voltados à organização territorial elou por temática, e não setoriais de } \\
\text { intervencão de atendimerto: }\end{array}$ & & & 1 \\
\hline & $\begin{array}{l}5 \text { Agenda e fluxos sistemáticos de diálogo e comunicação entre os atores, visando ao } \\
\text { monitoramento participativo e ao controle democrático como subsidios à tomada de } \\
\text { decisão e à construcão das estratéqias de intervencão. }\end{array}$ & 0,25 & & \\
\hline & Interação e publicização de irformações entre os setores sociais e níveis de governo; & 0,25 & & \\
\hline & $\begin{array}{|lr|}7 & \text { Apoio à produção colaborativa e compartilhamento de saberes e corhecimentos para } \\
\text { os diferentes atores na perspectiva de educacão continuada. }\end{array}$ & & 0,5 & \\
\hline & \begin{tabular}{|c|} 
TOTAL \\
\end{tabular} & & 3,5 & \\
\hline & Aspectos organizacionais e cooperativos & & & \\
\hline \multirow{8}{*}{ Transversalidade } & $\begin{array}{|lr|}1 & \text { Diretrizes normativas de articulação e perspectiva de planejamento entre os setores } \\
\text { governamertaise atores sociais (atuaç̃o multilateral); }\end{array}$ & & & 1 \\
\hline & $\begin{array}{l}2 \text { Instâncias transversais de consenso e pactuaç̃ão interinstitucionais (Arranjos de } \\
\text { Governanca, Comitês, Câmaras, Grupos Gestores); }\end{array}$ & 0,25 & & \\
\hline & $\begin{array}{l}\text { Descentralização dos processos e atividades entre os diferertes riveis de governo } \\
\text { (atuacão multinível); }\end{array}$ & & 0,5 & \\
\hline & $\begin{array}{l}4 \text { Atribuç̧ão de competências intersetoriais e implicação dos setores sociais e redes } \\
\text { de servicos: }\end{array}$ & & 0,5 & \\
\hline & $\begin{array}{l}5 \text { Institucionalização de espaços de coordenação intrasetorial (Estruturas de } \\
\text { coordenação e/ou equipe intersetoriais permanentes, grupos técnicos de trabalho - } \\
\text { Orqanograma formal e informal); }\end{array}$ & & & 1 \\
\hline & $\begin{array}{l}6 \text { Constituição e/ou acionamento de conselhos representativos e democráticos de } \\
\text { poltíicas públicas; }\end{array}$ & 0,25 & & \\
\hline & $\begin{array}{l}7 \quad \text { Desenvolvimerto de inovações e práticas para a irtegração de indicadores } \\
\text { gerenciais, recursos econômicos e financeiros (Termos e Acordos de Cooperação, } \\
\text { Convênios e outras parcerias). }\end{array}$ & & 0,5 & \\
\hline & TOTAL & & 4 & \\
\hline
\end{tabular}




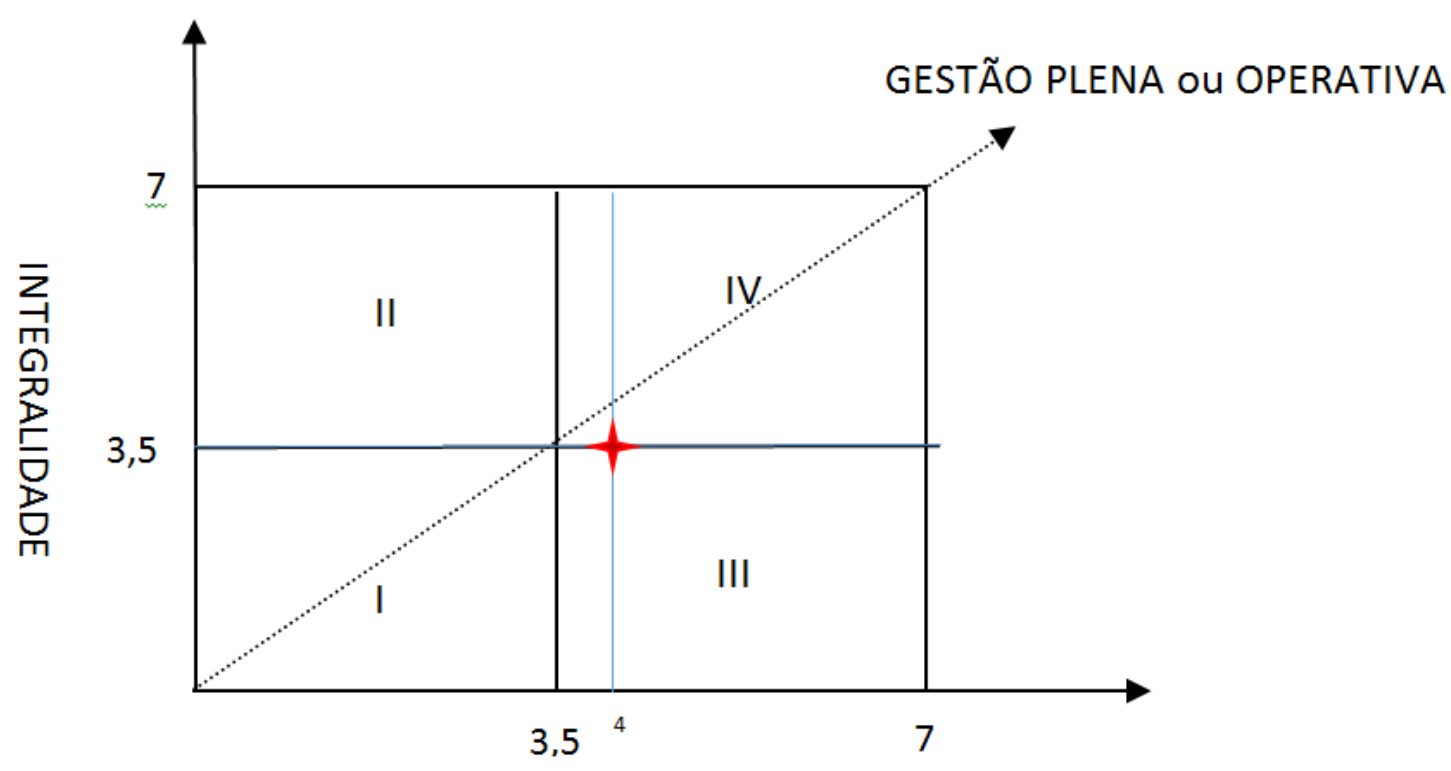

TRANSVERSALIDADE

Figura 8. Pontuação e classificação do arranjo intersetorial da PNPS/2006.

3.6.2 Portaria MS nº 2.446 de 11 de novembro de 2014

Conforme discutido anteriormente, com a institucionalização da Promoção da Saúde no âmbito do SUS, iniciou-se um período de discussão e implantação das estratégias para a implementação da PNPS e qualificação das ações e serviços de Vigilância e Atenção Básica em saúde. Os problemas e desafios priorizados por esta aproximação intrassetorial, nos diferentes níveis de gestão e participação do SUS, impulsionaram um amplo processo de reflexão e revisão acerca da PNPS, que culminou com a publicação da Portaria MS n 2.446, de 11 de novembro de 2014.

Considerando ainda os avanços da perspectiva intersetorial, mencionada como estratégia central no âmbito das suas agendas, o processo de revisão da PNPS mobilizou diferentes setores, como forma de ampliar o escopo dessa política para além do setor saúde, visando o diálogo, a sinergia e a construção de possibilidades para fazer frente às iniquidades e aos determinantes sociais. Logo, tendo em vista a construção histórica da Promoção da Saúde e o fortalecimento conjuntural dos processos de gestão intersetorial observados no campo de atuação social do Estado na última 
década, era esperado que o novo arcabouço normativo e regulatório da PNPS pudesse fortalecer a consolidação de um aparato organizacional mais representativo para a coordenação dos processos de formulação e implementação de políticas públicas saudáveis, voltadas ao enfrentamento das desigualdades sociais, à promoção da qualidade de vida e ao desenvolvimento sustentável, considerando a necessidade de cooperação e colaboração entre os diferentes setores sociais e níveis de gestão governamental, alcançando assim, a evolução dos seus componentes e aspectos de gestão intersetorial (Tabela 1).

Por isso, entendemos que o processo de revisão e atualização de uma política intersetorial, do ponto de vista gerencial, pretende superar as dificuldades e incorporar os avanços já experimentados na sua implementação, combinando inovações organizacionais com a adoção de boas práticas para o aprimoramento da governança e participação social, qualificação dos resultados programáticos e setoriais e a ampliação do impacto e sustentabilidade das políticas envolvidas.

Desse modo, ao analisarmos seu novo marco normativo e a situação conjuntural do atual momento de implementação da PNPS, a partir do nosso gráfico de classificação do arranjo intersetorial, identificamos um aprimoramento dos aspectos dialógicos e colaborativos do componente de integralidade (de 3,5 para 4), impulsionado pela melhor conexão e disposição dos seus elementos conceituais (Figura 9), Essa condição pode ser evidenciada pelo fortalecimento da perspectiva de territorialização das ações, a partir dos preceitos de fortalecimento da regionalização da atenção e assistência à saúde, e, principalmente, pela perspectiva de fortalecimento de agendas e fluxos de comunicação e monitoramento, com aperfeiçoamento dos instrumentos de interação e publicização de informações estratégicas para análise de situação e o planejamento de ações direcionadas a promover a atenção integral à saúde.

Nestes últimos aspectos em particular, cabe considerar a consolidação de inquéritos e pesquisas em saúde, como a pesquisa telefônica de Vigilância de Fatores de Risco e Proteção para Doenças Crônicas (Vigitel); A Pesquisa Nacional de Saúde do Escolar (PeNSE), realizada em 2009 e 2012 pelo 
Instituto Brasileiro Brasileiro de Geografia Estatítica (IBGE), sob a coordenação do MS e apoio do MEC, que tem sido utilizada como uma ferramenta para subsidiar políticas e dar sustentabilidade ao sistema de vigilância da saúde dos escolares no país; e a Pesquisa Nacional de Saúde (PNS), considerada a mais completa pesquisa sobre as condições de saúde da população brasileira relacionada às doenças crônicas não transmissíveis, a estilos de vida e ao acesso à atenção em saúde.

A PNS é considerada como parte do Plano de Enfrentamento das DCNT 2011-2022. É uma pesquisa de base domiciliar e de âmbito nacional, realizada e coordenada em parceria entre o MS e o IBGE. Iniciada em 2013, ela fará parte do Sistema Integrado de Pesquisas Domiciliares do IBGE e deverá ser repetida a cada cinco anos. $O$ inquérito é composto por três questionários: 0 domiciliar, referente às características do domicílio; o relativo a todos os moradores do domicílio; e o individual, a ser respondido por um morador de 18 anos ou mais de idade do domicílio (Brasil, 2015).

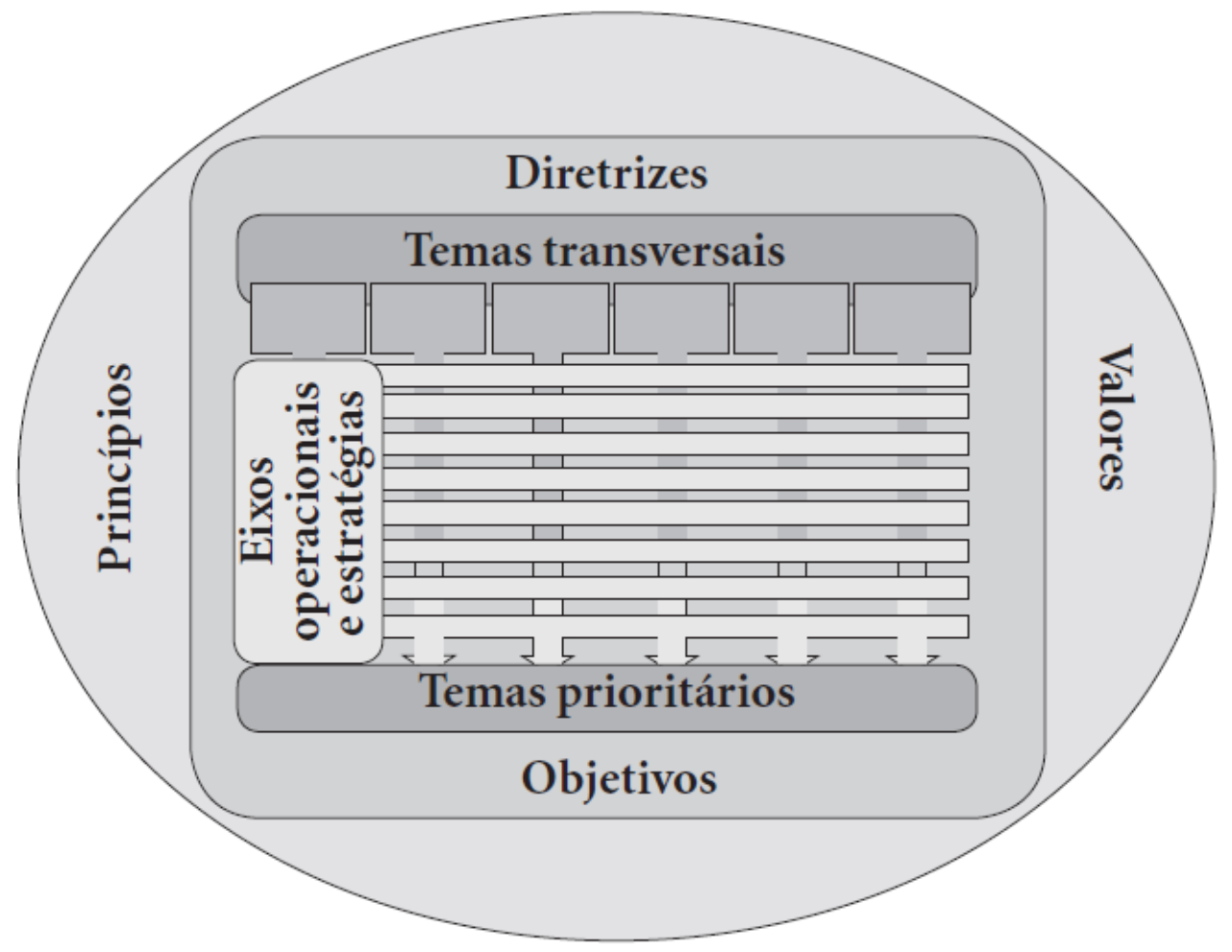

Figura 9. Matriz de conexão entre os componentes da PNPS (Brasil, 2014). 
Contudo, no que se refere à consolidação dos aspectos organizacionais e cooperativos dos arranjos institucionais para a implementação dos mecanismos e instrumentos de coordenação, planejamento e gestão intersetorial, abordados no componente de transversalidade, consideramos que, apesar do aprofundamento conceitual observado nas diretrizes e objetivos do documento, e das diversas frentes de integração intersetorial institucionalizadas entre MS e distintos setores, por diferentes instrumentos normativos e regulatórios no âmbito do governo federal (Leis, Decretos e Portarias Intermenisteriais), ainda não houve impacto na reorganização institucional das estruturas de coordenação e governança da PNPS e na consolidação de produtos efetivos de planejamento integrado. No entanto, vale destacar que a publicação da nova portaria ainda é muito recente para produzir alterações nas estruturas e espaços de gestão e participação do SUS. Nesta direção, também se faz necessária uma atualização dos materiais instrutivos para a publicização de estratégias organizacionais e capacitação dos gestores e atores sociais em todos os níveis de gestão da PNPS, a partir da nova portaria. A indisponibilidade desses materiais limita nossa análise quanto aos aspectos de compartilhamento de inovações e práticas para a integração de indicadores gerenciais e resultados.

É importante destacar que os objetivos de combate às vulnerabilidades sociais, promoção da inclusão social e qualidade de vida da população figuram no cerne da Agenda Social do governo e na essência da concepção ampliada de promoção da saúde, e criaram uma "janela de oportunidade" para a consolidação política e institucional da PNPS. No entanto, entendemos que a nova portaria não apresentou inovações quanto à natureza do normativo e para o aprimoramento do seu arranjo institucional na lógica interinstitucional, o que poderia potencializar o desenvolvimento de capacidades relacionais mais condizentes com a participação dos demais setores e políticas sociais na construção das estratégias e ações de promoção da saúde.

Portanto, a atualização institucional da PNPS, apesar do seu amplo e participativo processo de discussão, parece ter deixado escapar a oportunidade de coordenar, otimizar e potencializar os diferentes arranjos 
intersetoriais multiplicados durante a sua implementação, em favor da conjuntura de convergência dos distintos fluxos de problemas, de políticas públicas e da emergência das políticas sociais, buscando consolidar sua representatividade e legitimidade técnica e política na Agenda Estratégica do governo federal, como política transversal, integradora, dialógica e participativa. Contudo, seus maiores avanços nessa Agenda se deram pela articulação e estruturação de mecanismos de operacionalização vinculados ao Programa Saúde na Escola, compartilhados apenas entre os níveis de gestão da Saúde e Educação.

Do mesmo modo, o potencial de convocação estratégica e transversal na perspectiva de desenvolvimento sustentável e qualidade de vida, que poderia potencializar a indução de políticas pública saudáveis por outros setores, ficou limitado pela atuação fragmentada de políticas específicas do setor saúde, sem a merecida ênfase à centralidade das dimensões da Promoção da Saúde na coordenação técnica e política dos demais setores governamentais.

Entretanto, no que alcança a qualificação da gestão intersetorial na perspectiva de descentralização, o Decreto Presidencial $n^{\circ} 7.508$, de 28 de junho de $2011^{21}$, aponta para a qualificação dos mecanismos de pactuação e planejamento para a gestão e integração regional das Redes de Atenção.

A Constituição Federal de 1988 e a Lei № 8080/1990 definem o papel central da regionalização na estruturação do serviço de saúde, no entanto sua implantação tem acontecido de forma paulatina, visto que se privilegiou ao longo dos anos o fortalecimento do processo de descentralização dos serviços de saúde sem que houvesse uma necessária correspondência com a temática da regionalização dos processos de planejamento e gestão.

O Decreto № 7.508 regulamenta a Lei ํo 8.080 , de 19 de setembro de 1990, dispondo sobre a organização do SUS, o planejamento e a assistência à saúde e a articulação interfederativa. Este decreto fortalece o planejamento, a assistência e a vigilância em saúde; garante mais segurança jurídica às relações interfederativas e maior controle social; favorece o entendimento do

21 Disponível em:

http://bvsms.saude.gov.br/bvs/folder/regionalizacao saude decreto 7508.pdf 
Ministério Público e do Poder Judiciário com relação às responsabilidades dos entes federativos e define o Contrato Organizativo da Ação Pública da Saúde (Coap), que prevê: a oferta de ações e serviços de vigilância; responsabilidades individuais e solidárias, indicadores, metas; critérios de avaliação de desempenho e de recursos financeiros; e meios de controle e de fiscalização das ações e dos serviços (BRASIL, 2015).

Vale destacar, ainda, que, antes da atualização da PNPS, o MS já havia passado por um processo de reformulação do seu aparato institucional por meio do Decreto № 8.065, de 7 de agosto de 2013. Nessa ocasião, a Promoção da Saúde passou a contar com maior legitimidade política e institucional para a articulação intrassetorial no MS, e possivelmente no SUS, pela sua nominação explícita não só no âmbito de uma coordenação-geral, mas também do departamento. No entanto, ainda não foram observadas alterações na sua estrutura de governança, o que não exclui a possibilidade de isso ocorrer com a publicação de normativos complementares.

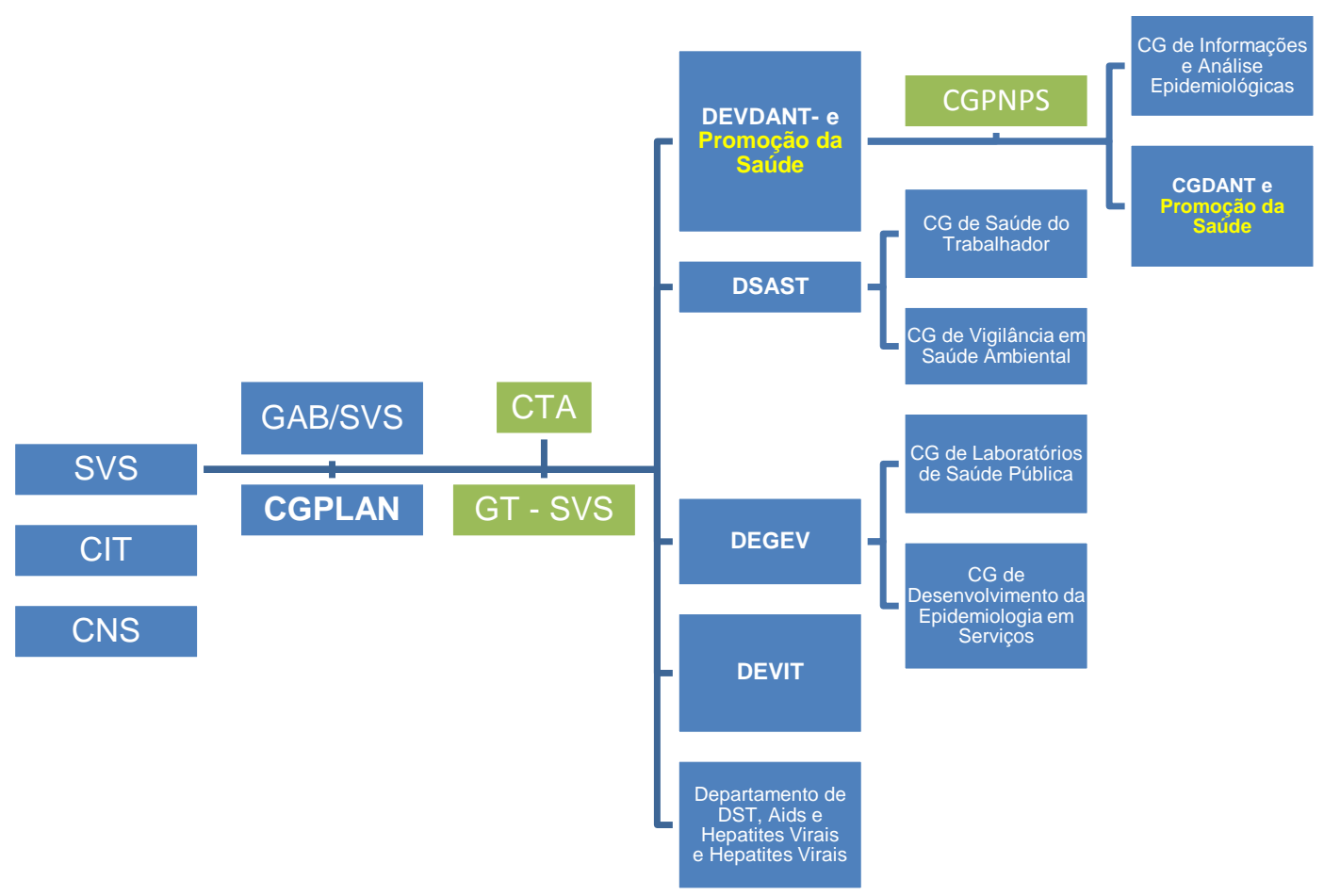

Figura 10. Organograma do MS com destaque das estruturas envolvidas na gestão da PNPS (elaborado pelo autor). 
No que se refere à classificação do arranjo intersetorial da PNPS a partir da análise da Portaria MS $n^{\circ} 2.446$, de 11 de novembro de 2014, foram considerados o aprimoramento dos aspectos 5 e 6 do componente de intregralidade, relativos a agenda e fluxos de diálogo e comunicação; e a interação e publicização de informações que passam a ser considerados de média intensidade, destacando-se que as relações multinível representam apenas uma parte do esforços de gestão intersetorial, uma vez que precisam ser complementadas pela interação multilateral. Na mesma direção, ressaltando a interconexão com o componente de transversalidade, foi considerado o aumento do aspecto 3 , relacionado à descentralização de processos e atividades entre os níveis de governo, definido como de alta consistência ao considerarmos o fortalecimento da perspectiva de territórios e a qualificação dos processos na direção da regionalização da gestão.

Assim, considerando o gráfico proposto para a classificação dos níveis de gestão intersetorial, observamos uma qualificação do arranjo institucional da PNPS/2014 para o Nível VI - Gestão Plena ou Operativa, identificada como de alta integralidade e alta transversalidade. Consequentemente, apesar das limitações multilateriais da estrutura de governança específica da PNPS, foi possível perceber maior coerência entre os aspectos de integralidade e transversalidade no processo de evolução do arranjo intersetorial da política, assim como esperado, principalmente em função do amadurecimento histórico e institucional da temática. Contudo, apesar do fortalecimento da atuação e do planejamento da PNPS na lógica da regionalização e da nova estrutura regimental do MS favorecer a indução de mudanças institucionais para gestão intersetorial entre os níveis de gestão, bem como a articulação com outros partícipes, a PNPS ainda permanece com um deficit institucional significativo para a atuação e coordenação de processos de gestão interinstitucional.

Tabela 6. Pontuação dos aspectos para classificação do arranjo intersetorial da PNPS/2014. 


\begin{tabular}{|c|c|c|c|c|}
\hline Componentes & Aspectos dialógicos e colaborativos & Baixa & Média & Alta \\
\hline \multirow{9}{*}{ Integralidade } & $\begin{array}{|lc|} & \text { Principios voltados à análise de determinantes e condicionartes sociais de forma } \\
\text { ampliada e multidimensional: }\end{array}$ & & & 1 \\
\hline & \begin{tabular}{|lrl}
2 & Mobilização de setores govemamentais, organizações de ustários e redes de \\
servicos dos diferertes atores sociais e qrupos de interesses;
\end{tabular} & 0,25 & & \\
\hline & 3 Parâmetros de representatividade, participação e controle social; & & 0,5 & \\
\hline & $\begin{array}{ll}4 & \text { Critérios voltados à organização territorial e/ou por temática, e não setoriais de } \\
\text { intervencão de atendimerto: }\end{array}$ & & & 1 \\
\hline & 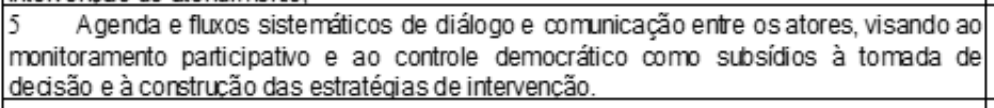 & & 0,5 & \\
\hline & 6 Interação e publicização de irformações entre os setores sociais e niveis de governo; & & 0,5 & \\
\hline & $\begin{array}{|lc|}7 & \text { Apoio à produção colaborativa e compartilhamento de saberes e corhecimentos para } \\
\text { os diferentes atores na perspectiva de educacão continuada. }\end{array}$ & & 0,5 & \\
\hline & TOTAL & & 4,25 & \\
\hline & Aspectos organizacionais e cooperativos & & & \\
\hline \multirow{7}{*}{ Transversalidade } & $\begin{array}{|lc|}1 & \text { Direttizes normativas de articulação e perspectiva de planejamento entre os setores } \\
\text { governamertais e atores sociais (atuacão multilateral): }\end{array}$ & & & 1 \\
\hline & $\begin{array}{|lr|}2 & \text { Instâncias transversais de consenso e pactuação interinstitucionais (Arranjos de } \\
\text { Governanca, Comitês, Câmaras, Grupos Gestores); }\end{array}$ & 0,25 & & \\
\hline & $\begin{array}{l}\text { Descentralização dos processos e atividades entre os diferertes niveis de governo } \\
\text { (atuacão mutinivel): }\end{array}$ & & & 1 \\
\hline & $\begin{array}{l}4 \begin{array}{l}\text { Atribução de competências intersetoriais e implicação dos setores sociais e redes } \\
\text { de servicos: }\end{array} \\
\end{array}$ & & 0,5 & \\
\hline & $\begin{array}{l}5 \text { Institucionalização de espaços de coordenação intrasetorial (Estruturas de } \\
\text { coordenação elou equipe intersetoriais permanentes, grupos técnicos de trabalho - } \\
\text { Organograma formal e informal): }\end{array}$ & & & 1 \\
\hline & $\begin{array}{l}\begin{array}{l}\text { Constituição e/ou acionamento de conselhos representativos e democráticos de } \\
\text { politicas públicas: }\end{array} \\
\end{array}$ & 0,25 & & \\
\hline & \begin{tabular}{|l}
7 Desenvolvimerto de inovações e práticas para a irtegração de indicadores \\
gerenciais, recursos econômicos e financeiros (Termos e Acordos de Cooperação, \\
Convênios e outras parcerias).
\end{tabular} & & 0,5 & \\
\hline
\end{tabular}

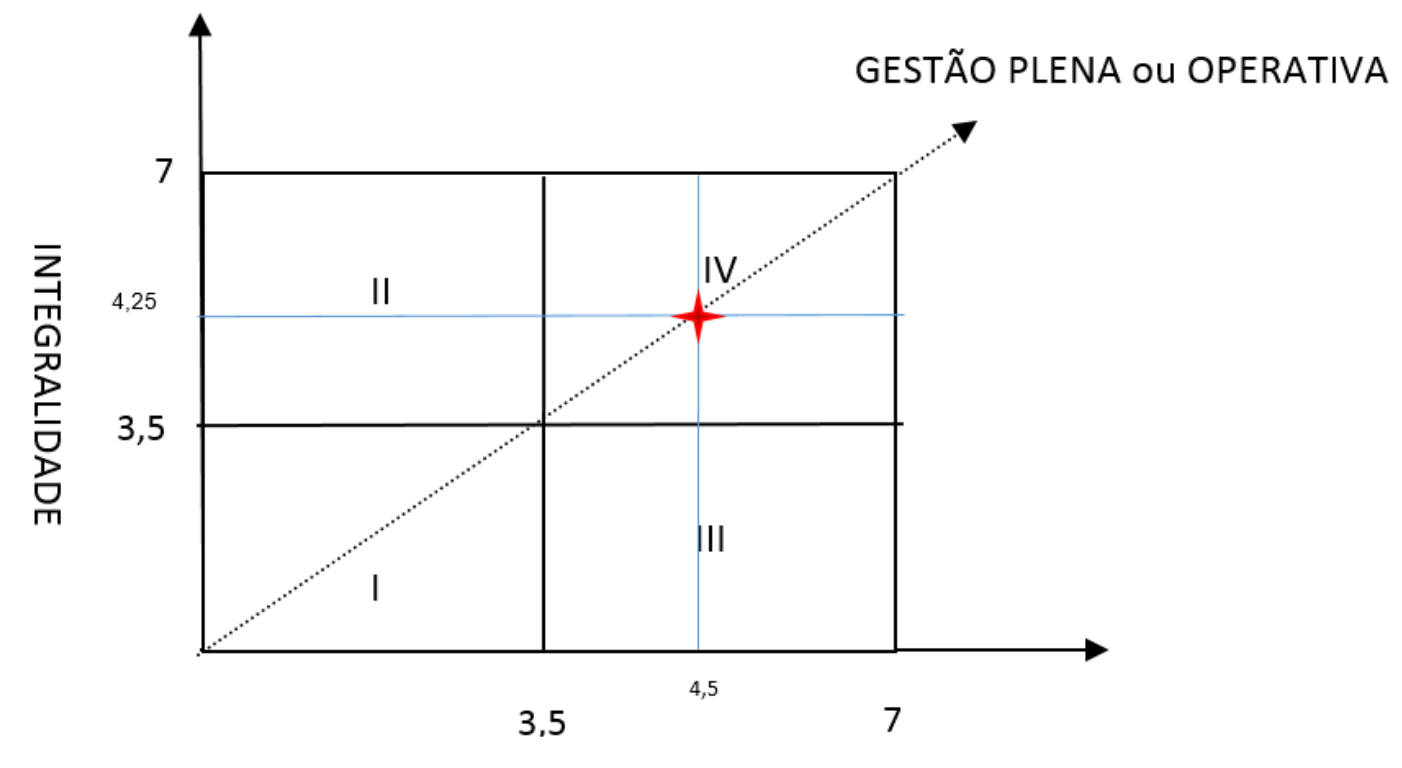

TRANSVERSALIDADE

Figura 11. Pontuação e classificação do arranjo intersetorial da PNPS/2014. 


\section{CONSIDERAÇÕES FINAIS}

Ao finalizarmos nossa análise, podemos constatar que, nas últimas décadas, houve avanços significativos na apropriação de conteúdos teóricos e na aplicação de práticas intersetoriais para a coordenação e integração de políticas públicas, em especial no campo de atuação social do Estado em nível federal. Assim, os modelos alternativos de colaboração multilateral e multinível, que pretendem superar as práticas tradicionais da administração pública, têm encontrado respaldo a partir de experiências distintas nas diferentes dimensões, alcances e amplitude do tema da multi-inter-transdisciplinaridade, que sustentam o paradigma da intersetorialidade. No que se refere às noções de Promoção da Saúde e desenvolvimento sustentável, a gestão intersetorial tem encontrado espaços significativos entre os diferentes setores e níveis de governo.

Entretanto, a acomodação dos interesses sociais e econômicos e a distribuição de poder e voz entre os atores governamentais e societais, buscando atender de forma mais efetiva as demandas sociais, são desafios que exigem o desenvolvimento de novas capacidades estatais. No caso das políticas de saúde, esses desafios são corroborados pela ausência de modelos ideais para se avaliar uma gestão intersetorial, assim como por dificuldades de se gerir a representação e as relações democráticas entre as instâncias de participação social e os distintos espaços institucionais consolidados ao longo de um vasto aparato legal e regulatório do SUS.

A análise de gestão intersetorial da PNPS desenvolvida neste trabalho apontou para a necessidade de estudos mais aprofundados que pudessem captar melhor a significação da intersetorialidade entre os gestores de políticas públicas dos diferentes setores e níveis governamentais, bem como contribuir para a compreensão e desenho dos modelos e fluxos de gestão intersetorial entre as políticas de desenvolvimento social e de Promoção da Saúde. Isso poderia ter sido alcançado pela combinação de métodos quantitativos e qualitativos que pudessem favorecer a avaliação da composição da Rede Nacional de Promoção da Saúde; e a qualificação dos componentes e 
aspectos propostos para esta análise a partir da percepção de diferentes atores estratégicos envolvidos na PNPS.

Contudo, a abordagem ampliada e flexível, utilizada com base na abordagem da análise de políticas públicas, facilitou o desenvolvimento deste Estudo de Caso, e permitiu aventarmos uma classificação do arranjo institucional de gestão intersetorial da PNPS por meio da revisão bibliográfica e análise documental. Assim, seguindo os aspectos e níveis de organização institucional propostos neste estudo para a classificação dos arranjos intersetoriais, identificamos que o grau de gestão intersetorial da PNPS apresenta-se entre os níveis de uma Gestão Intersetorial Coordenada ou Organizacional e de uma Gestão Plena ou Operativa.

$\mathrm{Na}$ primeira classificação - Gestão Intersetorial Coordenada ou Organizacional -, observa-se coerência entre a definição de princípios e diretrizes de integralidade com o estabelecimento de arranjos transversais de colaboração técnica e articulação política, principalmente daqueles arranjos voltados para as dimensões intrassetorial e multinível, ficando evidente o esforço de integração entre as estratégias de atenção e vigilância em saúde e entre os níveis de gestão do SUS. Entretanto, o componente de integralidade no campo da saúde encontra-se muito voltado para a interação entre os níveis de atenção, prevenção e tratamento de saúde, apresentando uma visão limitante em relação às interações sociais entre o processo de adoecimento e a Promoção da Saúde, sendo muito focado em abordagens biológicas e comportamentais. Logo, a formulação e implementação da PNPS é excessivamente concentrada nos gestores do setor saúde, sem uma efetiva articulação interinstitucional, mecanismos de participação social e percepção dos aspectos territoriais, o que limita seu alcance de integralidade para a análise ampliada e participativa dos determinantes sociais da saúde junto aos usuários e da responsabilização dos demais setores de políticas sociais.

$\mathrm{Na}$ segunda classificação, já é possível identificar uma ampliação do componente de integralidade na perspectiva social, bem como a incorporação de espaços de articulação intersetorial, com o aprofundamento de abordagens territoriais para o diagnóstico de situação de saúde e de planejamento interfederativo para além das abordagens comportamentais. Contudo, 
observa-se uma multiplicação de instâncias de pactuação intersetorial sem um efetivo processo de coordenação e integração entre elas. Por isso, mesmo que haja o envolvimento de diferentes setores e atores sociais, a PNPS parece atuar de forma fragmentada, sem centralidade e protagonismo na indução de políticas públicas saudáveis.

É importante observar que a recente revisão da PNPS limitou uma análise mais apurada das transformações institucionais e dos processos de trabalho vinculados à Promoção da Saúde, principalmente pela ausência de publicação de novos materiais orientativos direcionados à organização e operacionalização das redes de ações e serviços após a atualização do marco normativo.

Neste sentido, consideramos que a PNPS ainda pode ampliar sua contribuição para a formulação e implementação de políticas públicas saudáveis voltadas à equidade social e ao desenvolvimento sustentável, por meio do aprimoramento e da otimização dos espaços de articulação interinstitucional. Para tanto, precisa alcançar maior legitimidade política e institucional na coordenação das diferentes políticas intersetoriais do Ministério da Saúde, como a Política Nacional de Alimentação e Nutrição, de Saúde Indígena, de Vigilância Ambiental, das Populações Negras, de Saúde Integral para as Populações dos Campos, das Águas e das Florestas, entre outras, já identificadas na construção das agendas transversais dos planos de governo vigentes. Vale destacar que o setor saúde já dispõe de responsabilidades e atribuições de forma integrada com outros setores sociais, consolidadas em diferentes instrumentos legais e normativos em nível federal, mas ainda carece de arranjos institucionais com maior qualificação técnica e política para a coordenação interinstitucional e a efetiva implementação de uma Gestão Intersetorial Plena e Operativa em todas as suas dimensões.

Um dos entraves identificados para maior qualificação nesse sentido encontra-se na própria formação dos profissionais da área da saúde, com abordagens excessivamente especializadas, o que dificulta o diálogo participativo e democrático com outras áreas sociais de governo. Mesmo com o crescimento da abordagem multidisciplinar e comunitária, especialmente impulsionada pelas Estratégias do Programa Saúde da Família (PSF), 
indicada como central para as ações de Promoção da Saúde, esta atuação ainda encontra-se muito focada na interação multidisciplinar entre diferentes profissionais da área de saúde, sendo necessário aperfeiçoar as diretrizes de diálogo e integração gerencial com outros setores sociais que atuam no mesmo território.

Essa integração gerencial depende do aperfeiçoamento de processos de apoio institucional entre os setores e níveis de governo, de forma que se possa organizar ou fortalecer estruturas de concertação intersetorial nos diferentes níveis de atuação, bem como ampliar os espaços de diálogo e participação entre os setores e a sociedade sobre os determinantes sociais da saúde. Vale observar que os temas prioritários da Promoção da Saúde permeiam as discussões dos diferentes fóruns e conferências das áreas sociais. Dessa forma, poder-se-ia ampliar as capacidades governamentais para a negociação das tensões sociais e para a mediação dos interesses governamentais e societais, buscando coordenar e harmonizar os princípios de autonomia e independência entre os poderes, setores e níveis de governo, com os princípios éticos da justiça social e da equidade.

Assim, as transformações nos processos de trabalho gerenciais e assistenciais passam por investimentos na formação acadêmica e profissional de forma mais intersetorial e dialógica, assim como em processos de educação permanente voltados à qualificação da gestão em saúde. Desse modo, a superação das barreiras tradicionais de especialização e fragmentação entre políticas econômicas e sociais, ainda muito evidenciadas no cotidiano da gestão pública e das práticas profissionais em saúde, poderão alcançar maior legitimidade e representatividade no provimento dos bens e serviços públicos essenciais.

No mesmo sentido, investir no fortalecimento dos espaços de formulação e gestão do SUS, buscando ampliar a contribuição e a representatividade dos diferentes atores sociais e grupos de interesses, assim como na configuração de arranjos institucionais mais voltados para a coordenação, cooperação e comunicação entre os diferentes setores, torna-se essencial para qualificar a mediação dos conflitos de interesses e para o fortalecimento de ações conjuntas. O que pode favorecer a elaboração de 
respostas às demandas sociais de forma mais sinérgica e integral, e prover maior consistência a abordagem social e coletiva da Promoção da Saúde.

No campo da Saúde, as ambiguidades e incertezas entre a lógica assistencialista e emancipatória presentes no Sistema Único de Saúde ainda não foram totalmente clareadas para consolidar a intensificação das estratégias de superação das iniquidades em saúde e de promoção do desenvolvimento sustentável, sendo necessária a superação de lacunas na produção e difusão das informações, a organização e interação de sistemas e indicadores integrados, assim como a otimização e qualificação de arranjos intersetoriais que sejam mais adequados à dinâmica atual das transformações tecnológicas, econômicas e sociais. As dimensões e resultados da gestão intersetorial para a Promoção da Saúde ainda precisam alcançar patamares de articulação técnica e políticas para além da transformação dos padrões de comportamentos individuais e coletivos. 


\section{REFERÊNCIAS}

ACKERKNECHT, E. H. Anticontagionism between 1821 and 1867. Bulletin of the History of Medicine, 22, p. 562, 1948. Curso de extensão em promoção da saúde para gestores do SUS com enfoque no programa academia da saúde / organização Cristiane Scolari Gosch ... [et al.] ; autores Alex Branco Fraga ... [et al.]. - Brasília: Ministério da Saúde, Secretaria de Vigilância em Saúde: Fundação Universidade de Brasília, CEAD, 2013. 144 p.

ANDRADE, L. O. M.; BARRETO, I. C. D. E. A Promoção da Saúde e o movimento de Cidades/Municípios Saudáveis: proposta de articulação entre saúde e ambiente. In: MINAYO M. C. S.; MIRANDA, A. C. (Org.). Saúde e Ambiente Sustentável: estreitando nós. Rio de Janeiro Abrasco e Ed. Fiocruz, p. 151-198, 2002.

ANDRADE, L.O.M. A saúde e o dilema da intersetorialidade. São Paulo: Hucitec, 2006.

AROUCA, S. O dilema preventivista: contribuição para a compreensão e crítica da medicina preventiva. São Paulo; Rio de Janeiro: UNESP; Fiocruz, 2003.

ASHTON, J. (Ed.). Ciudades sanas. Espanha: Masson S. A., 1993. In: Curso de extensão em promoção da saúde para gestores do SUS com enfoque no programa academia da saúde / organização Cristiane Scolari Gosch ... [et al.] ; autores Alex Branco Fraga ... [et al.]. - Brasília: Ministério da Saúde, Secretaria de Vigilância em Saúde: Fundação Universidade de Brasília, CEAD, 2013. 144 p.; $21 \mathrm{~cm}$.

AUGUSTO, M. H. O. Políticas públicas, políticas sociais e política de saúde: algumas questões para reflexão e debate. Tempo Social; Rev. Sociol. USP, S. Paulo, 1(2): 105-119, 2.sem 1989.

BLANCO, I.; GOMÀ, R. La crisis del modelo de gobierno tradicional: reflexiones en torno a la governance participativa y de proximidad. en Gestión y Política Pública, Vol XII № 1.

BENTO, L. V. Governança e governabilidade na reforma do Estado. Barueri, SP: Manole, 2003.

BOGASON P.; ZǿLNER M. (Ed.) Methods in Democratic Network Governance. Palgrave Macmillan: UK, 2007. 
BRASIL. Decreto № 6.286, de 5 de dezembro de 2007. Institui o Programa de Saúde na Escola. Disponível em http://www.planalto.gov.br/ccivil 03/ ato20072010/2007/decreto/d6286.htm

BRASIL, II PND, 1975, p. 54. Disponível em http://www.planalto.gov.br/ccivil 03/leis/1970-1979/anexo/ANL6151-74.PDF

BRASIL. Constituição da República Federativa do Brasil. Brasília: Senado Federal, 1988.

BRASIL. Curso de extensão em promoção da saúde para gestores do SUS com enfoque no programa academia da saúde / organização Cristiane Scolari Gosch ... [et al.] ; autores Alex Branco Fraga ... [et al.]. - Brasília: Ministério da Saúde, Secretaria de Vigilância em Saúde: Fundação Universidade de Brasília, CEAD, 2013.

BRASIL. Ministério da Saúde (MS). Secretaria de Vigilância em Saúde. Política Nacional de Promoção da Saúde. Portaria n687 MS/GM, de 30 de março de 2006. Brasília: MS; 2006a.

BRASIL. Ministério da Saúde. Secretaria - Executiva. Subsecretaria de Planejamento e Orçamento. Plano Nacional de Saúde - PNS: 2012-2015.

BRASIL. Vigilância em saúde: ações inovadoras e resultados: gestão 20112014 / Ministério da Saúde, Secretaria de Vigilância em Saúde. - Brasília: Ministério da Saúde, 2015. 204 p.

BRASIL. Ministério da Saúde. Secretaria de Vigilância à Saúde. Secretaria de Atenção à Saúde. Diretrizes Nacionais da Vigilância em Saúde / Ministério da Saúde, Secretaria de Vigilância em Saúde, Secretaria de Atenção à Saúde. Brasília: Ministério da Saúde, 2010. 108 p.: - (Série F. Comunicação e Educação em Saúde) (Série Pactos pela Saúde 2006; v. 13) http://bvsms.saude.gov.br/bvs/publicacoes/pacto saude volume13.pdf

BRASIL. Ministério da Saúde. Secretaria de Vigilância em Saúde. Ações transversais da vigilância em saúde: promoção, integração e análise: gestão 2007-2008 / Ministério da Saúde, Secretaria de Vigilância em Saúde. - Brasília: Ministério da Saúde, 2009a. 200 p.: il. - (Série C. Projetos, Programas e Relatórios). Disponível em http://bvsms.saude.gov.br/bvs/publicacoes/acoes transversais vigilancia saud e.pdf 
BRASIL. Ministério da Saúde. Secretaria de Vigilância em Saúde.

Departamento de Análise de Situação em Saúde. Saúde Brasil 2010: uma análise da situação de saúde e de evidências selecionadas de impacto de ações de vigilância em saúde. Brasília: Ministério da Saúde, 2011. 372 p. (Série G. Estatística e Informação em Saúde), 2011a.

BRASIL. Ministério da Saúde. Secretaria de Vigilância em Saúde. Diretoria de Apoio à Gestão em Vigilância em Saúde. Manual de gestão da vigilância em saúde / Ministério da Saúde, Secretaria de Vigilância em Saúde, Diretoria de Apoio à Gestão em Vigilância em Saúde. - Brasília: Ministério da Saúde, 2009b. 80 p. - (Série A. Normas e Manuais Técnicos) http://bvsms.saude.gov.br/bvs/publicacoes/manual gestao vigilancia saude.pd f

BRASIL. Ministério da Saúde. Secretaria de Vigilância em Saúde.

Departamento de Análise de Situação de Saúde. Plano de ações estratégicas para o enfrentamento das doenças crônicas não transmissíveis (DCNT) no Brasil 2011-2022 / Ministério da Saúde. Secretaria de Vigilância em Saúde. Departamento de Análise de Situação de Saúde. - Brasília: Ministério da Saúde, 2011. 160 p.: il. - (Série B. Textos Básicos de Saúde) 2011b

BRASIL. Ministério da Saúde. Secretaria-Executiva. Secretaria de Vigilância em Saúde. Glossário temático: promoção da saúde / Ministério da Saúde. Secretaria-Executiva. Secretaria de Vigilância em Saúde. Brasília: Ministério da Saúde, 2012. 48 p. - (Série A. Normas e Manuais Técnicos). disponível em http://bvsms.saude.gov.br/bvs/publicacoes/glossario promocao saude 1ed.pdf

BRONZO, C. Intersetorialidade como princípio e prática nas políticas públicas: reflexões a partir do tema do enfrentamento da pobreza. XX Concurso del CLAD sobre Reforma del Estado y Modernización de la Administración Pública "¿Cómo enfrentar los desafíos de la transversalidad y de la intersectorialidad en la gestión pública?" Caracas, 2007.

BUSS, P. M. Globalização, pobreza e saúde. Ciência e Saúde Coletiva, Rio de Janeiro, v. 12, n. 6, p. 1575-1589, 2007.

BUSS, P. M. Uma introdução ao conceito de Promoção da Saúde. In:

Promoção da Saúde: conceitos, práticas e reflexões. Rio de Janeiro: Fiocruz, 2003.

BUSS, P. M. et al. Promoción de la salud y la salud pública - Una contribución para el debate entre las escuelas de salud pública de América Latina y el Caribe. Brasil, Rio de Janeiro: ENSP/FioCruz, jul. 2000 (mimeo). 
BUSS, P. M.; PELLEGRINI FILHO, A. A saúde e seus determinantes sociais. Physis: Revista de Saúde Coletiva, Rio de Janeiro, v. 17, n. 1, p. 77-93, 2007.

CALAME, P. (Coord.). Cadernos de proposições para o Século XXI: repensar a gestão de nossas sociedades: 10 princípios para a governança, do local ao global. São Paulo: Polis, 2004.

CAMPOS, G. W. S.; BARROS, R. B.; CASTRO, A. M. Avaliação de política nacional de promoção da saúde. Ciência saúde coletiva, Rio de Janeiro, v. 9, n. 3, set. 2004.

CARVALHO, A. I. Da Saúde Pública às Políticas Saudáveis - Saúde e Cidadania na Pós-modernidade. Ciência e Saúde Coletiva, Rio de Janeiro, ABRASCO, v. 1, n. 1, p. 104-121, 1996.

CARVALHO, S. R. Saúde Coletiva e Promoção à Saúde: uma reflexão sobre os temas do sujeito e da mudança. Tese. Campinas: UNICAMP, 2002 (mimeo).

CARVALHO, S. R. Saúde Coletiva e Promoção da Saúde: sujeito e mudança. São Paulo: HUCITEC, 2005.

CZERESNIA, D. O conceito de saúde e a diferença entre promoção e prevenção. In: CZERESNIA, D.; FREITAS, C. M. (Org.). Promoção da Saúde: conceitos, práticas e reflexões. Rio de Janeiro: Fiocruz, p. 39-53, 2003.

DAMASIO, L. Desenvolvimento Institucional do INPEP: Conjuntura Crítica e Trajetória. Dissertação. Escola de Administração de Empresas de São Paulo.

FERES, J. C.; MACERO, X. Enfoques para la medición de la pobreza. Breve revisión de la literatura. Serie Estudios Estadísticos y Prospectivos 4. Santiago do Chile, Publicação das Nações Unidas, LC/L. 1479-P, 2001b.

FIORENTINI, D. Pesquisar Práticas Colaborativas ou Pesquisar colaborativamente? In: Pesquisa Qualitativa em Educação Matemática. Belo Horizonte: Autêntica, 2004.

FLEURY, S. Reforma Sanitária Brasileira: dilemas entre o instituinte e o instituído. Ciênc. saúde coletiva [online]. 2009, vol.14, n.3, pp. 743-752. 
FLEURY, S.; OUVERNEY, A. M. Política de Saúde: Uma Política Social. In: Giovanella L et al. Políticas e Sistemas de Saúde no Brasil. 2a. Ed. Editora Fiocruz; 2012.

FLICK, U. Desenho da pesquisa qualitativa. Porto Alegre: Artmed, 2009.

FREY, K. Políticas Públicas: Um debate conceitual e reflexões referentes à pratica da análise de políticas públicas no Brasil. Planejamento e Políticas Públicas n. 21 p. 211-259. Jun/2000.

GARCIA, L.M.T.; MAIO, I.G.; SANTOS, T.I.; FOLHA, C. B. C.; WATANABE, H.W. Saúde em Debate: Intersetorialidade na saúde no Brasil no início do século XXI: um retrato das experiências. Rio de Janeiro, v.38, n. 103, p. 966980, Out-Dez, 2014.

GOMIDE, A. A.; PIRES, R.R. Capacidades Estatais e Democracia - Arranjos Institucionais de Políticas Públicas. Brasília, IPEA, 2014.

INOSOJA, R. M. Intersetorialidade e a configuração de um novo paradigma organizacional. Revista de Administração Pública. Rio de Janeiro, FGV, 32(12):35-48, 1998.

INOSOJA, R. M. Sinergia em políticas e serviços públicos: desenvolvimento social com intersetorialidade. Cadernos Fundap, São Paulo, n.22, 2001, p. $102-$ 110.

JOHN, P. Analysing public policy: critical political studies. London: Continuum, 1999.

JUNQUEIRA, L.A.P. Descentralização e intersetorialidade na construção de um novo modelo de gestão. Rev. Adm. Publica, 1998. (no prelo no. 2)

JUNQUEIRA, L. A. P. Intersetorialidade, transetorialidade e redes sociais na saúde. Revista de Administração Pública, Rio de Janeiro 34(6); 35-45, Nov/Dez. 2000.

KENSKI, V. M. Tecnologias e ensino presencial e a distância. Campinas,SP: Papirus, 2003.

LEAVELL, H.; CLARK, E. G. Medicina Preventiva. São Paulo: McGraw-Hill Inc., 1976. In: Curso de extensão em promoção da saúde para gestores do SUS com enfoque no programa academia da saúde / organização Cristiane Scolari 
Gosch ... [et al.] ; autores Alex Branco Fraga ... [et al.]. - Brasília: Ministério da Saúde, Secretaria de Vigilância em Saúde: Fundação Universidade de Brasília, CEAD, 2013. 144 p.; $21 \mathrm{~cm}$.

LÉVY, P. O que é o virtual. São Paulo: Ed. 34, 1996.

LÉVY, P. Cibercultura. São Paulo: Editora 34, 1999.

MACHADO, M. de F. A. S. et al. Integralidade, formação de saúde, educação em saúde e as propostas do SUS: uma revisão conceitual. Ciênc. saúde coletiva [online]. 2007, vol.12, n.2, pp. 335-342.

MAGALHÃES, R.; BODSTEIN, R. Avaliação de iniciativas e programas intersetoriais em saúde: desafios e aprendizados, 2009. Disponível em http://www.scielo.br/pdf/csc/v14n3/21.pdf

MALTA, D.C. et al. Política Nacional de Promoção da Saúde, descrição da implementação do eixo atividade física e práticas corporais, 2006 a 2014. Ver. Bras. Ativ. Fis. Saúde p. 286-299. Disponível em http://periodicos.ufpel.edu.br/ojs2/index.php/RBAFS/article/viewFile/3427/3280

MALTA, D.C.; CASTRO, A.M. A Política Nacional de Promoção da Saúde e a agenda da atividade física no contexto do SUS Epidemiologia e Serviços de Saúde, vol. 18, n.1. Brasília, 2009. Disponível em http://scielo.iec.pa.gov.br/scielo.php?pid=S1679$\underline{49742009000100008 \& \text { script=sci } \text { arttext\&tlng=es }}$

MINAYO, M. C. S.; HARTZ, Z. M. A.; BUSS, P. M. Qualidade de Vida e saúde: um debate necessário. Ciência \& Saúde Coletiva. Rio de Janeiro, v. 5, n.1, 2000 , p. 7-18.

MINAYO, M.C. Qualidade de Vida e Saúde: um debate necessário. Ciência \& Saúde Coletiva, 5(1):7-18, 2000. Disponível em http://adm.online.unip.br/img ead dp/35428.PDF

MONNERAT, G. L.; SOUZA, R. G. de. Política Social e intersetorialidade: consensos teóricos e desafios práticos. IN: SER Social, Brasília, v.12, n 26. p. 200-220, jan/jun. 2009. 
MONNERAT, G.L.; XX. Da Seguridade Social à intersetorialidade: reflexões sobre a integração das políticas sociais no Brasil. R. Katál., Florianópolis, v. 14, n. 1, p. 41-49, jan./jun. 2011.

NAVARRO, N. A Intersetorialidade como Modelo de Gestão das Políticas de Combate à Pobreza no Brasil: O Caso do Programa Bolsa Família no Município de Guarulhos / Natalia Navarro dos Santos. - 2011. 166 f.

NETTO, G. F. Conexões da saúde com a agenda da sustentabilidade Saúde em Debate. Desenvolvimento e Sustentabilidade: desafios da Rio +20, Rio de Janeiro, v. 36, número especial, p. 20-22, jun. 2012.

ORGANIZAÇÃO MUNDIAL DA SAÚDE. Conferência Mundial sobre os Determinantes Sociais da Saúde. Diminuindo as diferenças: a prática das políticas sobre os determinantes sociais de saúde. Documento para discussão. Rio de Janeiro, out. 2011. Disponível em: http://www.who.int/sdhconference/discussion paper/Discussion Paper PT.p f Acesso em: 16 set. 2012.

OPAS. Desenvolvimento Sustentável e Saúde: tendências dos indicadores e desigualdades no Brasil. Brasília, DF: OPAS, 2014. 30 p.. il. (Série Desenvolvimento Sustentável e Saúde, 1). ISBN: 978-85-7967-089-3

ORGANIZACIÓN PAN AMERICANA DE SALUD. Promoción de salud: una antología. Washington: D. C; OPS, n. 557, 1996.

PAIM, J. S. A reorganização das práticas de saúde em distritos sanitários. In: Mendes, E. V. (org.) Distrito Sanitário: o processo social de mudança das práticas sanitárias do Sistema Único de Saúde. São Paulo - Rio de Janeiro: Hucitec-Abrasco, 1993. p. $187-220$.

PROMOCIÓN DE LA SALUD. Una contribución para el debate entre las escuelas de salud pública de América Latina y Caribe. Rio de Janeiro: ENSP/Fiocruz, 2000. (mimeo) (originais publicados pela Organização Mundial de Saúde).

QUEROL, C. Governanza y desarrollo sostenible (Cataluña). Diálogos na Universidade de Vigo, 1-3, xuño 2004. Disponível em: http://www.academia.edu/6752420/Di\%C3\%A1logos na Universidade de Vig O 13 xU\%C3\%B10 2004 GOVERNANZA Y DESARROLLO SOSTENIBLE CATALU\%C3\%91A 
REINACH, S. Gestão transversal das políticas públicas no âmbito federal brasileiro: uma leitura inicial , 2013. Disponível em:

http://bibliotecadigital.fgv.br/dspace/bitstream/handle/10438/10667/Dissertacao \%20Sofia.pdf?sequence $=1$ \&isAllowed $=y$

RESTREPO, H. E.; MALAGA, H. (Org.). Promoción de la salud: como construir vida saludable. Bogotá: Ed. Medica Internacional, 2001.

RIZZOTTO, M. L. F. A saúde na proposta de desenvolvimento da Comissão Econômica para a América Latina e o Caribe (CEPAL)/Organização PanAmericana da Saúde (OPAS). Saúde debate [online]. 2013, vol.37, n.96, pp. 20-31. ISSN 0103-1104.

ROCHA, D. G. et al. Processo de revisão da Política Nacional de Promoção da Saúde: múltiplos movimiento simultáneos. Ciência \& Saúde Coletiva, 19(11). 2014. Pp. 4313-4322.

RODRIGUEZ NETO, E. A Reforma Sanitária e o Sistema Único de Saúde: suas origens, suas propostas, sua implantação, suas dificuldades e suas perspectivas. In: Brasil. Ministério da Saúde. Coordenação de Informação, Educação e Comunicação. Núcleo de Estudos em Saúde Pública - NESP. Incentivo à Participação Popular e Controle Social no SUS: textos técnicos para conselheiros de saúde. Brasília: IEC, 1994, p. 7-17.

SANTANA, J. P. (Org). A negociação como instrumento de gerencia nos serviços de saúde. Brasília: Opas, 1997. Texto de apoio da unidade III do Programa: desenvolvimento gerencial de unidades básicas do Sistema Único de Saúde (SUS).

SANTOS, W. G. dos. Cidadania e justiça. A política social na ordem brasileira. Rio de Janeiro, Campus, 1979.

SERRA, A. La gestión transversal: expectativas y resultados. Documento presentado en el IX Congreso Internacional del CLAD sobre la Reforma del Estado y de la Administración Pública, Madrid, 2 al 5 de noviembre,2004.

SCHERER-WARREN, I. Redes de movimentos sociais na américa latina: caminhos para uma política emancipatória?. Cad. CRH [online]. 2008, vol.21, n.54, pp. 505-517. ISSN 1983-8239. Disponível em: http://www.scielo.br/pdf/ccrh/v21n54/07.pdf 
SEN, A. 2000. Desenvolvimento como liberdade. São Paulo: Companhia das Letras.

SOARES, S. Análise de bem-estar e decomposição por fatores da queda na desigualdade entre 1995 e 2004. Econômica. Rio de Janeiro, v. 8, n. 1, p. 83115. 2006. In: Políticas sociais para o desenvolvimento: superar a pobreza e promover a inclusão; Simpósio Internacional sobre Desenvolvimento Social. Organizadoras: Maria Francisca Pinheiro Coelho, Luziele Maria de Souza Tapajós e Monica Rodrigues. Brasília: Ministério do Desenvolvimento Social e Combate à Fome, UNESCO, 2010. 360p.

SOLAR, O.; IRWIN, A. A conceptual framework for action on the social determinants of health. Social determinants of health discussion paper 2 (policy and practice). Geneva: World Health Organization, 2010. Disponível em: <http://whqlibdoc.who.int/publications/ 2010/9789241500852_eng.pdf>. Acesso em: 10 jan. 2015.

TEIXEIRA, C. F.; PAIM, J.S. Planejamento e programação de ações intersetoriais para a promoção da saúde e da qualidade de vida. Revista de Administração Pública, Rio de Janeiro 34(6): 63-80, Nov./Dez. 2000.

TEIXEIRA, C. F.; PINTO, L. L.; VILASBÔAS, A. L. Q. O Processo de trabalho da vigilancia em saúde. Rio de Janeiro: Fiocruz/EPSJV/Proformar, 2004, 60 p. (Série: Material Didático do Programa de Formação de Agentes Locais de Vigilância em Saúde; 5)

TUMELERO, S. M. A intersetorialidade na gestão social de políticas públicas. 2012. Disponível em:

http://uab.ufac.br/moodle/pluginfile.php/10246/mod label/intro/Texto1 Silvana Marta.pdf

VEIGA, L.; BRONZO, C. Desafios, possibilidades e limites de programas locais de combate à pobreza e à exclusão: as iniciativas das cidades de São Paulo e de Belo Horizonte. Documento presentado en el X Congreso Internacional del CLAD sobre la Reforma del Estado y de la Administración Pública, Santiago, 18 al 21 de octubre.2005.

VERDI M.; CAPONI, S. Reflexões sobre a promoção da saúde numa perspectiva bioética. Texto Contexto Enferm. 2005 Jan-Mar; 14 (1): 82-8.

VIANA, A. L. Novos riscos, a cidade e a intersetorialidade das políticas públicas. Revista de Administração Pública, Rio de Janeiro: Fundação Getúlio Vargas, Escola Brasileira de Administração Pública, 1998. 
WESTPHAL, M. F. Promoção da Saúde e prevenção de doenças. In: CAMPOS, G. W. et al. Tratado de Saúde Coletiva. São Paulo: HUCITEC; Ed. Fiocruz, p. 635-667, 2006.

WESTPHAL, M. F. Promoção da Saúde e qualidade de vida. In: FERNANDEZ, J. C. A. E.; MENDES, R. Promoção da Saúde e gestão local. SÃO PAULO: Hucitec; CEPEDOC Cidades saudáveis, 2007.

YIN, R. K. Estudo de caso - planejamento e métodos. (2Ed.). Porto Alegre: Bookman, 2001. 